\title{
Dinuclear Pd' Catalysts in Equilibrium Isomerizations: Mechanistic Understanding, in Silico Casting, and Catalyst Development
}

\author{
Sriman De, ${ }^{\text {ał }}$ Nardana Sivendran, ${ }^{\mathrm{b}}$ Bholanath Maity, ${ }^{\mathrm{a}, \mathrm{c}}$ Nico Pirkl, ${ }^{\mathrm{b}}$ Debasis Koley ${ }^{\mathrm{a} *}$ and Lukas J. \\ Gooßen ${ }^{b *}$ \\ aDepartment of Chemical Sciences, Indian Institute of Science Education and Research (IISER) Kolkata, Mohanpur - 741246 , \\ India \\ ${ }^{b}$ Fakultät Chemie und Biochemie, Ruhr Universität Bochum, Universitätsstr. 150, 44801 Bochum Germany \\ cPresent Address: KAUST Catalysis Center (KCC), King Abdullah University of Science and Technology (KAUST), Thuwal, \\ 23955-6900 (Saudi Arabia) \\ KEYWORDS: Catalysis, DFT, Mechanistic Study, Palladium, Isomerizing Metathesis
}

\begin{abstract}
The unique reactivity profile of the dinuclear $\mathrm{Pd}^{\mathrm{I}}$ complex $\left[\mathrm{Pd}^{\mathrm{I}}(\mu-\mathrm{Br})^{t} \mathrm{Bu}_{3} \mathrm{P}\right]_{2}$ as an isomerization co-catalyst has enabled orthogonal tandem processes ranging from styrene syntheses to biodiesel refining. We have now elucidated the mechanistic basis of its distinct catalytic profile by DFT calculations and experimental studies. Activation of the catalyst proceeds intramolecularly, giving rise to a dinuclear complex composed of a reactive palladium hydride and an inert palladacycle. This complex mediates double-bond migrations with an energy span of $9.5 \mathrm{kcal} / \mathrm{mol}$, which is well below those calculated for known catalysts. Its dissociation leads to an even more active monophosphinopalladium hydride catalyst and an inert dinuclear bispalladacycle. In the main deactivation pathway, two mononuclear Pd species react with each other, liberating a hydrogenation product and regenerating the catalyst precursor $\left[\mathrm{Pd}^{\mathrm{I}}(\mu-\mathrm{Br})^{t} \mathrm{Bu}_{3} \mathrm{P}\right]_{2}$. The experimentally observed build-up of dinuclear palladacycles during the catalysis is, thus, the result of a conversion of binuclear into mononuclear $\mathrm{Pd}-\mathrm{H}$ catalyst. Phosphines, which would deactivate metathesis cocatalysts, are not liberated at any stage. This explains the unique suitability of $\left[\mathrm{Pd} \mathrm{d}^{\mathrm{I}}\left(\mu-\mathrm{Br}^{t} \mathrm{Bu}_{3} \mathrm{P}\right]_{2}\right.$ for isomerizing metatheses. The mechanistic insights were used for the in silico casting of a catalyst generation, targeting complexes with a reduced barrier towards the formation of dinuclear $\mathrm{Pd}-\mathrm{H}$ species, a low energy span of the catalytic cycles, and increased barriers either towards deactivation or, alternatively, towards dissociation to short-lived mononuclear complexes. Complexes with bisadamantyl- $n$-butylphosphine ligands were identified as lead structures. Experimental studies with model catalysts confirmed the validity of the predicted structureactivity relationship.
\end{abstract}

\section{INTRODUCTION}

Metal-catalyzed double-bond isomerizations are widely used in chemical value creation. ${ }^{1}$ A prominent example is the Takasago process for the production of menthol, which features a ruthenium/Tol-BINAP-catalyzed asymmetric isomerization of a prochiral enamine. ${ }^{2}$ The discovery of synthetically meaningful isomerizing functionalizations has further boosted the significance of isomerization catalysis. ${ }^{3}$ The general reaction concept is that a widely available $\mathrm{C}-\mathrm{C}$ double-bond isomer with limited synthetic potential is converted in situ into a mixture of double-bond isomers from which one is drawn forth by follow-up functionalization, leading to a value-added product. It has been widely implemented, e.g., in isomerizing hydroformylations, ${ }^{4}$ hydroborations, ${ }^{5}$ alkoxycarbonylations, ${ }^{6}$ and hydroaminomethylations (Scheme 1). ${ }^{7}$ Striking examples include the synthesis of valeraldehyde from 2-butene, ${ }^{8}$ and of $\omega$-functionalized aliphatic carboxylates from unsaturated fatty acids. ${ }^{9}$ The latter products are of great interest for accessing biobased long-chain polyesters, i.e. "nature's polyethylene". ${ }^{10}$ In most of these processes, double-bond migration is promoted by the same catalyst that mediates the functionalization step, e.g. a rhodium, palladium or iridium system.
The latest development in this field is the incorporation of catalytic double-bond migrations into bimetallic orthogonal tandem catalyses. ${ }^{11}$ In this reaction concept, two different catalysts are independently yet cooperatively active within a single reaction vessel. It is an enabling technology for the valorization of natural products or waste streams, often leading to compounds that would be inaccessible by consecutive action of the same catalysts. Hydration/dehydration olefin metatheses ${ }^{12}$ and isomerizing olefin metatheses ${ }^{13}$ showcase its innovative potential.

Scheme 1. Isomerizing hydroaminomethylation or hydroformylation of internal olefins.

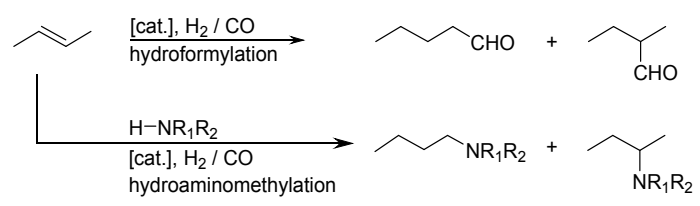

Isomerizing metatheses work by the simultaneous action of an isomerization catalyst, which constantly moves double bonds up and down along the alkyl chains of the substrate molecules, and an olefin metathesis co-catalyst, which continually shuffles 
the alkyl substituents of each double bond. ${ }^{14}$ This iterative, cooperative action of two orthogonal catalysts can be used to convert single olefins or olefin mixtures into defined product blends with carbon-chain lengths evenly distributed around the mean chain length of the starting materials. Pioneering experiments were performed already in the 1990s by Porri and Grubbs, later by Consorti and Dupont, who combined a modified Hoveyda-Grubbs metathesis catalyst with a ruthenium-hydride isomerization catalyst. ${ }^{13,15}$ The key requirement for transforming such isomerizing metatheses from a laboratory curiosity into a powerful synthetic methodology was the development of a set of highly active metathesis and isomerization catalysts that operate under identical conditions with neither catalyst deactivating the other. This mutual compatibility is difficult to achieve for isomerizations, since most catalyst systems call for strong acid or base additives, which are incompatible with sensitive co-catalysts Schrock et al. have demonstrated the utility of product-specific isomerizing metathesis processes with a $\mathrm{Ru} / \mathrm{W}$ system that allows to selectively produce $(Z)$-5-decene from $(E)$-3-hexene. ${ }^{16}$ In the context of equilibrium isomerizing olefin metathesis technology, the discovery of $\left[\mathrm{Pd}^{\mathrm{I}}(\mu-\mathrm{Br})^{t} \mathrm{Bu}_{3} \mathrm{P}\right]_{2}\left(\mathbf{P d} 1^{\mathbf{B r}}\right)$ as highly reactive, one-component isomerization catalyst that is mutually compatible with ruthenium metathesis catalysts has led to a major advance(Figure 1). In the context of equilibrium isomerizing olefin metathesis technology, the discovery of $\left[\mathrm{Pd}^{\mathrm{I}}(\mu-\mathrm{Br})^{t} \mathrm{Bu}_{3} \mathrm{P}\right]_{2}\left(\mathbf{P d} \mathbf{1}^{\mathrm{Br}}\right)$ as a highly reactive, one-component isomerization catalyst that is mutually compatible with ruthenium metathesis catalysts has led to a major advance (Figure 1). It is not only a highly active catalyst for single bond flips, ${ }^{17}$ but is able to continuously move double bonds up and down long carbon chains, allowing metathesis reactions to take place at any time. ${ }^{14 a}$

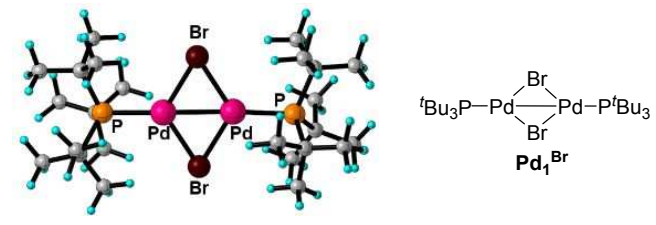

Figure 1. Structure and optimized geometry of dinuclear $\mathrm{Pd}^{\mathrm{I}}$ catalyst $\left[\mathrm{Pd}^{\mathrm{I}}(\mu-\mathrm{Br})^{t} \mathrm{Bu}_{3} \mathrm{P}\right]_{2}\left(\mathbf{P d 1}^{\mathrm{Br}}\right)$.

Isomerizing metatheses using $\mathbf{P d 1}{ }^{\mathrm{Br}}$ along with Grubbs- or Hoveyda-type catalysts have been implemented in the synthesis of dicarboxylic acid blends from fatty acids for applications in polymers and coatings, ${ }^{18}$ of valuable vinylarenes from naturally abundant allylarenes, ${ }^{19}$ of tsetse-fly attractants from cashew nutshell liquid, ${ }^{20}$ and of non-estrogenic bisphenol A surrogates from clove oil (Scheme 2, top). ${ }^{21} \mathrm{~A} \mathrm{Pd} / \mathrm{Pd} / \mathrm{Ru}$ three-component isomerization/ethenolysis/metathesis catalyst has enabled the one-pot, low-energy, solvent- and waste-free refining of rapeseed oil methyl ester (RME) and (bio)ethylene into a biofuel for conventional diesel engines. ${ }^{22}$ Its evenly rising boiling point curve fulfils the strict specifications prescribed by the fuel standard EN 590 for modern (petrol) diesel engines. This refining via isomerizing cross-metathesis requires negligible energy input $\left(60{ }^{\circ} \mathrm{C}\right)$, no solvents, and does not produce waste (Scheme 2, bottom). Simulations revealed that around 30 alternating isomerization and metathesis steps have to occur for every substrate molecule to bring the reaction mixture close to equilibrium composition. Many state-of-the-art isomerization catalysts have been tested in extensive studies, but for processes that require multiple double-bond migrations under conditions that are compatible with sensitive ruthenium complexes, $\mathbf{P d 1}{ }^{\mathrm{Br}}$ was the sole catalyst to give promising results. ${ }^{14 \mathrm{a}}$

Scheme 2. Synthetic utility of isomerizing metathesis processes catalyzed by $\mathrm{Ru} / \mathrm{Pd}$ systems.

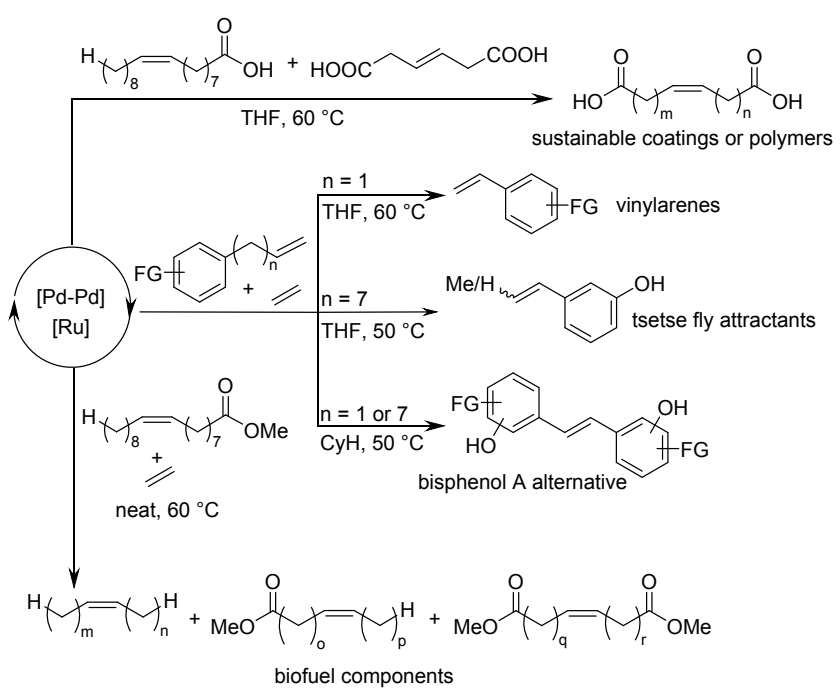

The $\left[\mathrm{Pd}^{\mathrm{I}}(\mu-\mathrm{Br})^{t} \mathrm{Bu}_{3} \mathrm{P}\right]_{2}$ isomerization catalyst at the basis of these recent developments in equilibrium isomerizing metathesis ${ }^{18-22}$ was first reported by Mingos, ${ }^{23}$ Prashad, ${ }^{24}$ and Hartwig, ${ }^{25}$ who first utilized the $\mathrm{Pd}^{\mathrm{I}}$ dimer as precatalyst in $\mathrm{Pd}^{0}$ promoted cross-couplings. They found it to be an excellent catalyst for couplings of aryl chlorides and bromides e.g. with hindered anilines. Hartwig also demonstrated the applicability of this catalyst in Suzuki couplings. Additionally, $\mathbf{P d 1}{ }^{\mathrm{Br}}$ was used in a variety of reactions including $\alpha$-arylations of esters and amides, ${ }^{26-28} \alpha$-vinylations of carbonyl compounds, ${ }^{29} \mathrm{C}-$ $\mathrm{CN},{ }^{30} \mathrm{C}-\mathrm{S},{ }^{31}$ and $\mathrm{C}-\mathrm{Si}$ bond-forming reactions, ${ }^{32}$ Kumada couplings, ${ }^{33}$ and the amination of heterocyclic halides. ${ }^{34}$ Schoenebeck et al. reported its use for catalytic aromatic halideexchange reactions ${ }^{35}$ and also presented trifluoromethylthiolations of aryl iodides using the iodo analogue Pd1 ${ }^{\mathbf{I}}{ }^{36}$

Several mechanistic studies were undertaken to understand why the catalytic activity of $\mathrm{Pd}^{\mathrm{I}}$ dimers goes beyond that of mononuclear Pd species in cross-coupling reactions. Hartwig et al. reasoned that the $\mathrm{Pd}^{\mathrm{I}}$ dimers are rapidly converted into the 12-electron species $\mathrm{Pd}^{0}-\mathrm{P}^{t} \mathrm{Bu}_{3}{ }^{25}$ Different mechanisms have been proposed for the conversion of $\mathrm{Pd}^{\mathrm{I}}$ dimers ${ }^{37}$ into active mononuclear catalysts, including e.g. disproportionation, ${ }^{23,38}$ reduction, ${ }^{39}$ or homolytic bond scission followed by reduction of the radical species (Scheme 3). ${ }^{40}$ Schoenebeck et al. also considered a homolytic bond cleavage with reduction of a $\mathrm{Pd}^{\mathrm{I}}$ radical to $\mathrm{Pd}^{0}$, but ruled this out in a follow-up publication in favor of a nucleophile-assisted fragmentation. ${ }^{33,41}$ In only few cases, preservation of the $\mathrm{Pd}-\mathrm{Pd}$ bond during the catalytic process is proposed, but this is not further elaborated or proven. ${ }^{42}$ However, for $\left[\mathrm{Pd}^{\mathrm{I}}(\mu-\mathrm{I})^{t} \mathrm{Bu}_{3} \mathrm{P}\right]_{2}$, it has been shown that the dinuclear structure stays intact e.g. in aromatic substitution reactions with weak nucleophiles. ${ }^{43}$ These mechanistic investigations focus on the role of the $\mathrm{Pd}^{\mathrm{I}}$ dimer in crosscoupling and halide exchange reactions. With the present work, it was our aim to elucidate the mechanistic pathways of $\left[\operatorname{Pd}^{\mathrm{I}}(\mu\right.$ $\left.\mathrm{Br})^{t} \mathrm{Bu}_{3} \mathrm{P}\right]_{2}$ in the equilibrium isomerization part of isomerizing 
olefin metathesis processes, and ultimately use the results to improve the efficiency of these orthogonal tandem processes.

Scheme 3. Proposed pathways for the formation of catalytically active species from Pd1 ${ }^{\mathrm{Br}}$.

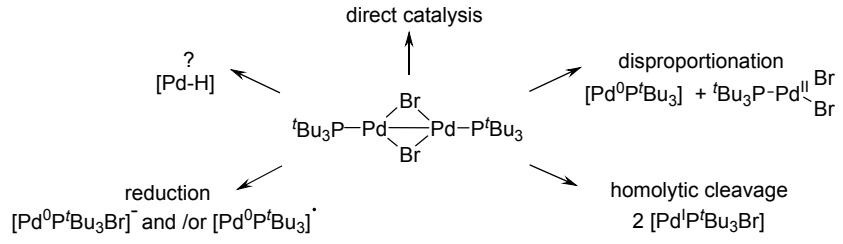

The use of Pd complexes as isomerization catalysts is well established. ${ }^{44}$ State-of-the-art systems such as Brookhart's 2,9dimethylphenanthroline-palladium catalyst promote isomerizations over several carbon atoms under rather mild conditions, usually in the presence of acids or hydride sources. ${ }^{45}$ In the context of isomerizations of allyl- to vinylbenzenes, catalysts and isomerization mechanisms have recently been reviewed comprehensively. ${ }^{46,47}$ For Pd catalysts, two main pathways are proposed, one of which is initiated by insertion of alkenes into $\mathrm{Pd}-\mathrm{H}$ catalysts, ${ }^{48}$ the other by allylic $\mathrm{C}-\mathrm{H}$ cleavage. ${ }^{49}$ Preformed diphosphinopalladium hydride species show high catalytic activities only at $80^{\circ} \mathrm{C}$ or above. Mechanistic investigations by Mazet et al. have confirmed the intermediacy of such $\left(\mathrm{PR}_{3}\right)_{2} \mathrm{Pd}-\mathrm{H}$ species in an addition $/ \beta$ hydride elimination pathway with an energy span of 20 $\mathrm{kcal} / \mathrm{mol}{ }^{50}$ Studies by Hartwig et al. revealed that during the autocatalytic oxidative addition of aryl bromides to $\operatorname{Pd}^{0}\left(\mathrm{P}^{t} \mathrm{Bu}_{3}\right)_{2}$, various species are formed, amongst which the side product $\mathrm{Pd}\left(\mathrm{P}^{t} \mathrm{Bu}_{3}\right)_{2}(\mathrm{H})(\mathrm{Br})$ has also shown catalytic activity. ${ }^{51}$ However, Skrydstrup et al. found that $\left({ }^{t} \mathrm{Bu}_{3} \mathrm{P}\right)_{2} \mathrm{PdHCl}$ systems selectively flip terminal double bonds into the adjacent, thermodynamically favored position, but do not catalyze chainwalking processes. ${ }^{52}$

In contrast to such $\left(\mathrm{PR}_{3}\right)_{2} \mathrm{Pd}-\mathrm{H}$ species, $\mathbf{P d} 1^{\mathrm{Br}}$ catalyzes isomerizations over any number of positions along a carbon chain already at room temperature. Its specific activity is so high that it isomerizes even allyl to vinyl esters, rather than inserting into their allyl-carboxylate bond. ${ }^{18}$ This is quite counterintuitive in view of the proverbial stability of Pd-allyl complexes. No mechanistic studies have yet been performed to explain the unique isomerizing profile of $\mathbf{P d} \mathbf{1}^{\mathbf{B r}}$. It is entirely unclear why $\mathbf{P d} \mathbf{1}^{\mathbf{B r}}$ is so effective in mixtures with sensitive ruthenium metathesis catalysts, with both catalysts retaining their full activity. It is also uncertain what makes the tert-butyl phosphine ligands so exceptionally efficient in this context. Finally, it is not understood what causes $\mathbf{P d 1}{ }^{\mathbf{B r}}$ to degrade within only several hours, and how this may be avoided.

The present mechanistic study addresses these questions, thus providing a blueprint for the development of isomerization catalysts with new levels of activity and durability in orthogonal tandem catalysis. It delivers in-depth understanding of the catalyst activation, double-bond migration, and catalyst degradation processes, and provides a rational basis for further catalyst development with the goal of advancing isomerizing olefin metathesis towards industrial application. Propene was used as the model substrate because substrate and isomerization product are identical. This makes it a good model for equilibrium isomerizing metatheses e.g. of rapeseed methyl ester, in which the individual steps have almost no thermodynamic driving force (Scheme 4). ${ }^{22}$ The key findings are counterintuitive and will support improvement in catalyst design: The build-up of palladacycles in the reaction medium in the course of the reaction was confirmed to be an indispensable part of catalyst activation rather than a result of its degradation. ${ }^{17}$ Hence, ligand design must be directed towards facilitating rather than avoiding cyclometalation.

Scheme 4. Isomerizing ethenolysis of rapeseed methyl ester.

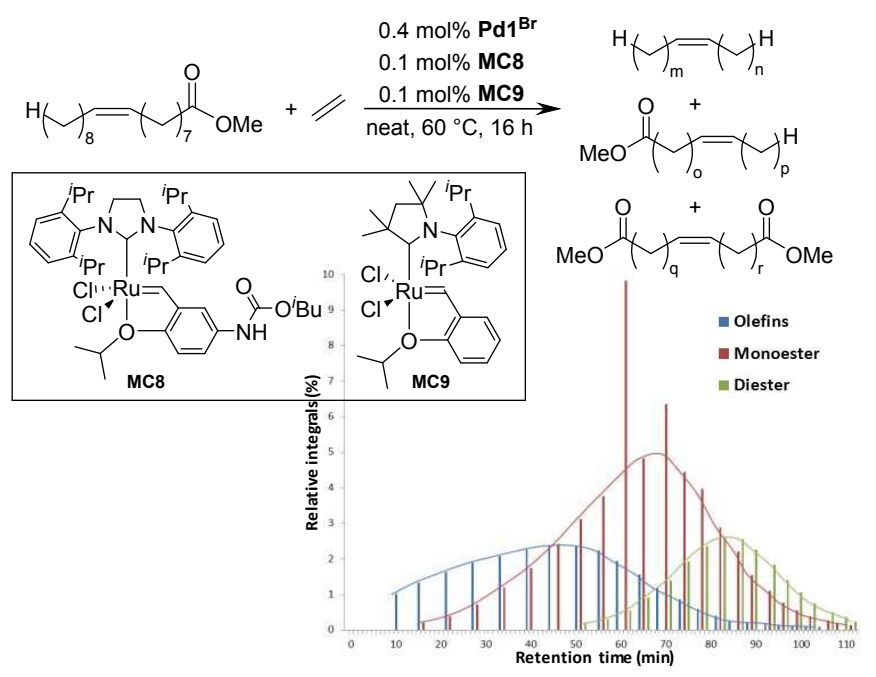

\section{COMPUTATIONAL METHODS}

All theoretical calculations were carried out using the Gaussian03 $3^{53}$ and Gaussian09 program packages. ${ }^{54}$ All geometries of reactants, products, intermediates, and transition states were optimized with the B3LYP exchange-correlation functional $^{55}$ including the Grimme empirical dispersion correction D3. ${ }^{56}$ In the geometrical optimizations, the 6$31+\mathrm{G}(\mathrm{d})$ basis set ${ }^{57}$ was considered for the lighter atoms $\mathrm{H}, \mathrm{C}$, $\mathrm{N}, \mathrm{O}, \mathrm{P}$ and $\mathrm{Br}, \mathrm{Cl}$. For the heavier $\mathrm{Pd}$, I atoms, we employed the double- $\zeta$-quality basis set with the relativistic effective core potential of Hay and Wadt (LANL2DZ). ${ }^{58}$ Each optimized structure was subsequently analyzed by harmonic vibration frequencies to characterize the stationary point as minima or saddle point. Geometries were fully optimized without symmetry constraints. The intermediates were verified as true minima by the absence of negative eigenvalue, whereas the transition states were characterized by a single imaginary frequency corresponding to the reaction coordinate. The rigidrotator harmonic oscillator approximation was applied for evaluating the thermal and entropic contributions that are needed to derive the enthalpies $H$ and Gibbs free energies $G$ at $323.15 \mathrm{~K}$. All transition states were located using the linear synchronous transit (LST) method, ${ }^{59}$ in which the reaction coordinate was kept fixed at different distances while all other degrees of freedom were relaxed. After the linear transit search, the transition states were optimized using the default Berny algorithm implemented in the Gaussian09 code. ${ }^{54}$ All transition states were confirmed by Intrinsic Reaction Coordinate (IRC) calculations. ${ }^{60}$ To obtain more reliable relative energies, the single-point calculations of optimized geometries were carried out at the level of B3LYP-D3/6-311++G(d)* $(\mathrm{H}, \mathrm{C}, \mathrm{N}, \mathrm{O}, \mathrm{P}, \mathrm{Br}$, $\mathrm{Cl})$, SDD (I), LANLZTZ(f) Pd, taking into account the solvation effect of toluene $(\varepsilon=2.374)$. Solvation energies $\left(E_{\mathrm{L}} \mathrm{s}\right)$ were evaluated by a self-consistent reaction field (SCRF) approach for all intermediates and transition states using the 
SMD continuum solvation model ${ }^{61}$ implemented in Gaussian09. To reduce computational cost, the two-layer ONIOM(MO:MO) ${ }^{62}$ method was employed for the adamantyl substituents. The ONIOM high level was designated to the whole molecules except for the adamantyl fragments from phosphines. The high level was treated at the B3LYP-D3/6$31+\mathrm{G}^{*}(\mathrm{H}, \mathrm{C}, \mathrm{N}, \mathrm{O}, \mathrm{P}, \mathrm{Br})$, LANL2DZ(Pd, I) level, whereas the ONIOM low level has been described using the B3LYP-D3/3$21 \mathrm{G}$ method. Natural bond orbital $(\mathrm{NBO})^{63}$ analysis was performed on the optimized geometry using the NBO Version 3.1 program. Quantum Theory of Atoms in Molecules (QTAIM) calculations were also performed to characterize the electronic distribution around some selected bonds in the chemical species applying Bader's atoms-in-molecule (AIM) theory. ${ }^{64}$

In the Gaussian program, the concentration can be specified by adjusting the pressure value based on the ideal gas law $P_{i}=$ $R T n_{i} / V$, where $P_{i}, R, T, n_{i}$ and V signify pressure, universal gas constant, absolute temperature, molar quantity, and reaction volume, respectively. The experimental concentrations of catalyst and reactants at the reaction temperature $(323.15 \mathrm{~K})$ are approximated by setting the partial pressures of the substrates as follows: propene (1) and propane (2): $1.0 \times 10^{-3} \mathrm{~mol}=13.2$ atm; and of the intermediates of the catalytic cycle as follows: catalyst $\left(\mathbf{P d 1}{ }^{\mathrm{Br}}\right): 2.5 \times 10^{-6} \mathrm{~mol}=0.033 \mathrm{~atm}$ (for details, see Scheme S1).

In the present study, we considered two energy values: $G_{323.15 K^{S}} \mathrm{~s}$ $\mathrm{L}$ and $H_{323.15 \mathrm{~K}} \mathrm{~S}$, , which represent Gibbs free energy and the enthalpy, respectively, in the solution phase at the higher basis set mentioned earlier. The solution-phase Gibbs free energy

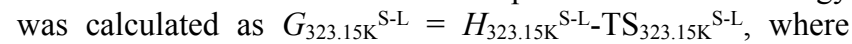
$H_{323.15 \mathrm{~K}}{ }^{\mathrm{S}-\mathrm{L}}$ represents the solution-phase enthalpy calculated

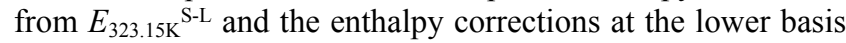
set, whereas the solvation entropy $\left(S_{323.15 \mathrm{~K}}^{\mathrm{S}-\mathrm{L}}\right)$ was estimated as $2 / 3$ of the gas-phase value. ${ }^{65}$ All single-point calculations were performed with tight wave-function convergence criteria, and an "ultrafine" (99950) grid was used in numerical integration. Throughout the text, all bond lengths are given in Ångström, and relative energies are expressed in $\mathrm{kcal} / \mathrm{mol}$. The values

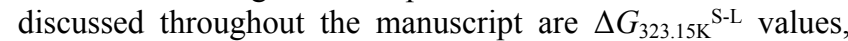
unless otherwise specified. All pictures are rendered with ChemDraw Ultra 16.0 and CYLview software. ${ }^{66}$

\section{RESULTS AND DISCUSSION}

Several facts known from experimental results form the boundaries for the DFT study. (1) Double-bond isomerizations with $\mathbf{P d} \mathbf{1}^{\mathbf{B r}}$ as the catalyst proceed rapidly at room temperature with a negligible induction period, whereas $\mathrm{Pd}^{\mathrm{II}}$ and $\mathrm{Pd}^{0}$ phosphine complexes do not display any reactivity under the optimized conditions. ${ }^{17}$ (2) In isomerizing metathesis reactions, the activity of ruthenium catalysts is diminished upon addition of tert-butyl phosphine or its oxide, whereas the presence of Pd1 $^{\text {Br }}$ does not adversely affect the performance of Ru-based metathesis co-catalysts. ${ }^{14 a}$ This means that during catalyst activation, neither $\mathrm{P}^{t} \mathrm{Bu}_{3}$ nor the corresponding phosphine oxide are released. (3) The dinuclear palladacycle $\mathbf{P d 2}{ }^{\mathbf{B r}}$ is the predominant $\mathrm{Pd}$ species detected after completion of isomerizing metatheses. One might speculate that this doubly cyclometalated product forms via consecutive cyclometalation steps via a dinuclear palladium monohydride intermediate (Scheme 5). (4) Upon addition of phosphines, mononuclear Pd-
$\mathrm{H}$ species were detected in NMR investigations of reaction solutions, presumably $\left({ }^{t} \mathrm{Bu}_{3} \mathrm{P}\right)_{2} \mathrm{PdHBr} \quad\left(\mathbf{P d 5}^{\mathrm{Br}}\right)$. (5) Diphosphinopalladium hydride species show isomerizing activity beyond single bond flips only above $80^{\circ} \mathrm{C}$, so that they are unlikely to play a role. ${ }^{52}$ The energy span of the actual catalytic cycle starting from $\mathbf{P d} 1^{\mathrm{Br}}$ must be smaller than the 20 $\mathrm{kcal} / \mathrm{mol}$ calculated by Mazet and coworkers for $\mathrm{L}_{2} \mathrm{Pd}^{\mathrm{II}}-\mathrm{H}$ cycles. ${ }^{67}$

Scheme 5. Top: Degradation of $\mathrm{Pd} 1^{\mathrm{Br}}$ to $\mathrm{Pd}^{\mathrm{Br}}$ with possible intermediates; bottom: optimized $\mathrm{Pd}^{\mathrm{Br}}$ geometry.

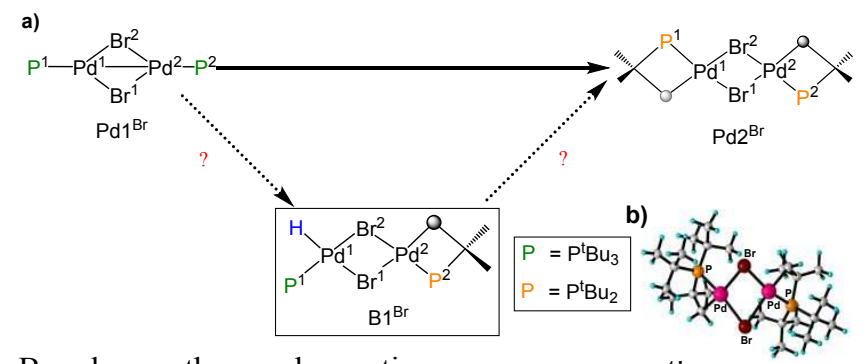

Based on these observations, numerous pathways were computed starting from $\mathbf{P d} 1^{\mathrm{Br}}$, of which the most relevant are depicted in Scheme 6. All pathways were calculated along the pathway from propene (1) to the isomerized product (1i), as well as the other way around, to cross-validate all values and ensure that they represent the actual energy minimum. Pathway A is representative of catalytic double-bond isomerization cycles that are initiated by the reaction of an alkene directly with the dinuclear $\mathrm{Pd}^{\mathrm{I}}$ complex. It features carbene intermediates similar to those proposed by Iluc et al. for mononuclear Pd ${ }^{\mathrm{II}}$ catalysis. ${ }^{67}$ This pathway has an energy span of $54.4 \mathrm{kcal} / \mathrm{mol}$, much too high for a reaction that proceeds rapidly at RT (For further details: see SI, Pathway A: dinuclear $\mathrm{Pd}^{\mathrm{I}}$ catalysis).

Several alternative pathways starting from $\mathbf{P d} 1^{\mathrm{Br}}$ were investigated, but were all ruled out based on unrealistically high-energy steps. No energetically feasible entry to established allylpalladium pathways ${ }^{68}$ opened up when shortening the distance between the alkene $\mathbf{1}$ and the dinuclear $\mathrm{Pd}^{\mathrm{I}}$ complex $\mathbf{P d} 1^{\mathrm{Br}}$. The formation of dinuclear allyl hydride complexes was found to be endergonic by 26.2 and $23.7 \mathrm{kcal} / \mathrm{mol}$, depending on whether the hydride ends up at the same Pd atom as the allyl group $\left(\mathbf{A} 1 \mathbf{a}^{\mathbf{B r}}\right)$ or at the neighboring one $\left(\mathbf{A} 1 \mathbf{b}^{\mathbf{B r}}\right.$, Scheme S2, I and II). We also probed whether a base-assisted allylic $\mathrm{C}-\mathrm{H}$ activation starting directly from $\mathbf{P d 1} \mathbf{1}^{\mathbf{B r}}$ was conceivable. However, the transfer of an allylic proton to a bridging bromine atom resulting in the formation of a dinuclear allyl-Pd complex $\left(\mathbf{A 1} \mathbf{c}^{\mathbf{B r}}\right.$ ), along with $\mathrm{HBr}$, is endergonic by $32.2 \mathrm{kcal}$ (Scheme S2, III). All these investigations render a dinuclear allylic isomerization mechanism even less likely than the carbene mechanism outlined as Pathway A.

Pathway B is representative of catalytic cycles starting from the dinuclear $\mathrm{Pd}-\mathrm{H}$ species $\mathbf{B 1}{ }^{\mathrm{Br}}$ generated from $\mathbf{P d 1}{ }^{\mathbf{B r}}$ via intramolecular $\mathrm{C}-\mathrm{H}$ activation, en route to the experimentally observed bis-palladacycle $\mathbf{P d} 2^{\mathbf{B r}}$. Among them, the depicted pathway was found to be by far the most energetically favorable, with an energy span of $9.5 \mathrm{kcal} / \mathrm{mol}$.

Pathway $\mathbf{C}$ is initiated by formation of the monophosphine $\mathrm{Pd}-$ $\mathrm{H}$ species $\mathbf{C 1}^{\mathrm{Br}}$ with release of the stable palladacycle $\mathbf{P d} \mathbf{2}^{\mathrm{Br}}$ from $\mathbf{B} 1^{\mathrm{Br}}$. The actual catalytic cycle consists of a $\mathrm{Pd}-\mathrm{H}$ insertion/ $\beta$-hydride elimination sequence analogous to that proposed for diphosphinopalladium hydride catalysts, ${ }^{48,50,69}$ but 
with one less phosphine ligand. It has an energy span of only $5.4 \mathrm{kcal} / \mathrm{mol}$.

In direct comparison to these three pathways involving monoligated $\mathrm{Pd}$, we also investigated several catalytic pathways starting from the bisphosphine complex $\left({ }^{\mathrm{B}} \mathrm{Bu}_{3} \mathrm{P}\right)_{2} \mathrm{PdHBr}\left(\mathbf{P d 5} 5^{\mathrm{Br}}\right.$, Scheme S2, IV-VI). However, the addition of propene to coordinatively saturated $\mathbf{P d 5} 5^{\mathbf{B r}}$ is endergonic by $20.3 \mathrm{kcal} / \mathrm{mol}$ $\left(\mathbf{P d 5}^{\mathbf{B r}} \rightarrow \mathbf{A 1} \mathbf{d}^{\mathrm{Br}}\right)$. Base-assisted allylic $\mathrm{C}-\mathrm{H}$ activations in which the bromide or phosphine act as the base also turned out to be unfavorable. A reaction leading to the cationic bisphosphine complex $\left(\mathrm{Al}^{\mathrm{Br}}\right)$ is endergonic by $\Delta G_{323.15 \mathrm{~K}} \mathrm{~S}-\mathrm{L}=45.5 \mathrm{kcal} / \mathrm{mol}$. Mechanisms involving temporary liberation and recoordination of phosphines in exchange for propene ligands were ruled out, since they must also be expected to result in phosphine transfer, thereby inevitably deactivating the ruthenium co-catalyst (Scheme S2, IV-VI). This would be in contrast to experimental findings.

Scheme 6. Selected isomerization pathways starting from pre-catalyst $\left[\mathrm{Pd}^{\mathrm{I}}(\mu-\mathrm{Br})^{t} \mathrm{Bu} u_{3} \mathbf{P}\right]_{2} \mathbf{P d} 1^{\mathrm{Br}}$.

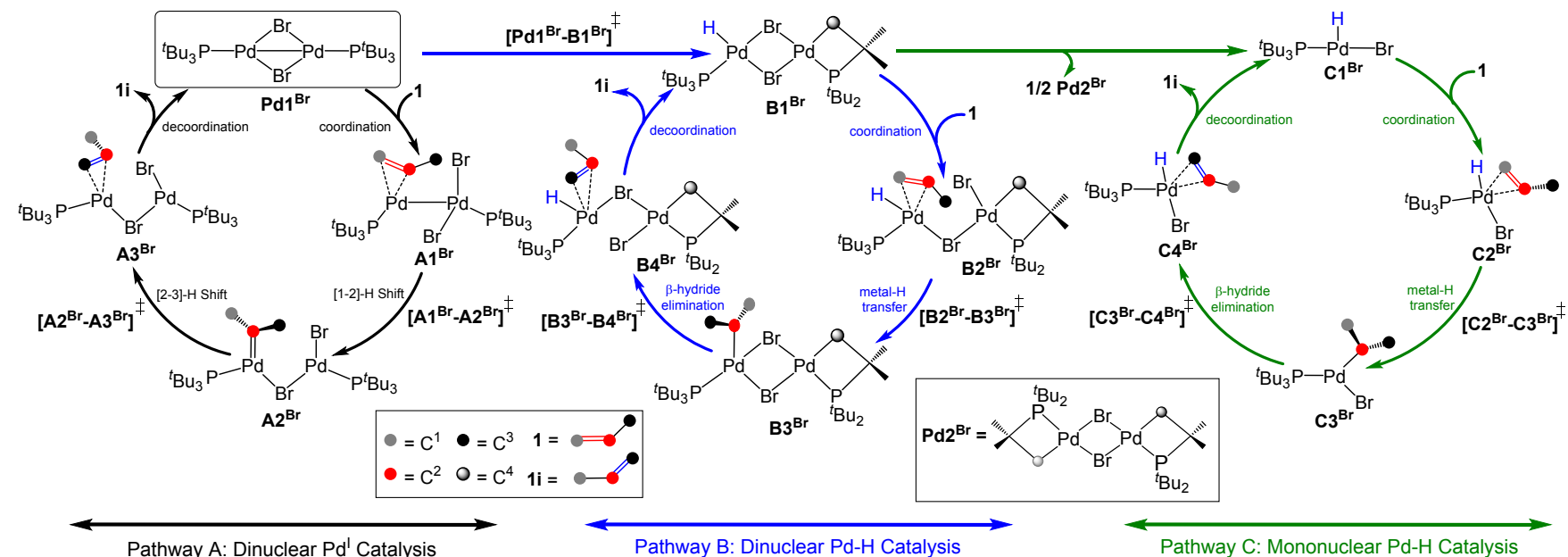

\section{Pathway B: dinuclear Pd-H catalysis}

Formation of dinuclear Pd-H species

Exploration of pathway A has made clear that the isomerization activity of dinuclear $\mathrm{Pd}^{\mathrm{I}}$ complex $\mathbf{P d 1} \mathbf{1}^{\mathrm{Br}}$ is not a consequence of its ability to directly activate alkenes. Another possible reason for this catalytic activity is that $\mathbf{P d} \mathbf{1}^{\mathrm{Br}}$ easily transforms into $\mathrm{Pd}-$ $\mathrm{H}$ species, which are widely postulated to be the active species in double-bond isomerizations. The conversion of $\mathbf{P d 1} \mathbf{1}^{\mathbf{B r}}$ to doubly cyclometalated $\mathrm{Pd}^{\mathrm{II}}$ dimer $\mathbf{P d} \mathbf{2}^{\mathrm{Br}}$ is well documented experimentally, and takes place already at room temperature in solution. ${ }^{17}$ It is reasonable to assume that it proceeds stepwise, and the first cyclometalation may well give rise to a $\mathrm{Pd}-\mathrm{H}$ intermediate capable of catalyzing double-bond isomerizations.

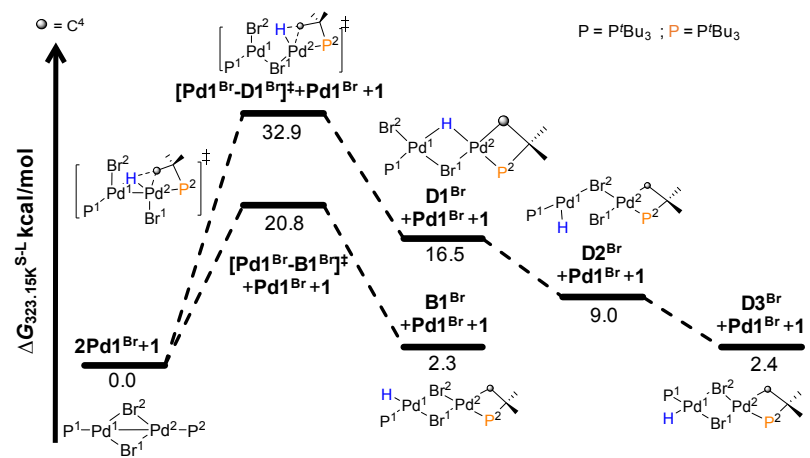

Figure 2. Energy profile diagram $\left(\Delta G_{323.15 \mathrm{~K}} \mathrm{~S}-\mathrm{L}\right.$ in $\left.\mathrm{kcal} / \mathrm{mol}\right)$ for potential catalyst activation pathways.
Indeed, when investigating potential pathways for the intramolecular $\mathrm{C}-\mathrm{H}$ activation of the tert-butyl ligand, we found two energetically favorable pathways in which the hydride liberated during $\mathrm{Pd}^{2}-\mathrm{C}$ bond formation transfers to $\mathrm{Pd}^{1}$ (Figure 2; structures and relevant geometrical parameters on the potential energy surface along the reaction coordinates depicted in Figure S3). The optimal pathway involves concerted $\mathrm{C}-\mathrm{H}$ bond activation of the tri(tert-butyl)phosphine ligand and hydride transfer, leading to the dinuclear $\mathrm{Pd}-\mathrm{H}$ complex $\mathbf{B} \mathbf{1}^{\mathrm{Br}}$ via a single transition state $\left[\mathbf{P d} \mathbf{1}^{\mathbf{B r}}-\mathbf{B} \mathbf{1}^{\mathrm{Br}}\right]^{\ddagger}$. Species $\mathbf{B} 1^{\mathbf{B r}}$ is thermodynamically less stable than $\mathbf{P d} 1^{\text {Br }}$ by only $2.3 \mathrm{kcal} / \mathrm{mol}$. The activation barrier of $20.8 \mathrm{kcal} / \mathrm{mol}$ for $\mathbf{P d 1} \mathbf{1}^{\mathbf{B r}} \rightarrow \mathbf{B} 1^{\mathbf{B r}}$ is rather low, which is in agreement with the experimental observation that the cyclopalladation proceeds swiftly at room temperature (Table S1). Based on simplified model studies, ${ }^{70}$ the dissociation of a phosphine from $\mathbf{P d} 1^{\mathrm{Br}}$ also appeared feasible. However, a comparative study revealed that the dissociation of a phosphine from $\mathbf{P d} \mathbf{1}^{\mathrm{Br}}$, which might also have opened up a viable catalyst activation pathway, is strongly endergonic (33.4 kcal/mol) and therefore less favorable (Scheme S3).

In $\mathbf{B} 1^{\mathbf{B r}}$, the two Pd centers adopt distorted square planar geometries, the phosphorous atoms are oriented syn to each other, and both the $\mathrm{Pd}^{1}$ and $\mathrm{Pd}^{2}$ nuclei are in oxidation state II (Figures 2 and S3). Whereas in $\mathbf{P d 1} 1^{\mathbf{B r}}$, a $\mathrm{Pd}-\mathrm{Pd}$ bond was manifested by an electron density maximum $(\rho(r)=0.051)$ between the two atoms and a short Pd-Pd distance of $2.636 \AA$, this bond is absent in $\mathbf{B 1}{ }^{\mathrm{Br}}$. This leads to a $\mathrm{Pd}-\mathrm{Pd}$ distance longer by $0.815 \AA$. The calculated electron density of $\mathrm{Pd}^{1}-$ $\mathrm{Br}^{2} / \mathrm{Pd}^{2}-\mathrm{Br}^{2}$ bonds at $(3,-1)$ bond critical points $(\mathrm{BCPs})$ in $\mathbf{P d} \mathbf{1}^{\mathrm{Br}}$ and $\mathbf{B 1}^{\mathrm{Br}}\left(\mathbf{P d 1}^{\mathrm{Br}}\right.$ : $0.057 / 0.057 ; \mathbf{B 1}^{\mathrm{Br}}$ : 0.054/0.054) indicates bridging $\mathrm{Pd}-\mathrm{Br}$ bonds in both complexes. 
In the transition state $\left[\mathbf{P d} \mathbf{1}^{\mathrm{Br}}-\mathbf{B} \mathbf{1}^{\mathrm{Br}}\right]^{\star}$, both of these bridging $\mathrm{Pd}-$ $\mathrm{Br}$ bonds are temporarily cleaved, resulting in increased electron densities $(0.069 / 0.068)$ for the terminal $\mathrm{Pd}-\mathrm{Br}$ bonds as well as increased negative NPA charges on the $\mathrm{Br}^{1}$ and $\mathrm{Br}^{2}$ atoms (-0.349/-0.361 e for $\mathbf{P d 1}{ }^{\mathbf{B r}}$ vs $-0.439 /-0.501$ e in $\left[\mathbf{P d 1}{ }^{\mathbf{B r}}\right.$ $\left.\mathbf{B} 1^{\mathbf{B r}}\right]^{\ddagger}$. In the transition state $\left[\mathbf{P d} \mathbf{1}^{\mathrm{Br}}-\mathbf{B} \mathbf{1}^{\mathrm{Br}}\right]^{\ddagger}$, the $\mathrm{Pd}^{1}-\mathrm{H}$ and $\mathrm{Pd}^{2}-\mathrm{C}^{4}$ bond distances are shortened to $1.805 \AA$ and $2.256 \AA$, whereas the $\mathrm{C}^{4}-\mathrm{H}$ bond is elongated to $1.585 \AA$ (Figure S3). The single imaginary frequency $\left(867.8 \mathrm{i} \mathrm{cm}{ }^{-1}\right)$ of $\left[\mathbf{P d 1} \mathbf{1}^{\mathbf{B r}}-\mathbf{B} 1^{\mathrm{Br}}\right]^{\ddagger}$ reflects the concerted formation of the $\mathrm{Pd}^{1}-\mathrm{H}$ and $\mathrm{Pd}^{2}-\mathrm{C}^{4}$ bonds and concomitant cleavage of the $\mathrm{Pd}^{1 / 2}-\mathrm{Br}^{1 / 2}$ and $\mathrm{C}^{4}-\mathrm{H}$ bonds (Figure S3).

Comparative studies revealed that the anti-isomer of $\mathbf{B} \mathbf{1}^{\mathrm{Br}}$ is less stable than $\mathbf{B 1}{ }^{\text {Br }}$ by only $0.1 \mathrm{kcal} / \mathrm{mol}$. We thus probed whether it is accessible with similar ease. Indeed, $\mathbf{D 3}^{\mathbf{B r}}$ can be generated through a distinct reaction channel in which initial activation of the tri(tert-butyl)phosphine $\mathrm{C}-\mathrm{H}$ bond takes place at a single $\mathrm{Pd}$ nucleus. However, the transition state $\left[\mathbf{P d} 1^{\mathbf{B r}}-\mathbf{D} 1^{\mathrm{Br}}\right]^{+}$has a substantially higher activation barrier of $32.9 \mathrm{kcal} / \mathrm{mol}$ (Figure 2). The resulting intermediate $\mathbf{D 1}^{\mathbf{B r}}$ features bridging hydride and bromide atoms and a $\mathrm{Pd}^{1}-\mathrm{Pd}^{2}$ distance of $2.799 \AA$. Its formation is endergonic by $16.5 \mathrm{kcal} / \mathrm{mol}$. The anti-configured dinuclear $\mathrm{Pd}-\mathrm{H}$ species $\mathbf{D 3}^{\mathrm{Br}}$ can be accessed by cleavage of the bridging hydrogen bond and subsequent conformational rearrangement reinstating the bridging bromide. This barrierless two-step process $\left(\mathbf{D 1}^{\mathrm{Br}} \rightarrow \mathbf{D 3}^{\mathrm{Br}} ; \Delta G_{323.15 \mathrm{~K}}{ }^{\mathrm{S}-\mathrm{L}}=-14.1\right.$ $\mathrm{kcal} / \mathrm{mol}$ ) occurs via a transient intermediate $\mathbf{D} 2^{\mathrm{Br}}$. The overall formation of active species $\mathbf{D 3}^{\mathbf{B r}}$ is endergonic by only 2.4 $\mathrm{kcal} / \mathrm{mol}$, but due to the high barrier of the first reaction step, this alternative pathway can be ruled out.

\section{Catalytic cycles involving a dinuclear $\mathrm{Pd}-\mathrm{H}$ species}

In principle, the alkene $\mathbf{1}$ can coordinate to either $\mathrm{Pd}$ atom of the dinuclear $\mathrm{Pd}-\mathrm{H}$ species $\mathbf{B} \mathbf{1}^{\mathrm{Br}}$, but only its coordination to the hydride-bearing $\mathrm{Pd}^{1}$ opened up an energetically reasonable pathway for double-bond isomerization. Following a coordination of 1 to $\mathrm{Pd}^{2}$, the only isomerization pathway that could be identified was calculated to have an excessive activation energy barrier of $79.3 \mathrm{kcal} / \mathrm{mol}$ (Figures S4 and S5), so that it was not considered to be relevant.

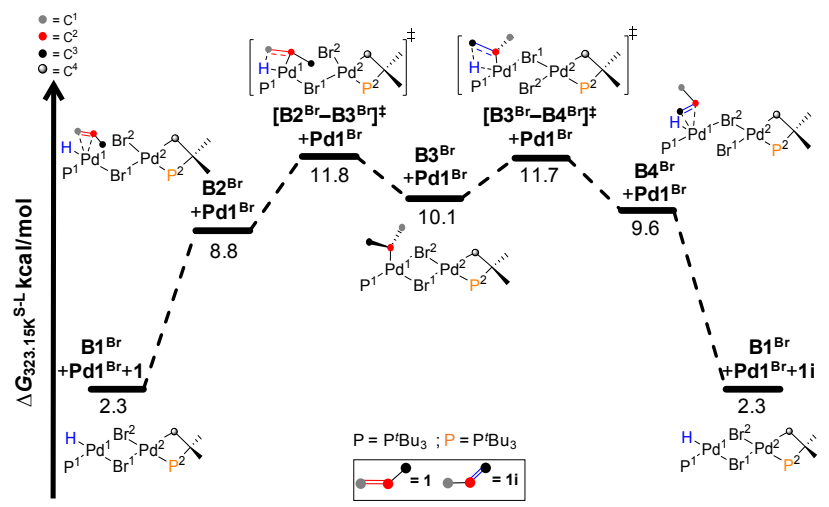

Figure 3. Energy profile diagram $\left(\Delta G_{323.15 \mathrm{~K}}^{\mathrm{S}-\mathrm{L}}\right.$ in $\left.\mathrm{kcal} / \mathrm{mol}\right)$ for dinuclear $\mathrm{Pd}-\mathrm{H}$ catalysis (pathway $\mathrm{B}$ ).

Coordination of propene to the $\mathrm{Pd}^{1}$ center within complex $\mathbf{B} 1^{\mathrm{Br}}$ affords the intermediate $\mathbf{B 2}^{\mathbf{B r}}$. It is endergonic by $6.5 \mathrm{kcal} / \mathrm{mol}$, which is a reasonable value for an entropically disfavored adduct formation $\left(\Delta S_{323.15 \mathrm{~K}}{ }^{\mathrm{S}-\mathrm{L}}=-0.022 \mathrm{kcal} / \mathrm{mol}-\mathrm{K}\right)$. In $\mathbf{B} 1^{\mathrm{Br}}$,
$\mathrm{Br}^{2}$ has left the coordination sphere of $\mathrm{Pd}^{1}$, creating a distorted trigonal-pyramidal geometry at $\left(\mathrm{Pd}^{1}\right)^{\mathrm{II}}$, while $\left(\mathrm{Pd}^{2}\right)^{\mathrm{II}}$ remains square planar (Figure 3). The ensuing insertion of the coordinated olefin into the $\mathrm{Pd}^{1}-\mathrm{H}$ bond with formation of the alkyl-Pd complex $\mathbf{B 3}^{\mathbf{B r}}$ is almost thermoneutral, and involves an activation barrier of only $3.0 \mathrm{kcal} / \mathrm{mol}$. It proceeds via the fourmembered transition state $\left[\mathbf{B 2}^{\mathbf{B r}}-\mathbf{B 3}^{\mathbf{B r}}\right]^{\ddagger}$ (Figure 3, see Figure S6 for details). In $\left[\mathbf{B 2}^{\mathrm{Br}}-\mathbf{B 3}^{\mathrm{Br}}\right]^{\ddagger}$, the $\mathrm{Pd}^{1}-\mathrm{H}$ bond is elongated to $1.589 \AA$ and the $\mathrm{C}^{1}-\mathrm{H}$ distance is shortened to $1.641 \AA$. Progressing from intermediate $\mathbf{B} 2^{\mathbf{B r}}$ to $\left[\mathbf{B 2}^{\mathbf{B r}}-\mathbf{B} 3^{\mathrm{Br}}\right]^{\ddagger}$, the NPA charge on the hydrogen atom is significantly increased by 0.121 e $\left(\mathbf{B 2}^{\mathbf{B r}} /\left[\mathbf{B 2}^{\mathbf{B r}}-\mathbf{B 3}^{\mathbf{B r}}\right]^{\ddagger}=-0.002 / 0.119\right.$ e), reflecting a reversal in charge during its migration from $\mathrm{Pd}^{1}$ to $\mathrm{C}^{1}$. Importantly, the $\mathrm{C}^{1}-$ $\mathrm{C}^{2}$ bond length is slightly elongated in $\left[\mathbf{B 2}^{\mathrm{Br}}-\mathbf{B 3}^{\mathrm{Br}}\right]^{\ddagger}$ compared to that in $\mathbf{B 2}^{\mathbf{B r}}\left(\left[\mathbf{B 2}^{\mathbf{B r}}-\mathbf{B 3}^{\mathbf{B r}}\right]^{\ddagger} / \mathbf{B 2}^{\mathbf{B r}}=1.402 / 1.359 \AA\right)$, indicating a change in hybridization. The successful conversion of double to single bond in the propene fragment is evident from the comparison of the calculated $\mathrm{C}^{1}-\mathrm{C}^{2}$ bond length in $\mathbf{B 3}^{\mathbf{B r}}$ with that of free propene $\left(\mathbf{B 3}^{\mathrm{Br}} / \mathbf{1}=1.518 / 1.337 \AA\right)$.

The double-bond migration is achieved by $\beta$-hydride elimination from the $\mathrm{C}^{3}$ atom. Elongation of $\mathrm{C}^{3}-\mathrm{H}$ bond leads to transition state $\left[\mathbf{B 3}^{\mathrm{Br}}-\mathbf{B} 4^{\mathrm{Br}}\right]^{+}$, which is only $1.6 \mathrm{kcal} / \mathrm{mol}$ higher in energy than $\mathbf{B 3}^{\mathbf{B r}}$. The transition vector in $\left[\mathbf{B 3}^{\mathbf{B r}}\right.$ $\left.\mathbf{B 4}^{\mathrm{Br}}\right]^{ \pm}$represents the simultaneous formation of the $\mathrm{Pd}^{1}-\mathrm{H}$ bond and cleavage of the $\mathrm{C}^{3}-\mathrm{H}$ bond $\left(\mathrm{Pd}^{1}-\mathrm{H}: 2.852 / 1.588 \AA ; \mathrm{C}^{3}-\mathrm{H}\right.$ : $1.102 / 1.641 \AA$ in $\mathbf{B 3}^{\mathrm{Br}}$ vs. $\left.\left[\mathbf{B 3}^{\mathrm{Br}}-\mathbf{B} 4^{\mathrm{Br}}\right]^{\ddagger}\right)$. Furthermore, the $\mathrm{C}^{2}$ $\mathrm{C}^{3}$ bond shortens $\left(1.518 / 1.401 \AA\right.$ in $\left.\mathbf{B 3}^{\mathrm{Br}} /\left[\mathbf{B 3}^{\mathrm{Br}}-\mathbf{B 4}^{\mathrm{Br}}\right]^{\ddagger}\right)$, suggesting an increase in double-bond character. Finally, the double-bond migration product $\mathbf{1 i}$ (which in this case is also propene) is released from $\mathbf{B} 4^{\mathrm{Br}}$ in a barrierless process, thereby regenerating the isomerization catalyst $\mathbf{B} 1^{\mathrm{Br}}$.

The energy profile of the double-bond isomerization via dinuclear $\mathrm{Pd}-\mathrm{H}$ catalysis (pathway B, Figure 3 ) has an overall energy span of only $9.5 \mathrm{kcal} / \mathrm{mol}$, which is realistic for a reaction that proceeds rapidly at room temperature. In order to benchmark Pd1 ${ }^{\text {Br }}$ against state-of-the-art systems, we calculated the isomerization of allyl alcohol in analogy to pathway B (Table S2). For this reaction, Mazet et al. have computed an energy span of $20.0 \mathrm{kcal} / \mathrm{mol}$ for cationic bis(ditert-butylphosphino)ethane palladium hydride. ${ }^{50}$ For $\mathbf{P d 1} 1^{\mathrm{Br}}$, we found an energy span of only $11.9 \mathrm{kcal} / \mathrm{mol}$.

\section{Pathway C: mononuclear Pd-H catalysis}

Formation of mononuclear $\mathrm{Pd}-\mathrm{H}$ species

Rather than acting as an isomerization catalyst itself, the dinuclear $\mathrm{Pd}-\mathrm{H}$ species $\mathbf{B 1}^{\mathrm{Br}}$ might also function as a key intermediate en route to a catalytically highly active mononuclear $\mathrm{Pd}-\mathrm{H}$ species. However, when we investigated potential pathways leading from $\mathbf{P d} \mathbf{1}^{\mathrm{Br}}$ to various $\mathrm{Pd}-\mathrm{H}$ species (Schemes 3 and 6; Figure 4), we initially came across excessive energetic barriers. For example, while the homolytic dissociation of $\mathbf{P d} \mathbf{1}^{\mathbf{B r}}$ with generation of the coordinatively unsaturated doublet $\mathrm{Pd}^{\mathrm{I}}$ species $\mathbf{P d 6}^{\mathrm{Br}}$ requires only moderate energy input $(20.7 \mathrm{kcal} / \mathrm{mol})$, a subsequent cyclopalladation step with formation of a $\mathrm{Pd}^{\mathrm{III}}-\mathrm{H}$ species $\left(\mathbf{P d} 7^{\mathbf{B r}}\right)$ turned out to be extremely endergonic $(91.7 \mathrm{kcal} / \mathrm{mol}$, Figure 4$)$. 


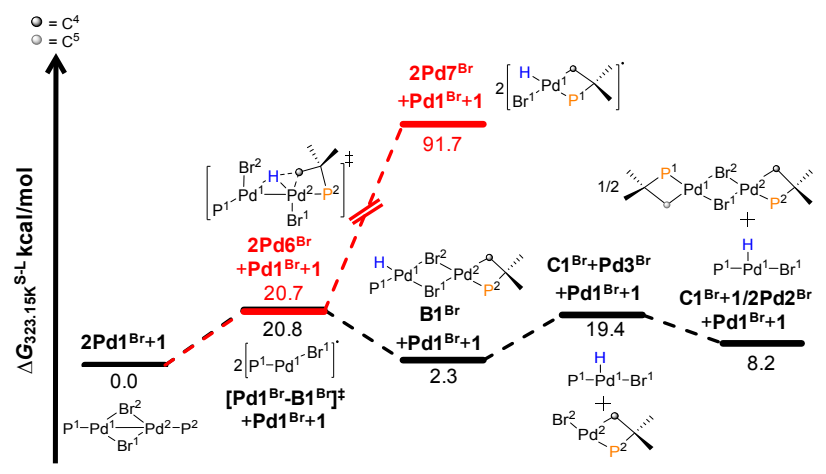

Figure 4. Energy profile diagram $\left(\Delta G_{323.15 \mathrm{~K}}{ }^{\mathrm{S}-\mathrm{L}}\right.$ in $\left.\mathrm{kcal} / \mathrm{mol}\right)$ for the formation of mononuclear $\mathrm{Pd}-\mathrm{H}$ species.

Finally, we identified an energetically favorable dissociation mechanism. The dissociation of the dinuclear $\mathrm{Pd}-\mathrm{H}$ species $\mathbf{B} 1^{\mathrm{Br}}$ to give the mononuclear $\mathrm{Pd}-\mathrm{H}$ species $\mathbf{C} 1^{\mathrm{Br}}$ along with the coordinatively unsaturated palladacycle $\mathbf{P d} 3^{\mathrm{Br}}$ requires a reasonable energy input of $19.4 \mathrm{kcal} / \mathrm{mol}$ (Figure 4). The exergonic dimerization of $\mathbf{P d} 3^{\mathbf{B r}}$ to give the dimeric bispalladacycle $\mathbf{P d 2} 2^{\mathrm{Br}}(-11.2 \mathrm{kcal} / \mathrm{mol})$ further reduces the overall energy demand of the overall reaction of two molecules of $\mathbf{B 1}{ }^{\mathrm{Br}}$ to two molecules of mononuclear $\mathrm{Pd} \mathrm{d}^{\mathrm{II}}-\mathrm{H}\left(\mathbf{C 1}^{\mathrm{Br}}\right)$ along with one molecule of the bispalladacycle $\operatorname{Pd}^{\mathrm{Br}}\left(\Delta G_{323.15 \mathrm{~K}} \mathrm{~S}-\mathrm{L}=\right.$ $4.1 \mathrm{kcal} / \mathrm{mol}$ per $\mathrm{Pd}-\mathrm{H}$ species). The strong enthalpic driving force $\left(\Delta H_{323.15 K^{\text {S-L }}}=-16.7 \mathrm{kcal} / \mathrm{mol}\right)$ overrides the loss in entropy for the dimerization of $\mathbf{P d} 3^{\mathrm{Br}}$ to $\mathbf{P d 2}{ }^{\mathrm{Br}}\left(\mathrm{T} \Delta S_{323.15 \mathrm{~K}} \mathrm{~S}-\mathrm{L}=-\right.$ $5.6 \mathrm{kcal} / \mathrm{mol}$ ). The simultaneous formation of an active $\mathrm{Pd}-\mathrm{H}$ catalyst along with inert $\mathbf{P d} 2^{\mathbf{B r}}$ is in excellent agreement with the experimentally observed build-up of the latter over the course of catalytic double-bond isomerizations. The presence of a coordinatively unsaturated monophosphinopalladium hydride $\mathbf{C 1}^{\mathrm{Br}}$ would also explain why the known diphosphinopalladium hydride complex $\mathbf{P d} 5^{\mathbf{B r}}$ was experimentally observed when excess phosphine was added to a catalytic isomerization reaction medium. ${ }^{17}$

The mononuclear Pd-H species $\mathbf{C} 1^{\mathrm{Br}}$ has a Pd oxidation state of II, and the d-electrons are localized in four lone pairs (Figure S7). The addition of another phosphine to $\mathbf{C 1}{ }^{\mathbf{B r}}$ was calculated to be energetically downhill by $\Delta G_{323.15 \mathrm{~K}}^{\mathrm{S}-\mathrm{L}}\left(\mathbf{C 1}^{\mathrm{Br}} \rightarrow \mathbf{P d} 5^{\mathrm{Br}}\right)=-$ $15.2 \mathrm{kcal} / \mathrm{mol}$ (see Scheme S4). However, even if free phosphine was available for this step - which is unlikely since the surplus ligand is irreversibly incorporated within palladacycle $\mathbf{P d} 2^{\mathbf{B r}}$ - the coordination of a propene substrate to the bisphosphino complex $\mathbf{P d 5}^{\mathrm{Br}}$ was calculated to lead preferentially to the release of a $\mathrm{P}^{t} \mathrm{Bu}_{3}$ ligand rather than of a bromide counterion (Scheme S2, IV). This is another indication that the mononuclear catalytic cycle is likely to proceed via monophosphine-Pd species. Additional ligand, as is present in the Skrydstrup system, is predicted to retard the isomerization due to the abovementioned competitive coordination to $\mathrm{Pd}$, which would explain why the $\operatorname{Pd}\left(\mathrm{P}^{t} \mathrm{Bu}_{3}\right)_{2} \mathrm{HBr}$ system is selective for single bond flips whereas catalysts generated from $\mathbf{P d 1}^{\mathrm{Br}}$ lead to full equilibration of double-bond isomers. ${ }^{52}$

\section{Catalytic cycle involving mononuclear $\mathrm{Pd}-\mathrm{H}$ species}

Since the $\mathrm{Pd}-\mathrm{H}$ species $\mathbf{C 1}^{\mathrm{Br}}$ is higher in free energy than the precatalyst $\mathbf{P d 1} 1^{\mathrm{Br}}$ by only $8.2 \mathrm{kcal} / \mathrm{mol}$ and accessible via an activation pathway with an overall barrier of only 20.8 $\mathrm{kcal} / \mathrm{mol}$, it is conceivable that it forms spontaneously from $\mathbf{P d 1}^{\mathrm{Br}}$ in organic solvents at room temperature. Further calculations revealed that $\mathbf{C 1}^{\mathrm{Br}}$ is an excellent isomerization catalyst. Figure 5 shows structures and energies of the most favorable catalytic cycle starting from $\mathrm{Pd}-\mathrm{H}$ species $\mathbf{C 1}{ }^{\mathrm{Br}}$. It is initiated by $\eta^{2}$-coordination of propene to $\mathbf{C 1}^{\mathrm{Br}}$, which is isoenergetic $\left(\Delta G_{323.15 \mathrm{~K}}^{\mathrm{S}-\mathrm{L}}=-0.5 \mathrm{kcal} / \mathrm{mol}\right)$. The bond angle of $\mathrm{H}-\mathrm{Pd}^{1}-\mathrm{Br}^{1}$ widens from $94.9^{\circ}$ in $\mathbf{C 1}^{\mathrm{Br}}$ to $172.6^{\circ}$ when propene approaches the $\mathrm{Pd}^{1}$ center between the $\mathrm{H}$ and $\mathrm{Br}$ ligands. In the resulting complex $\mathbf{C 2}^{\mathrm{Br}}$, the $\mathrm{Pd}^{1}-\mathrm{C}^{1}$ and $\mathrm{Pd}^{1}-\mathrm{C}^{2}$ bonds have comparable lengths $\left(\mathrm{Pd}^{1}-\mathrm{C}^{1 / 2}=2.345 / 2.395 \AA\right)$. Starting from $\mathbf{C 2}^{\mathrm{Br}}$, migratory insertion of the coordinated alkene into the $\mathrm{Pd}^{1}-\mathrm{H}$ bond with formation of the palladium isopropyl intermediate $\mathbf{C 3}^{\mathrm{Br}}$ is almost thermoneutral $(1.8 \mathrm{kcal} / \mathrm{mol})$. Complex $\mathbf{C 3}^{\mathrm{Br}}$ has a T-shaped geometry with $\angle \mathrm{P}^{1}-\mathrm{Pd}^{1}-\mathrm{Br}^{1}$ and $\angle \mathrm{C}^{2}-\mathrm{Pd}^{1}-\mathrm{Br}^{1}$ bond angles of $104.8^{\circ}$ and $88.0^{\circ}$, respectively (Figure S8). The elongation of the $\mathrm{C}^{1}-\mathrm{C}^{2}$ bond in intermediate $\mathbf{C 3}^{\mathrm{Br}}$ with respect to $\mathbf{C 2}^{\mathrm{Br}}\left(\mathrm{C}^{1}-\mathrm{C}^{2}\left(\mathbf{C 3}^{\mathrm{Br}} \mathbf{C}^{\mathrm{Br}}\right)=1.498 / 1.368 \AA\right)$ resembles the conversion of the $\mathrm{C}-\mathrm{C}$ double bond to a single bond.

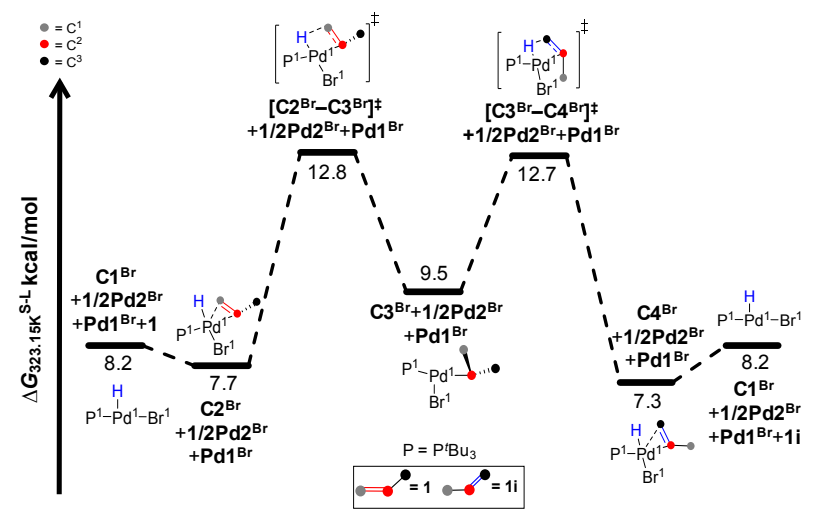

Figure 5. Energy profile diagram $\left(\Delta G_{323.15 \mathrm{~K}} \mathrm{~S}-\mathrm{L}\right.$ in $\left.\mathrm{kcal} / \mathrm{mol}\right)$ for mononuclear $\mathrm{Pd}-\mathrm{H}$ catalysis (pathway $\mathrm{C}$ ).

Formation of $\mathbf{C 3}^{\mathrm{Br}}$ requires a small activation barrier of 5.1 $\mathrm{kcal} / \mathrm{mol}$. It occurs via a four-membered transition state $\left[\mathbf{C 2}^{\mathrm{Br}}\right.$ $\left.\mathbf{C 3}^{\mathrm{Br}}\right]^{\ddagger}$, in which the $\mathrm{Pd}^{1}-\mathrm{H}$ and $\mathrm{C}^{1}-\mathrm{C}^{2}$ bond distances increase to $1.600 \AA$ and $1.406 \AA$, respectively, indicating the transfer of the hydride from $\mathrm{Pd}^{1}$ to $\mathrm{C}^{1}$ and the conversion of the $\mathrm{C}-\mathrm{C}$ double bond to a single bond. This process is also reflected in the imaginary frequency of $-662.9 \mathrm{i} \mathrm{cm}{ }^{-1}$. In order to shift the double bond from $\mathrm{C}^{1}-\mathrm{C}^{2}$ to $\mathrm{C}^{2}-\mathrm{C}^{3}$, the isopropyl residue can be rotated by $180^{\circ}$ for the pathway from $\mathbf{C 1}^{\mathbf{B r}}$ to $\mathbf{C 3}^{\mathrm{Br}}$ to be traced backwards to $\mathbf{C 1}^{\mathrm{Br}}$ and the isomerized propene 1i. When omitting the rotation step and shortening the $\mathrm{Pd}-\mathrm{H}^{1}$ distance, an alternative pathway with marginally divergent structures and energies was identified. The presence of two pathways for the double-bond isomerization with energy spans below 10.0 $\mathrm{kcal} / \mathrm{mol}$ suggests that $\mathbf{C 1}^{\mathrm{Br}}$ is a catalytic species with tremendous isomerization activity.

\section{Catalyst deactivation}

Deactivation of the isomerization catalyst within several hours at room temperature even under strictly anaerobic and anhydrous conditions has become the limiting factor in the development of $\mathrm{Pd} / \mathrm{Ru}$ bimetallic isomerizing metathesis. Since the bispalladacycle $\mathbf{P d} 2^{\mathrm{Br}}$ has been found to accumulate in the reaction mixture over the course of the reaction, it was 
reasonable to assume that there is a direct deactivation pathway starting from $\mathbf{B} 1^{\mathbf{B r}}$ or $\mathbf{C 1}^{\mathbf{B r}}$ leading to $\mathbf{P d 2}{ }^{\mathbf{B r}}$ with release of dihydrogen (Scheme S5a). However, after investigating numerous conceivable pathways, it became apparent that selfdeactivation of any of the catalytic intermediates, e.g. via cyclometalation processes, is prevented by high barriers that could never compete with the low-energy steps of the catalytic cycles (Scheme 7). For example, the first cyclometalation step, which converts $\mathbf{P d} 1^{\mathrm{Br}}$ to the monocyclometalated dinuclear $\mathrm{Pd}^{\mathrm{II}}$ species $\mathbf{B 1}^{\mathrm{Br}}$, has a low barrier of only $20.8 \mathrm{kcal} / \mathrm{mol}$. In contrast, a hypothetical second cyclometalation step with loss of hydrogen and formation of the experimentally observed bispalladacycle $\mathbf{P d} 2^{\mathrm{Br}}$ would not only be endergonic $\left(\Delta G_{323.15 \mathrm{~K}}{ }^{\mathrm{S}}\right.$ $\mathrm{L}=9.5 \mathrm{kcal} / \mathrm{mol})$, but would moreover have a high activation barrier $\left(\left[\mathbf{B 1}^{\mathrm{Br}} \mathbf{P d 2}^{\mathrm{Br}}\right]^{\star}, \Delta^{\ddagger} G_{323.15 \mathrm{~K}}{ }^{\mathrm{S}-\mathrm{L}}=44.1 \mathrm{kcal} / \mathrm{mol}\right.$; Scheme $\mathrm{S} 5 \mathrm{a})$. Similarly, when starting from the coordinatively unsaturated $\mathrm{Pd}^{\mathrm{II}}$ hydride species $\mathbf{C 1}^{\mathrm{Br}}$, the formation of $\mathbf{P d 2}{ }^{\mathbf{B r}}$ along with dihydrogen is endergonic $\left(\Delta G_{323.15 \mathrm{~K}} \mathrm{~S}-\mathrm{L}=3.6\right.$ $\mathrm{kcal} / \mathrm{mol})$, and the transition state $\left[\mathbf{C 1}^{\mathbf{B r}}-\mathbf{P d 8 ^ { \mathbf { B r } }}\right]^{\ddagger}$ is unrealistically high $\left(\Delta^{\ddagger} G_{323.15 \mathrm{~K}} \mathrm{~S}-\mathrm{L}=34.2 \mathrm{kcal} / \mathrm{mol}\right.$; Scheme S5a).

Since the release of energy-rich dihydrogen strongly contributes to the endergonicity of the process, we next investigated pathways in which the hydrogen is exergonically transferred to the propene substrate, i.e. leading from isopropyl$\mathrm{Pd}$ complexes to $\mathbf{P d} \mathbf{2}^{\mathrm{Br}}$ and propane (2). The overall reaction of two molecules of $\mathbf{C} 3^{\mathbf{B r}}$ to $\mathbf{P d 2}{ }^{\mathbf{B r}}$ with liberation of two propane molecules is indeed strongly exergonic $\left(\Delta G_{323.15 \mathrm{~K}}{ }^{\mathrm{S}-\mathrm{L}}=-46.3\right.$ $\mathrm{kcal} / \mathrm{mol}$ ), but the corresponding pathways have an unrealistically large energy span $\left(\Delta G_{323.15 \mathrm{~K}} \mathrm{~S}-\mathrm{L}=37.6 \mathrm{kcal} / \mathrm{mol}\right.$; Scheme S5b). Reactions of the isopropyl-Pd complex $\mathbf{C} 3^{\mathrm{Br}}$ with $\mathbf{C 1}^{\mathrm{Br}}$ to give $\mathbf{D 3}^{\mathrm{Br}}$ or $\mathbf{F 3}^{\mathrm{Br}}$ are also exergonic $\left(\Delta G_{323.15 \mathrm{~K}}{ }^{\mathrm{S}-\mathrm{L}}=-\right.$ $29.1 \mathrm{kcal} / \mathrm{mol}$ and $-2.5 \mathrm{kcal} / \mathrm{mol}$, respectively) but both require energetically unrealistically high transition states $\left(\Delta^{\ddagger} G_{323.15 \mathrm{~K}} \mathrm{~S}-\mathrm{L}\right.$ $=36.2 \mathrm{kcal} / \mathrm{mol}$ and $49.4 \mathrm{kcal} / \mathrm{mol}$, respectively).

Scheme 7. Catalyst deactivation pathways. Energy values $\left(\Delta G_{323.15 K^{S-L}}\right)$ are in $\mathrm{kcal} / \mathrm{mol}$.

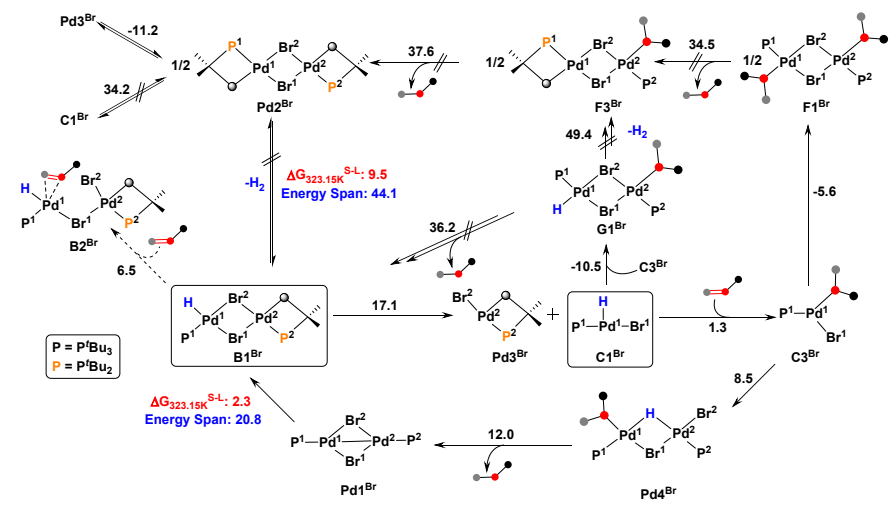

After many dead ends, we realized that the most favorable pathway to deactivation leads back to the precatalyst $\mathbf{P d} \mathbf{1}^{\mathbf{B r}}$ (Figure 6). It consists of the reaction of the $\mathrm{Pd}^{\mathrm{II}}$ hydride species $\mathbf{C 1}^{\mathbf{B r}}$ with the isopropyl-Pd species $\mathbf{C 3}^{\mathrm{Br}}$ to the catalyst precursor $\mathbf{P d 1}{ }^{\mathbf{B r}}$ with release of propane. This reaction requires an additional activation barrier of $20.5 \mathrm{kcal} / \mathrm{mol}$, but is exergonic by $23.3 \mathrm{kcal} / \mathrm{mol}$. The deactivation pathway starts with the endergonic adduct formation between $\mathbf{C 1}^{\mathrm{Br}}$ and $\mathbf{C 3}^{\mathrm{Br}}$ $\left(\Delta G_{323.15 \mathrm{~K}}{ }^{\mathrm{S}-\mathrm{L}}=8.5 \mathrm{kcal} / \mathrm{mol}\right)$ to give $\mathbf{P d} 4^{\mathrm{Br}}$ (Figure 6).

In most cases, this adduct will dissociate, and the majority of the catalyst molecules will continue their productive turnover along pathway $\mathrm{C}$ by crossing the barrier of only $3.2 \mathrm{kcal} / \mathrm{mol}$, leading to species $\mathbf{C} 4^{\mathrm{Br}}$. It is, however, conceivable that a small number of catalyst molecules will instead cross the higher energy barrier of $20.5 \mathrm{kcal} / \mathrm{mol}$ leading to the precatalyst $\mathbf{P d 1}{ }^{\mathrm{Br}}$ with release of propane.

Thus, it is the conversion of the catalytically active, dinuclear $\mathrm{Pd}-\mathrm{H}$ species $\mathbf{B} 1^{\mathbf{B r}}$ into the even more active but rather unstable mononuclear $\mathrm{Pd}-\mathrm{H}$ species $\mathbf{C} \mathbf{1}^{\mathrm{Br}}$ that leads to the continuous buildup of $\mathbf{P d 2} 2^{\mathbf{B r}}$, and ultimately to the decay of catalytic activity.

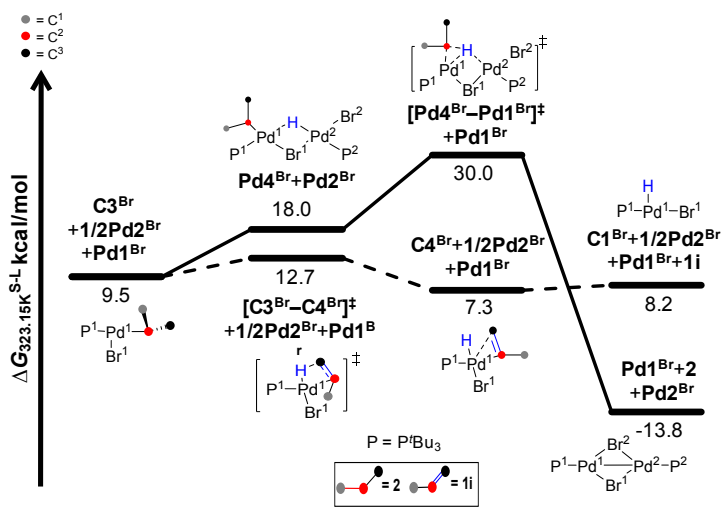

Figure 6. Energy profile $\left(\Delta G_{323.15 \mathrm{~K}}{ }^{\mathrm{S}-\mathrm{L}}\right.$ in $\left.\mathrm{kcal} / \mathrm{mol}\right)$ of catalyst deactivation (solid line) in relation to catalyst propagation (dotted line).

Compilation of the catalytic cycles

The free energy profiles $\left(\Delta G_{323.15 \mathrm{~K}}{ }^{\mathrm{S}-\mathrm{L}}\right)$ of the most relevant pathways including the activation and deactivation steps were calculated relative to $2 \cdot \mathbf{P d} \mathbf{1}^{\mathbf{B r}}+$ propene (1), and are overlaid in Figure 7.

The isomerization pathway $\mathrm{B} \quad\left(\mathbf{B} 1^{\mathrm{Br}} \rightarrow \mathbf{B 2}^{\mathrm{Br}} \rightarrow \mathbf{B 3}^{\mathrm{Br}} \rightarrow \mathbf{B} 4^{\mathrm{Br}} \rightarrow\right.$ $\mathbf{B} 1^{\mathrm{Br}}$; solid blue lines) is entered via generation of the dinuclear palladium hydride species $\mathbf{B 1}^{\mathbf{B r}}$ with a moderate activation barrier of $20.8 \mathrm{kcal} / \mathrm{mol}\left(\mathbf{P d 1} \mathbf{1}^{\mathbf{B r}} \rightarrow \mathbf{B} 1^{\mathbf{B r}}\right)$. The highest barrier in the actual isomerization process is contributed to by endergonic coordination of the alkene to $\mathbf{B} 1^{\mathbf{B r}}(6.5 \mathrm{kcal} / \mathrm{mol})$, immediately followed by migratory insertion $(3.0 \mathrm{kcal} / \mathrm{mol})$. The energy span of pathway B is only $9.5 \mathrm{kcal} / \mathrm{mol}$, which is in excellent agreement with a reaction that proceeds rapidly at room temperature.

The dissociation of $\mathbf{B} \mathbf{1}^{\mathrm{Br}}$ into the mononuclear $\mathrm{Pd}-\mathrm{H}$ species $\mathbf{C 1}^{\mathrm{Br}}$ along with $\mathbf{P d 3 ^ { \mathrm { Br } }}$ involves a lower barrier $(17.1 \mathrm{kcal} / \mathrm{mol})$ than is required for the formation of $\mathbf{B} 1^{\mathrm{Br}}$ from $\mathbf{P d 1} \mathbf{1}^{\mathrm{Br}}$. Thus, it is reasonable to assume that, once the $20.8 \mathrm{kcal} / \mathrm{mol}$ barrier for the formation of $\mathbf{B} \mathbf{1}^{\mathbf{B r}}$ is overcome, part of the catalyst will directly cross this additional barrier and enter pathway $\mathrm{C}$ $\left(\mathrm{C1}^{\mathrm{Br}} \rightarrow \mathrm{C2}^{\mathrm{Br}} \rightarrow \mathrm{C3}^{\mathrm{Br}} \rightarrow \mathbf{C 4}^{\mathrm{Br}} \rightarrow \mathbf{C 1}^{\mathrm{Br}}\right.$; solid green line). Pathway $\mathrm{C}$ is energetically the most advantageous. Following endergonic coordination of the alkene, all subsequent activation energies are below $6.0 \mathrm{kcal} / \mathrm{mol}$. The energy span for this cycle amounts to $5.4 \mathrm{kcal} / \mathrm{mol}$, which suggests that isomerization via this pathway would proceed extremely fast at room temperature.

The calculations reflect the chief characteristics of this catalyst system: Once the catalyst passes the low barrier from dinuclear to mononuclear $\mathrm{Pd}-\mathrm{H}$ species, it is tremendously active due to the energy span of only $5.4 \mathrm{kcal} / \mathrm{mol}$ for the isomerization cycle. However, catalyst propagation and deactivation pathways 
bifurcate at intermediate $\mathbf{C 3}^{\mathrm{Br}}$. Whereas the remaining energy barrier for propagation $\left[\mathrm{C3}^{\mathrm{Br}}-\mathrm{C}^{\mathrm{Br}}\right]^{*}$ is only $3.2 \mathrm{kcal} / \mathrm{mol}$, a barrier of $20.5 \mathrm{kcal} / \mathrm{mol}$ for $\left[\mathbf{P d}^{\mathrm{Br}}{ }_{-} \mathbf{P d} 1^{\mathrm{Br}}\right]^{\ddagger}$ relative to $\mathbf{C 3}^{\mathrm{Br}}$ $(30.0 \mathrm{kcal} / \mathrm{mol}$ overall) is associated with catalyst deactivation. This is in good agreement with the experimental finding that the catalyst is highly active but has a rather short lifetime.

The calculations also explain the unique ability of the dinuclear $\mathrm{Pd}^{\mathrm{I}}$ species $\mathbf{P d 1}{ }^{\mathrm{Br}}$ to act as a co-catalyst in orthogonal tandem catalysis: (1) a highly efficient dinuclear $\mathrm{Pd}-\mathrm{H}$ isomerization catalyst is formed by an intramolecular process that does not release any byproduct; (2) its dissociation gives rise to an even more active mononuclear $\mathrm{Pd}-\mathrm{H}$ catalyst along with a chemically inert bispalladacyclic byproduct; and (3) the predominating pathway for catalyst deactivation, which starts at the mononuclear species, actually leads back to the precatalyst. Consequently, in none of these steps, byproducts are released that might interfere with sensitive ruthenium cocatalysts. This rather unusual overall network of activation and deactivation processes is in excellent agreement with the experimental observations, and its elucidation will be of decisive importance for a rational catalyst development.

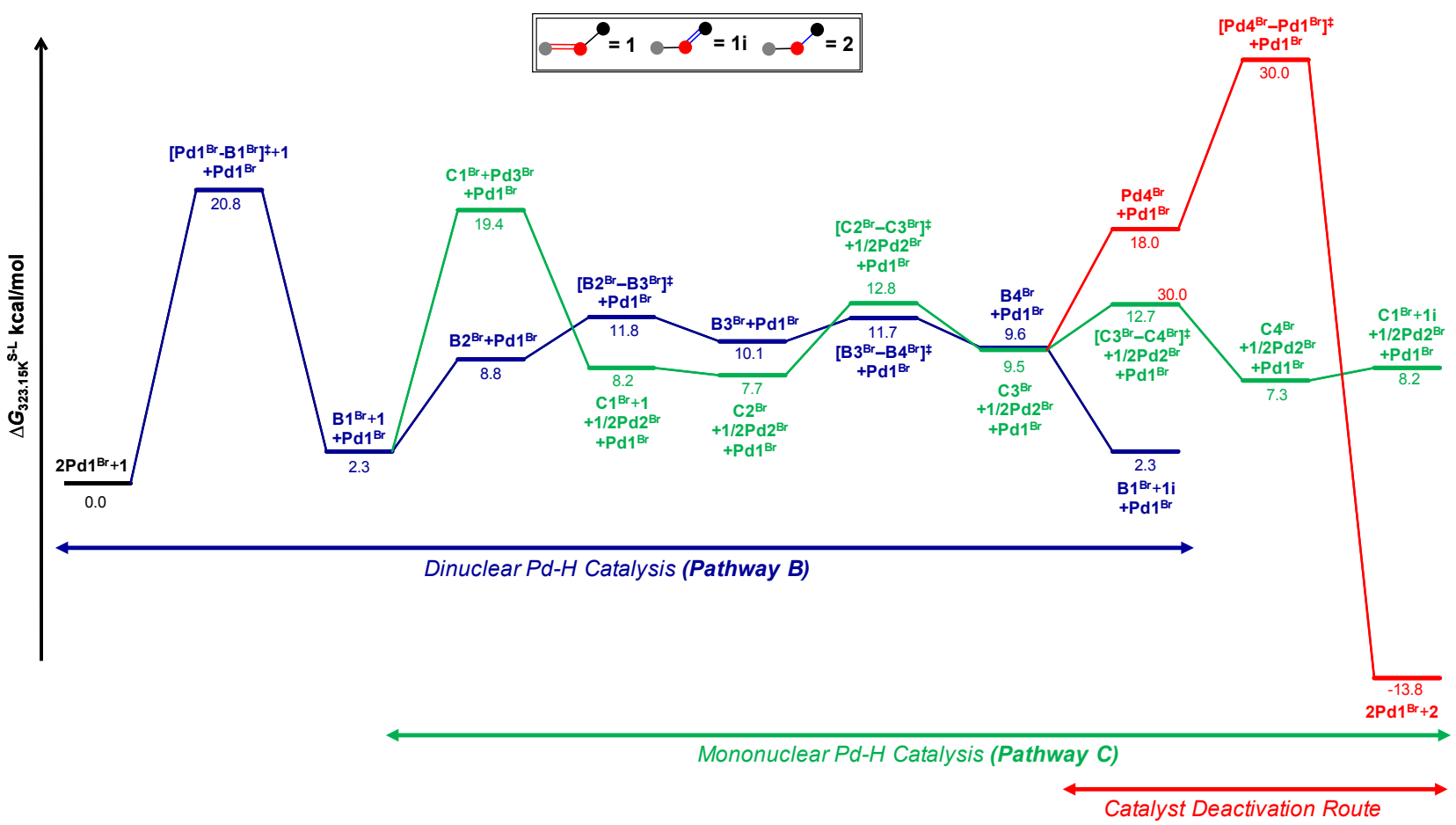

Figure 7. Comparative energy profiles $\left(\Delta G_{323.15 \mathrm{~K}} \mathrm{~S}-\mathrm{L}\right.$ in $\left.\mathrm{kcal} / \mathrm{mol}\right)$. The energy levels are labelled only with the most relevant species; other species included in the energy calculations are omitted for clarity.

\section{In silico casting of isomerization catalysts}

These insights into the catalytic pathway provide a solid basis for establishing structure-activity relationships for ligands and counterions. Systematic experimental studies using different ligands had so far been impossible, because the synthesis of dinuclear $\mathrm{Pd}^{\mathrm{I}}$ species critically depends on their selective crystallization from the reaction medium. Whereas this works very well for tris-tert-butylphosphine ligands, even small changes in the ligand structure lead to the formation of inseparable mixtures of $\mathrm{Pd}^{\mathrm{I}}, \mathrm{Pd}^{\mathrm{II}}$, and $\mathrm{Pd}^{0}$ complexes, unsuitable for reliable comparative kinetic studies. After much fruitless effort aimed at synthesizing structural variants for which it was unclear whether they would be better or worse catalysts, we decided to perform an in silico screening for promising catalysts upfront. This way, we hoped to be able to direct our synthetic efforts towards the most relevant catalyst targets.

Based on the energy profiles presented above, the ideal ligand would result in a catalyst with a low catalyst activation barrier (A), a low energy span $\left(S_{d}\right.$ and $\left.S_{m}\right)$ for the dinuclear and/or mononuclear catalytic cycles, and as high as possible a catalyst deactivation barrier (D). For catalysts with a low energy span for the dinuclear cycle $\left(S_{d}\right)$, another viable strategy to increase their lifetime would be to increase the barrier $\left(\mathrm{A}_{\mathrm{m}}\right)$ between the mononuclear and dinuclear catalytic cycles, which would also block access to deactivation. Any complex under investigation scoring better than $\mathbf{P d 1}{ }^{\mathbf{B r}}$ in these categories would be a promising lead structure for rational catalyst development.

The catalyst activation barrier (A) corresponds to the energetic difference between $\mathbf{P d} 1 \mathbf{x}^{\mathbf{i}}$ and $\left[\mathbf{P d} \mathbf{1} \mathbf{x}^{\mathbf{i}-B 1} \mathbf{x}^{\mathbf{i}}\right]^{\ddagger}$. The energy span for the dinuclear catalytic cycle $\left(\mathrm{S}_{\mathrm{d}}\right)$ consists of the energy difference between the lowest intermediate and highest transition state. The barrier for entering the mononuclear catalytic cycle $\left(\mathrm{A}_{\mathrm{m}}\right)$ is the difference between $\mathbf{B} 1 \mathbf{x}^{\mathbf{i}}$ and $\mathbf{C} 1 \mathbf{x}^{\mathbf{i}}$. The energy span of the mononuclear catalytic cycle $\left(\mathrm{S}_{\mathrm{m}}\right)$ is the difference between its lowest intermediate and highest transition state. The catalyst deactivation barrier (D) is somewhat harder to pin down. As can be seen from Figure 7, the first step towards catalyst deactivation is exergonic, and a 
high energy span for the deactivation pathway may not necessarily point towards a long-lived catalyst, since it may be caused by the particularly exergonic formation of intermediate $\mathbf{P d} 4^{\mathrm{Br}}$. We thus used the energy difference between intermediate $\mathbf{C 3}^{\mathrm{Br}}$ and the highest transition state $\left[\mathbf{P d} 4^{\mathrm{Br}}\right.$ $\left.\mathbf{P d 1}^{\mathrm{Br}}\right]^{*}$ as a measure to assess catalyst longevity.
The above measures for various catalyst candidates are summarized in Figure 8. Out of the complexes shown in Figure 8, $\mathbf{P d 1}^{\mathrm{Br}},{ }^{34,}{ }^{35} \mathbf{P d 1}^{\mathrm{I}}$, ${ }^{43 \mathrm{~b}}$ and $\mathbf{P d 1 c ^ { \mathrm { Br } } 2 5}$ have been synthesized before, whereas all others are purely speculative (marked with $*$ in Figure 8). The full data for each structure are listed in Table S6, and the energy profiles for the most relevant structures are displayed in Figure 9.

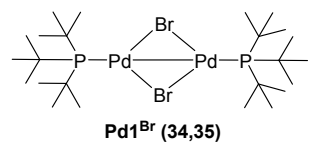

$A=20.8 ; S_{d}=9.5 ; A_{m}=17.2$; $\mathrm{S}_{\mathrm{m}}=5.4 ; \mathrm{D}=20.5$

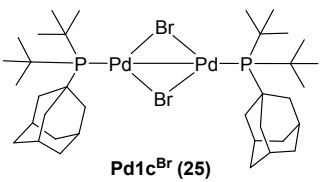

$A=20.2 ; S_{d}=9.3 ; A_{m}=16.7$; $S_{m}=5.2 ; D=21.3$

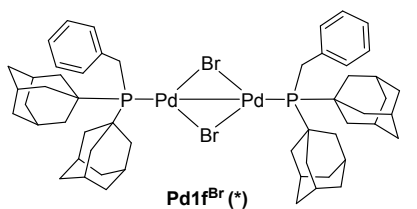

$A=2.1 ; S_{d}=8.1 ; A_{m}=25.4$ $\mathrm{S}_{\mathrm{m}}=4.5 ; \mathrm{D}=-8.4$

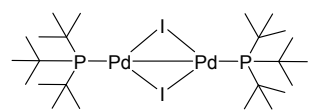

Pd1' (43b)

$A=26.2^{\mathrm{a}} ; \mathrm{Sd}=7.3 ; \mathrm{A}_{\mathrm{m}}=16.4$ $\mathrm{S}_{\mathrm{m}}=4.1 ; \mathrm{D}=19.9$

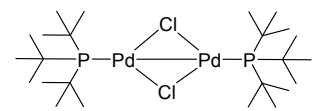

$\operatorname{Pd} 1^{\mathrm{Cl}}\left({ }^{*}\right)$

$$
A=16.2 ; S_{d}=8.6 ; A_{m}=16.9 \text {; }
$$

$\mathrm{S}_{\mathrm{m}}=5.4 ; \mathrm{D}=13.6$

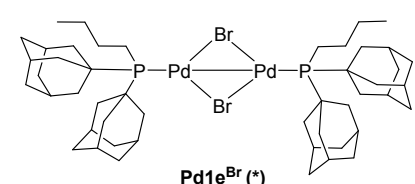

$A=13.4 ; S_{d}=8.0 ; A_{m}=12.2$; $\mathrm{S}_{\mathrm{m}}=4.8 ; \mathrm{D}=3.1$

$=18.6 ; S_{d}=9.2 ; A_{m}=17.4$; $\mathrm{S}_{\mathrm{m}}=4.8 ; \mathrm{D}=20.5$

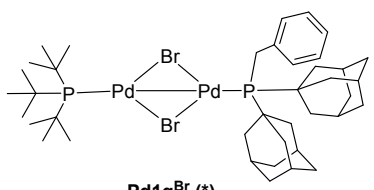

Pd19 ${ }^{\mathrm{Br}}\left({ }^{*}\right)$

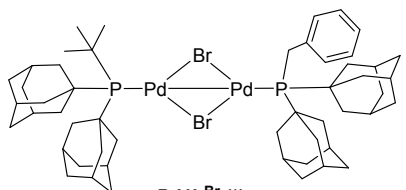

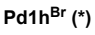

$A=7.0 ; S_{d}=9.1 ; A_{m}=22.2$;

$\mathrm{S}_{\mathrm{m}}=5.3 ; \mathrm{D}=8.2$

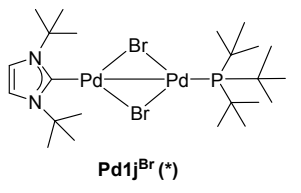

$A=20.7 ; S_{d}=11.9 ; A_{m}=19.4 ;$
$A=9.1 ; S_{d}=10.6 ; A_{m}=22.9$; $\mathrm{S}_{\mathrm{m}}=4.8 ; \mathrm{D}=7.5$

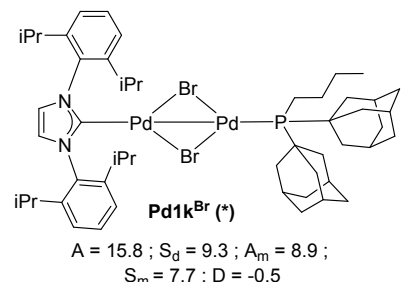

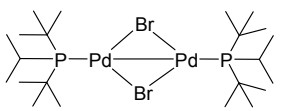

$\operatorname{Pd} 1 a^{\mathrm{Br}}\left({ }^{*}\right)$

$0 ; S_{d}=8.1 ; A_{m}=16.9$; $\mathrm{S}_{\mathrm{m}}=5.6 ; \mathrm{D}=11.4$

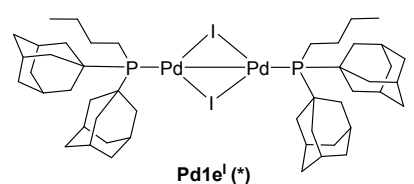

$A=21.5^{a} ; S_{d}=5.8 ; A_{m}=10.1$;

$\mathrm{S}_{\mathrm{m}}=3.8 ; \mathrm{D}=14.0$

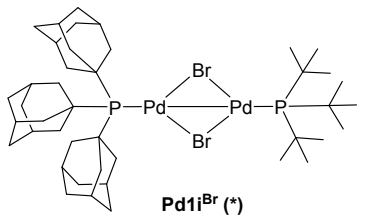

$A=19.1 ; S_{d}=9.0 ; A_{m}=16.5$; $\mathrm{S}_{\mathrm{m}}=4.8 ; \mathrm{D}=20.0$

Figure 8. Catalyst structures screened in silico, and key descriptors of their catalytic performance. Literature references of known Pd1 $\mathbf{x}^{\mathbf{i}}$ dimers are provided in parentheses. $\left(^{*}\right)$ identifies purely speculative structures. A: catalyst activation barrier $\mathbf{P d 1} \mathbf{x}^{\mathbf{i}} \rightarrow\left[\mathbf{P d 1} \mathbf{x}^{\mathbf{i}-}\right.$ $\left.\mathbf{B} 1 \mathbf{x}^{\mathbf{i}}\right]^{ \pm}, \mathrm{S}_{\mathrm{d}, \mathrm{m}}$ : energy spans of the catalytic isomerization cycles, $\mathrm{A}_{\mathrm{m}}$ : activation barrier towards mononuclear isomerization cycle $\mathbf{B} 1 \mathbf{x}^{\mathrm{i}}$ $\rightarrow \mathbf{C 1} \mathbf{x}^{\mathbf{i}}$; D: highest barrier of catalyst deactivation $\mathbf{C} 3 \mathbf{x}^{\mathbf{i}} \rightarrow\left[\mathbf{P d 4} \mathbf{x}^{\mathbf{i}-P d 1 x^{i}}\right]^{\ddagger}$. Relativistic corrected value. 


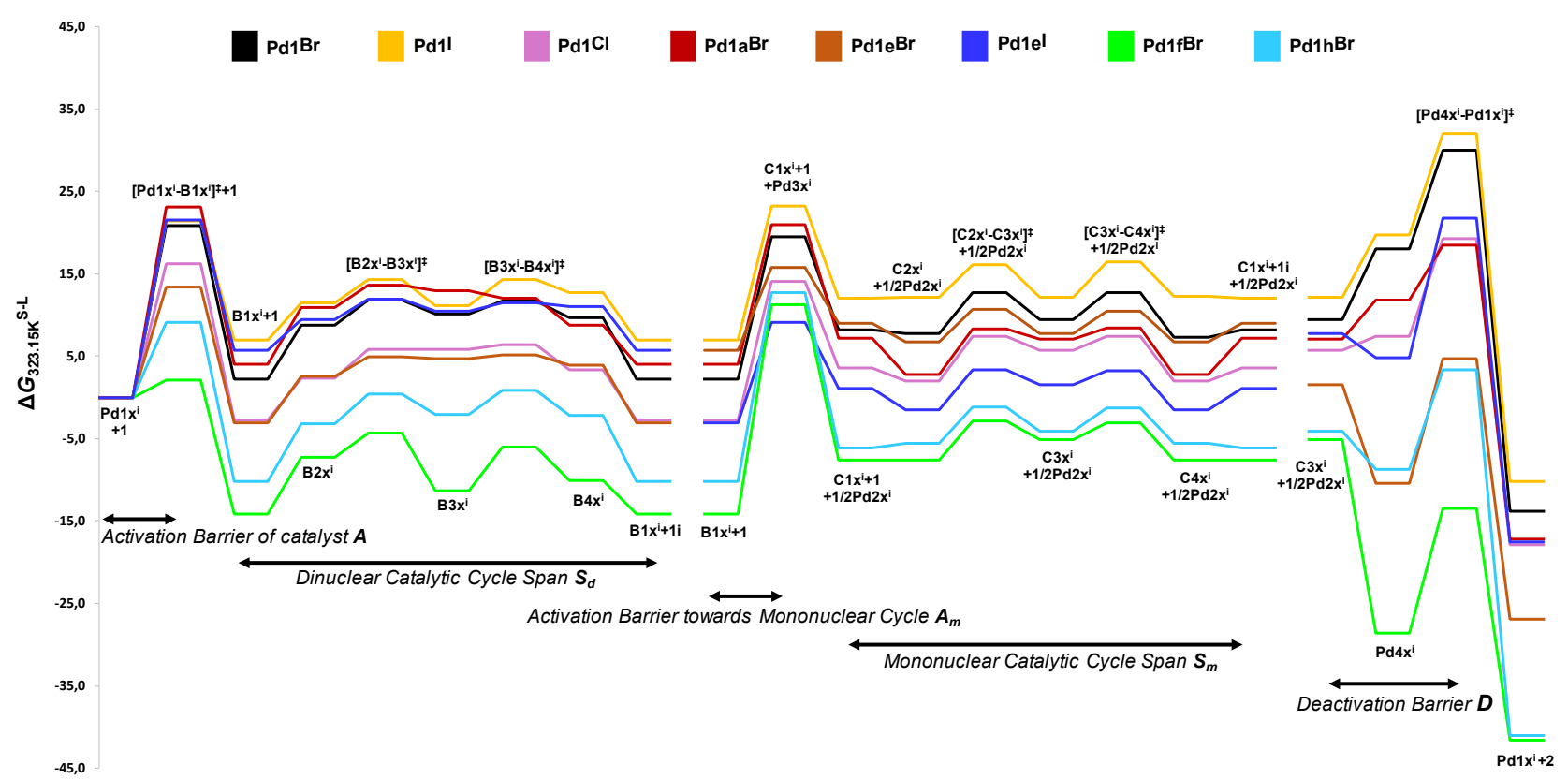

Figure 9. Overlay of selected energy profiles for all catalytic systems. The energy levels are labelled only with the most relevant species; other species included in the energy calculations (Table S6) are omitted for clarity.

We first investigated the effect of the bridging halide atoms using chloro and iodo analogs of $\mathbf{P d} \mathbf{1}^{\mathrm{Br}}$. The chloro-bridged complex $\mathbf{P d} \mathbf{1}^{\mathrm{Cl}}$ has a low activation barrier, and based on the small energy span of the catalytic cycle, it should be highly effective. However, its deactivation barrier was predicted to be lower than that of $\mathbf{P d} 1^{\mathrm{Br}}$, pointing towards faster decomposition. This may be the reason why such complexes could not yet be synthesized. The iodo-bridged complex Pd1 ${ }^{\mathrm{I}}$ was initially predicted to have an activation barrier nearly identical to that of $\mathbf{P d} \mathbf{1}^{\mathbf{B r}}$ and a similar energy span in the catalytic isomerization. However, we had observed experimentally that iodo complexes are less reactive than their bromo counterparts. We reasoned that our choice of basis sets, which had been confirmed upfront to be perfectly suitable for the treatment of bromine atoms, might be inadequate to fully cover the more complex iodine atoms. Indeed, when we repeated the calculations with the relativistic corrected basis set QZP-DKH for the iodine atoms (B3LYP-D3/6-311++G(d,p) $(\mathrm{H}, \quad \mathrm{C}, \quad \mathrm{P}), \quad$ QZP-DKH(I), LANL2TZ(f) (Pd)/SMD(Toluene)//B3LYP-D3/6-31+G(d), (H, C, P, I), LANL2DZ(Pd); see Computational Details), the activation barrier for Pd1 ${ }^{\mathbf{I}}$ increased by as much as $4.8 \mathrm{kcal} / \mathrm{mol}$. The increased activation barrier of $26.2 \mathrm{kcal} / \mathrm{mol}$ obtained in these refined calculations explains why Pd1 ${ }^{\mathrm{I}}$ had found to be more stable in solution but a less efficient isomerization catalyst than $\mathbf{P d} 1^{\mathbf{B r}}$. For a simple isomerization reaction, the reaction temperature could potentially be increased to overcome higher activation barriers. However, isomerizing metathesis reactions with $\mathrm{Ru}$ co-catalysts are rather temperature-sensitive, so that isomerization catalysts must show high activity already at room temperature to allow their application in this context. Then, we evaluated alternative phosphine ligands at $\mathrm{Pd}^{1}$ and $\mathrm{Pd}^{2}$ bearing $\alpha$-, $\beta$ - or $\gamma$ - hydrogens, which still allow the generation of $\mathrm{Pd}-$ $\mathrm{H}$ via cyclometalation $(14.0 / 16.7 / 13.4 \mathrm{kcal} / \mathrm{mol}$ for $\alpha / \beta / \gamma$ activations; Table S4). The stepwise replacement of the tertbutyl groups in $\mathrm{P}^{t} \mathrm{Bu}_{3}$ by the smaller and less electron-donating isopropyl groups $\left(\mathbf{P d 1} \mathbf{a}^{\mathrm{Br}}\right.$ and $\left.\mathbf{P d 1} \mathbf{b}^{\mathrm{Br}}\right)$ led to a decrease of the energy spans $S_{d}$ and $S_{m}$, which points towards increased catalytic activity. However, the activation barriers A for the isopropylphosphine complexes are very high and, in combination with the low deactivation barriers $\mathrm{D}$, suggest that such catalysts would be ineffective.

Replacing one or two tert-butyl substituents by bulky adamantyl substituents $\left(\mathbf{P d 1} \mathbf{c}^{\mathrm{Br}}\right.$ and $\left.\mathbf{P d 1} \mathbf{d}^{\mathrm{Br}}\right)$ had a beneficial effect. ${ }^{72}$ Hartwig has already synthesized one bromo-bridged adamantyl derivative $\left(\mathbf{P d 1} \mathbf{c}^{\mathbf{B r}}\right)$ of $\mathbf{P d 1} \mathbf{1}^{\mathbf{B r}}$, and applied it in cross coupling reactions. ${ }^{25}$ It thus appeared likely that such systems could also be used for isomerization reactions. Complex $\mathbf{P d 1 d}^{\mathrm{Br}}$, which bears two adamantyl groups, was calculated to have a similar energy spans for both catalytic cycles $\left(S_{d}=9.2\right.$ $\mathrm{kcal} / \mathrm{mol}$ and $\left.\mathrm{S}_{\mathrm{m}}=4.8 \mathrm{kcal} / \mathrm{mol}\right)$, the same deactivation $(\mathrm{D}=$ $20.5 \mathrm{kcal} / \mathrm{mol})$, but a lower activation barrier $(\mathrm{A}=18.6$ $\mathrm{kcal} / \mathrm{mol}$ ). Thus, we kept two adamantyl groups, and varied the third substituent at phosphorus. The resulting complexes with $n$-butyl $\left(\mathbf{P d 1}^{\mathrm{Br}}\right)$ or benzyl substituents $\left(\mathbf{P d 1 f ^ { \mathrm { Br } } )}\right.$ had dramatically lower activation barriers $(\mathrm{A}=13.4$ and 2.1 $\mathrm{kcal} / \mathrm{mol}$, respectively), and reduced energy spans for the dinuclear catalytic cycle $\left(\mathrm{S}_{\mathrm{d}}=8.0\right.$ and $8.1 \mathrm{kcal} / \mathrm{mol}$, respectively). However, in both cases, the deactivation barriers were substantially lower. For $\mathbf{P d 1} \mathbf{f}^{\mathrm{Br}}$, the barrier from the dinuclear to the mononuclear cycle is so much increased that it should effectively suppress catalyst deactivation. Still, the activation barrier is so low for this precatalyst that it is doubtful whether it will be possible to synthesize and isolate it.

In contrast to the tert-butyl group, the benzyl substituent is able to cyclometalate via an aromatic position. The advantageous 5ring geometry of the transition state explains the low barrier A. The $n$-butyl substituent can cyclometalate in the $\alpha-, \beta$, and $\gamma$ positions. Comparative studies revealed that activation in the $\gamma$ position is most favorable (Table S4). 
Next, we evaluated unsymmetrical complexes with the intention of independently optimizing the ligand at $\mathrm{Pd}^{2}$ for cyclometalation and the ligand at $\mathrm{Pd}^{1}$ for stabilizing the mononuclear $\mathrm{Pd}-\mathrm{H}$ species. Unsymmetrical dinuclear species would be hard to access experimentally, and such calculations would reveal upfront whether it could be worthwhile to attempt their selective synthesis.

A comparison of the activation barriers for $\mathbf{P d} 1 \mathbf{g}^{\mathrm{Br}}$, which bears a benzyl-bis-adamantylphosphine ligand $\left(\mathrm{PAd}_{2} \mathrm{Bn}\right)$ on $\mathrm{Pd}^{2}\left(\mathrm{~A}_{\gamma}\right.$ $=7.0 \mathrm{kcal} / \mathrm{mol}$ ) with the two corresponding symmetrical complexes $\mathbf{P d 1}^{\mathrm{Br}}(\mathrm{A}=20.8 \mathrm{kcal} / \mathrm{mol})$ and $\mathbf{P d 1 f ^ { \mathrm { Br } }}(\mathrm{A}=2.1$ $\mathrm{kcal} / \mathrm{mol}$ ) revealed that the singled-out effect of the ligand that undergoes cyclometalation is visible, but not as strong as one could have expected.

An excellent overall profile is presented by $\mathbf{P d 1} \mathbf{h}^{\mathrm{Br}}$, which combines a $\mathrm{PAd}_{2} \mathrm{Bn}$ ligand at $\mathrm{Pd}^{2}$ with a $\mathrm{PAd}_{2}{ }^{t} \mathrm{Bu}$ ligand at $\mathrm{Pd}^{1}$, with a reasonable activation barrier $(\mathrm{A}=9.1 \mathrm{kcal} / \mathrm{mol})$ that should allow isolating the precatalyst, a low energy span for the dinuclear pathway $\left(S_{d}=10.6 \mathrm{kcal} / \mathrm{mol}\right)$, and a high barrier $A_{m}$ that should keep it from forming highly active but short-lived mononuclear $\mathrm{Pd}-\mathrm{H}$ species $\left(\mathrm{A}_{\mathrm{m}}=22.9 \mathrm{kcal} / \mathrm{mol}\right)$.

Because one of the ligands in unsymmetrical complexes does not need to be able to undergo cyclometalation, we also calculated complexes with tris-adamantylphosphine $\left(\mathrm{PAd}_{3}\right)$ or NHC ligands at $\mathbf{P d}^{2}$. For $\mathbf{P d 1 i}{ }^{\mathbf{B r}}$, the activation barrier is almost identical to that of $\mathbf{P d 1} \mathbf{1}^{\mathbf{B r}}$, and $\mathrm{PAd}_{3}$ improved neither the energy spans $\left(\mathrm{S}_{\mathrm{d}}, \mathrm{S}_{\mathrm{m}}\right)$ nor the deactivation barrier. Mixed dinuclear complexes bearing one phosphine and one NHC ligand $\left(\mathbf{P d} \mathbf{1} \mathbf{j}^{\mathbf{B r}}\right.$ and $\mathbf{P d} 1 \mathbf{k}^{\mathbf{B r}}$ ) also gave similar activation energies and energy spans to their symmetrical diphosphine analogs $\left(\mathbf{P d 1}{ }^{\mathbf{B r}}\right.$ and $\mathbf{P d 1 e}^{\mathrm{Br}}$, respectively). However, the barriers $\mathrm{A}_{\mathrm{m}}$ between the dinuclear and mononuclear cycles are lower than the corresponding activation energies. Worst of all, the initial step of ligand deactivation, i.e. the formation of the dinuclear adduct, is strongly exergonic and renders catalyst deactivation more favorable than propagation of the catalytic cycle $(\mathrm{D}=7.9$ and $0.5 \mathrm{kcal} / \mathrm{mol}$, respectively). Moreover, the catalytically active species cannot easily be regenerated from the symmetrical complexes resulting from catalyst deactivation, because the usual activation pathway is blocked for dinuclear $\mathrm{Pd}^{\mathrm{I}}$ species bearing two ligands incapable of undergoing cyclometalation (Scheme S6). Based on these evaluations, the use of NHC ligands is unfavorable both in symmetrical and unsymmetrical complexes.

Overall, these comparative studies show that the experimentally observed, unique isomerization activity of $\mathbf{P d 1} \mathbf{1}^{\mathbf{B r}}$ results from the fact that this complex almost ideally strikes the delicate balance between good synthetic accessibility, easy catalyst activation, a smooth energy profile for the catalysis, and a reasonably high barrier towards catalyst deactivation. Even small changes in the ligand structures were found to have adverse effects on at least one of these characteristics. Nevertheless, the symmetrical $\mathrm{PAd}_{2}{ }^{n} \mathrm{Bu}$ complex $\mathbf{P d 1 e ^ { \mathbf { B r } }}$ emerged as an interesting lead structure due to its low catalyst activation barrier ( $\mathrm{A}=13.4$ vs $20.8 \mathrm{kcal} / \mathrm{mol}$ for $\left.\mathbf{P d 1} \mathbf{1}^{\mathrm{Br}}\right)$ and its low energy spans for the catalysis $\left(\mathrm{S}_{\mathrm{d}}=8.0 \mathrm{vs} 9.5 \mathrm{kcal} / \mathrm{mol}\right.$ and $\mathrm{S}_{\mathrm{m}}=4.8$ vs $\left.5.4 \mathrm{kcal} / \mathrm{mol}\right)$. However, the calculations also predict a rather low barrier towards catalyst deactivation. It seems worthwhile to experimentally target complexes with two different phosphine ligands such as $\mathbf{P d} \mathbf{1} \mathbf{h}^{\mathbf{B r}}$, whereas NHCligated complexes were predicted to be inferior catalysts.

\section{Experimental studies on the isomerization activity}

We next set out to synthesize a set of dinuclear $\mathrm{Pd}^{\mathrm{I}}$ complexes with other counterions and ligands other than $\mathrm{P}^{t} \mathrm{Bu}_{3}$, with the aim to validate the results of the in silico casting. The iodo analog to $\mathbf{P d 1} \mathbf{1}^{\mathbf{B r}}$ proved to be stable and easily accessible. In contrast, the chloro analog did not selectively crystallize and was too unstable to allow purification e.g. by chromatography. Similar problems were also encountered for some bromobridged complexes. The main challenge was that the known synthetic strategies critically depend on the selective crystallization of the $\mathrm{Pd}^{\mathrm{I}}$ dimers from the reaction mixtures, and this step must be elaborately optimized for every single structure so that the products can be obtained in pure form. In order to be able to establish a structure-activity relationship for the ligand, an entire series of otherwise analogous complexes was required. We thus decided to conduct a systematic comparative catalytic study of ligand activity using the more accessible iodo- rather than the calculated bromo-bridged $\mathrm{Pd}^{\mathrm{I}}$ dimers.

Extensive experimental work led to the successful synthesis of a set of phosphine complexes, namely $\left.\left(\mathrm{P}^{t} \mathrm{Bu}_{3}\right)_{2} \mathrm{Pd}_{2}{ }_{2} \mathrm{I}_{2}(\mathbf{P d 1})^{\mathrm{I}}\right)^{43 \mathrm{~b}}$ and $\left(\mathrm{P}^{t} \mathrm{Bu}_{2}{ }_{2} \mathrm{Pr}\right)_{2} \mathrm{Pd}_{2}{ }_{2} \mathrm{I}_{2}\left(\mathbf{P d 1 a}^{\mathrm{I}}\right){ }^{41}$ following literature protocols, and of the new complex $\left(\mathrm{PAd}_{2}{ }^{n} \mathrm{Bu}\right)_{2} \mathrm{Pd}_{2}{ }_{2} \mathrm{I}_{2}\left(\mathbf{P d 1} \mathbf{e}^{\mathrm{I}}\right)$. During the course of these studies, we managed to synthesize an iodobridged NHC-ligated complex $\left[(\mathrm{IPr}) \mathrm{Pd}^{\mathrm{I}} \mathrm{I}\right]_{2}\left(\mathbf{P d}^{1} \mathbf{I}^{\mathrm{I}}\right)$, which we have since applied in cross-coupling reactions. ${ }^{72}$ The catalytic performance of these complexes was investigated using the isomerization of allylbenzene as a model reaction (Scheme 8). In the presence of $1 \mathrm{~mol} \%$ of our reference complex $\mathbf{P d 1} \mathbf{1}^{\mathbf{B r}}$, the allylbenzene is fully converted into the equilibrium mixture of allyl- (3\%) and vinylarenes $(97 \%)$ within 2 hours at $40^{\circ} \mathrm{C}$. In direct comparison, the iodo-bridged catalyst $\mathbf{P d 1} \mathbf{1}^{\mathbf{I}}$ is markedly less active, and gave a conversion of only $13 \%$. Only at $50^{\circ} \mathrm{C}$, full conversion is reached. This corresponds well with the calculations obtained at the QZP-DKH level, which indicate that this complex has a substantially higher activation barrier than $\mathbf{P d 1} \mathbf{1}^{\mathrm{Br}}$. As predicted by the calculations, replacing one of the tert-butyl groups by an isopropyl substituent $\left(\mathbf{P d 1} \mathbf{a}^{\mathrm{I}}\right)$ led to substantially lower catalytic activity. $\mathrm{PAd}_{2}{ }^{n} \mathrm{Bu}$ ligands $\left(\mathbf{P d 1} \mathbf{e}^{\mathrm{I}}\right)$, for which a superior profile with regard to activation barrier and energy span had been calculated, were confirmed to be better ligands than ${ }^{t} \mathrm{Bu}_{3} \mathrm{P}$.

It was not possible to synthesize $\mathrm{PAd}_{2} \mathrm{Bn}$ complexes $\mathbf{P d 1 f ^ { \mathrm { Br } }}$ with either bromo or iodo substituents in pure form. This is in line with the calculations, which predicted such a low barrier towards palladacycle formation that it appeared unlikely that the pre-catalyst would be stable under the condition of its synthesis.

Almost no conversion was observed for $\mathbf{P d 1} \mathbf{I}^{\mathbf{I}}$, which bears an NHC ligand. This is in line with the computational studies that had shown that the lowest-energy pathway towards catalytically active $\mathrm{Pd}-\mathrm{H}$ species requires an intramolecular cyclometalation step. This activation pathway is impossible for the NHC ligands. As this work focuses on the application of $\mathrm{Pd}^{\mathrm{I}}$ dimers in equilibrium isomerizing metathesis, the optimal synthetically accessible catalyst $\mathbf{P d 1} \mathbf{e}^{\mathrm{I}}$ was ultimately tested experimentally in a tandem reaction. We used the isomerizing metathesis of methyl oleate as a model, and found that Pd1e $\mathbf{e}^{\mathrm{I}}$ showed an

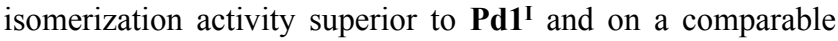
level to $\mathbf{P d 1}{ }^{\mathbf{B r}}$. This result confirms that performances observed in our test isomerization can be extrapolated to isomerizing metathesis (for further experimental details, see the SI). 
Scheme 8. Experimental study of isomerization activity.

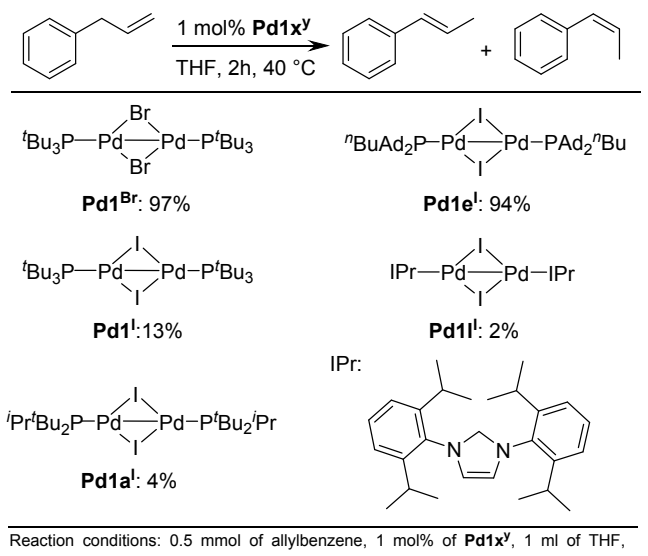

conction cleterined $0.5 \mathrm{~mol}$ of aly

In order to verify the reliability of our calculations, we calculated the energy profile for the complex $\mathbf{P d} \mathbf{1} \mathbf{e}^{\mathrm{I}}$, which showed the highest activity of all iodo-Pd complexes in this experimental study. As one can see from the data in Figure 8 and the profile in Figure 9, the energy spans of both catalytic cycles are almost identical, but the iodo complex has a slightly higher activation and lower deactivation barrier. This is in excellent agreement with the experimental finding that the iodo complex Pd1 $\mathrm{e}^{\mathrm{I}}$ almost, but not quite, reaches the performance of the unmodified bromo complex Pd1 ${ }^{\mathrm{Br}}$.

\section{CONCLUSION}

The unique activity profile of dinuclear $\mathrm{Pd}^{\mathrm{I}}$ complex $\left(\mathrm{P}^{t} \mathrm{Bu}_{3}\right)_{2} \mathrm{Pd}_{2}{ }_{2} \mathrm{Br}_{2}$ as an isomerization catalyst in orthogonal tandem processes is explained by the following factors:

(1) A bimetallic activation pathway with a moderate barrier allows the formation of a highly reactive monophosphinopalladium hydride species. The hydride atom at $\mathrm{Pd}^{1}$ originates from the phosphine ligand at $\mathrm{Pd}^{2}$, which in the $\mathrm{C}-\mathrm{H}$ insertion process gets tightly bound to $\mathrm{Pd}$ with formation of a chemically largely inert palladacycle. This activation mechanism suppresses the liberation of phosphine ligands, which would deactivate sensitive co-catalysts such as Grubbstype olefin metathesis catalysts.

(2) The actual double-bond migration at the mononuclear Pd$\mathrm{H}$ species has a remarkably low energy span, which is in line with the high activity observed for the dinuclear $\mathrm{Pd}^{\mathrm{I}}$ precatalyst.

(3) The rapid loss of catalytic activity and the experimentally observed build-up of a bispalladacycle $\left(\mathbf{P d} 2^{\mathrm{Br}}\right)$ is caused by a low barrier pathway leading to a mononuclear $\mathrm{Pd}-\mathrm{H}$ species along with $\mathbf{1} / \mathbf{2} \mathbf{P d 2} 2^{\mathrm{Br}}$. This mononuclear species $\mathbf{C 1}^{\mathrm{Br}}$ has tremendous catalytic activity but easily decomposes with formation of the dimeric $\mathrm{Pd}^{\mathrm{I}}$ precatalyst.

The key characteristics of an efficient catalyst are thus a low catalyst activation barrier (A), a low energy span $\left(\mathrm{S}_{\mathrm{d}}\right.$ and $\left.\mathrm{S}_{\mathrm{m}}\right)$ for the dinuclear and/or mononuclear catalytic cycles, and as high as possible a catalyst deactivation barrier (D). Catalysts that have a low energy span for the dinuclear cycle $\left(\mathrm{S}_{\mathrm{d}}\right)$ and a large the barrier $\left(\mathrm{A}_{\mathrm{m}}\right)$ between the dinuclear and mononuclear catalytic cycles would also be highly effective and long-lived.

The comparative evaluation of various structures showed how well $\left(\mathrm{P}^{t} \mathrm{Bu}_{3}\right)_{2} \mathrm{Pd}_{2}{ }_{2} \mathrm{Br}_{2}$ strikes the delicate balance between good synthetic accessibility, easy catalyst activation, a smooth energy profile for the catalysis, and a sufficiently high barrier towards catalyst deactivation. Most changes in the ligand structures had adverse effects on at least one of these characteristics.

These calculations were successfully used as a predictive tool for rational catalyst development. By in silico casting, the influence of various structural variations of the precatalysts on the activation barrier, the energy span of the catalytic cycles, and the catalyst deactivation barrier were probed. Based on the results, an experimentally inaccessible dinuclear complex $\mathbf{P d 1}^{\mathbf{B r}}$ with bisadamantyl- $n$-butylphosphine ligands was identified as a lead structure for an easily activated, highly active catalyst. The validity of this lead was confirmed by a comparative experimental study of stable but overall less reactive iodo analogues of the target complexes, in which the bisadamantyl- $n$-butylphosphine complexes by far outperform the established tris-tert-butylphosphine complexes.

This research can serve as a showpiece that illustrates how DFT calculations can be embedded directly into the rational development of new catalyst generations rather than being used to provide mechanistic explanation post hoc for results that have already been achieved using experimental screening techniques. The experimentally observed build-up of palladacycles $\mathbf{P d} \mathbf{2} \mathbf{x}^{\mathbf{i}}$ during the catalytic isomerization had suggested that their formation is a result of catalyst deactivation. It had appeared to be a logical conclusion that the catalyst deactivation should be suppressed by using ligands that cannot undergo ortho-metalation. Based on this, NHC and trisadamantylphosphine based complexes had been targeted. The DFT calculations became the basis for a paradigm change: They have established cyclometalation as an integral part of catalyst activation, not of its deactivation. This is why NHC complexes can be expected to be rather poor catalysts. This prediction was confirmed by our experimental studies.

The results derived from in silico casting and their experimental verification give confidence that tackling the preparative challenge is worth the amount of synthetic work that can be expected in order to develop a selective synthesis of new catalyst lead structures. We are convinced that new complexes designed according to the structure-activity relationships uncovered by the DFT calculations will bring major advances in activity and longevity of isomerizing metathesis catalysts.

\section{SUPPORTING INFORMATION}

The Supporting Information is available free of charge on the ACS Publications website at DOI: xx.xxxx/jacs.xxxxxxx.

- Further mechanistic routes and energy profiles

- Full experimental and computational details

\section{AUTHOR INFORMATION}

\section{Corresponding Author}

*E-mail: koley@iiserkol.ac.in (D. K.).

*E-mail: lukas.goossen@ruhr-uni-bochum.de (L. J. G.).

\section{Author Contributions}

these authors contributed equally.

\section{ACKNOWLEDGMENT}

This article is dedicated to the memory of Professor Walter Thiel. 
We thank the DFG for funding (SFB-TRR 88 "3MET" and GO 853/12-1), UMICORE for donating chemicals, BMBF and the state of NRW (Center of Solvation Science "ZEMOS"), as well as the UGC and CSIR (SRF fellowships to S.D. and B.M.) and Fonds der chemischen Industrie FCI (PhD fellowship to N.S.) for financial support. LKJ and DK also thank the funding from the bilateral DST-DFG (INT/FRG/DFG/P-05/2017) scheme. The authors acknowledge the computational facilities at TUK, ZEMOS, and IISER Kolkata.

Gefördert durch die Deutsche Forschungsgemeinschaft (DFG) im Rahmen der Exzellenzstrategie des Bundes und der Länder - EXC 2033 - Projektnummer 390677874 - RESOLV.

\section{REFERENCES}

(1) Hilt, G. Double Bond Isomerisation and Migration-New Playgrounds for Transition Metal-Catalysis. ChemCatChem 2014, 6, $2484-2485$.

(2) Cybulski. A. Fine Chemicals Manufacture: Technology and Engineering, Elsevier, Amsterdam, New York, 2001.

(3) Cramer, R.; Lindsey Jr, R. V. The Mechanism of Isomerization of Olefins with Transition Metal Catalysts. J. Am. Chem. Soc. 1966, 88, $3534-3544$.

(4) (a) van der Veen, L. A.; Kamer, P. C. J.; van Leeuwen, P. W. N. M. Hydroformylation of Internal Olefins to Linear Aldehydes with Novel Rhodium Catalysts. Angew. Chem., Int. Ed. 1999, 38, 336-338. (b) Klein, H.; Jackstell, R.; Wiese, K. D.; Borgmann, C.; Beller, M. Highly Selective Catalyst Systems for the Hydroformylation of Internal Olefins to Linear Aldehydes. Angew. Chem., Int. Ed. 2001, 40, 3408 3411. (c) Yan, Y.; Zhang, X.; Zhang, X. A Tetraphosphorus Ligand for Highly Regioselective Isomerization-Hydroformylation of Internal Olefins. J. Am. Chem. Soc. 2006, 128, 16058-16061. (d) Yu, S.; Chie, Y.; Guan, Z.; Zhang, X. Highly Regioselective Isomerization-Hydroformylation of Internal Olefins to Linear Aldehyde Using Rh Complexes with Tetraphosphorus Ligands. Org. Lett. 2008, 10, 3469-3472. (e) Kuil, M.; Soltner, T.; van Leeuwen, P. W. N. M.; Reek, J. N. H. High-Precision Catalysts: Regioselective Hydroformylation of Internal Alkenes by Encapsulated Rhodium Complexes. J. Am. Chem. Soc. 2006, 128, 11344-11345. (f) Gadzikwa, T.; Bellini, R.; Dekker, H. L.; Reek, J. N. H. Self-Assembly of a Confined Rhodium Catalyst for Asymmetric Hydroformylation of Unfunctionalized Internal Alkenes. J. Am. Chem. Soc. 2012, 134, 2860-2863. (g) Jennerjahn, R.; Piras, I.; Jackstell, R.; Franke, R.; Wiese, K. D.; Beller, M. Palladium-Catalyzed Isomerization and Hydroformylation of Olefins. Chem. - Eur. J. 2009, 15, 6383-6388. (h) Pandey, S.; Chikkali, S. H. Highly Regioselective Isomerizing Hydroformylation of Long-Chain Internal Olefins Catalyzed by a Rhodium Bis(Phosphite) Complex. ChemCatChem 2015, 7, 3468 3471. (i) Carvajal, M. A.; Kozuch, S.; Shaik, S. Factors Controlling the Selective Hydroformylation of Internal Alkenes to Linear Aldehydes. 1. The Isomerization Step. Organometallics 2009, 28, 3656-3665. (j) Fuchs, E.; Keller, M.; Breit, B. Phosphabarrelenes as Ligands in Rhodium-Catalyzed Hydroformylation of Internal Alkenes Essentially Free of Alkene Isomerization. Chem. - Eur. J. 2006, 12, 6930-6939. (k) Selent, D.; Wiese, K. D.; Röttger, D.; Börner, A. Novel Oxyfunctionalized Phosphonite Ligands for the Hydroformylation of Isomeric n-Olefins. Angew. Chem., Int. Ed. 2000, 39, 1639-1641. (1) Yuki, Y.; Takahashi, K.; Tanaka, Y.; Nozaki, K. Tandem Isomerization/Hydroformylation/Hydrogenation of Internal Alkenes to n-Alcohols Using Rh/Ru Dual- or Ternary-Catalyst Systems. J. Am. Chem. Soc. 2013, 135, 17393-17400. (m) Shichao, C. C.; Liu, G.; Zhang, X.; Zhang, X. Highly Regioselective IsomerizationHydroformylation of Internal Olefins Catalyzed by Rhodium/Tetraphosphine Complexes. Adv. Synth. Catal. 2011, 353, 2665-2670. (n) Beller, M.; Zimmermann, B.; Geissler, H. Dual Catalytic Systems for Consecutive Isomerization-Hydroformylation Reactions. Chem. - Eur. J. 1999, 5, 1301-1305. (o) Behr, A.; Obst, D.; Westfechtel, A. Isomerizing hydroformylation of fatty acid esters: Formation of $\omega$-aldehydes. Eur. J. Lipid Sci. Technol. 2005, 107, 213-219.
(5) Ghebreyessus, K. Y.; Angelici, R. J. Isomerizing-Hydroboration of the Monounsaturated Fatty Acid Ester Methyl Oleate. Organometallics 2006, 25, 3040-3044.

(6) (a) Goldbach, V.; Falivene, L.; Caporaso, L.; Cavallo, L.; Mecking, S. Single-Step Access to Long-Chain $\alpha, \omega$-Dicarboxylic Acids by Isomerizing Hydroxycarbonylation of Unsaturated Fatty Acids. ACS Catal. 2016, 6, 8229-8238. (b) Zhao, L.; Pudasaini, B.; Genest, A.; Nobbs, J. D.; Low, C. H.; Stubbs, L. P.; Meurs, M. V.; Rösch, N. Palladium-Catalyzed Hydroxycarbonylation of Pentenoic Acids. Computational and Experimental Studies on the Catalytic Selectivity. ACS Catal. 2017, 7, 7070-7080. (c) Roesle, P.; Caporaso, L.; Schnitte, M.; Goldbach, V.; Cavallo, L.; Mecking, S. A Comprehensive Mechanistic Picture of the Isomerizing Alkoxycarbonylation of Plant Oils. J. Am. Chem. Soc. 2014, 136, 16871-16881. (d) del Río, I.; Claver, C.; Van Leeuwen, P. W. N. M. On the Mechanism of the Hydroxycarbonylation of Styrene with Palladium Systems. Eur. J. Inorg. Chem. 2001, 2001, 2719-2738. (e) Jiménez-Rodriguez, C.; Eastham, G. R.; Cole-Hamilton, D. J. Dicarboxylic acid esters from the carbonylation of unsaturated esters under mild conditions. Inorg. Chem. Commun. 2005, 8, 878-881. (f) Jiménez-Rodriguez, C.; Eastham, G. R.; Cole-Hamilton, D. J. Highly selective formation of linear esters from terminal and internal alkenes catalysed by palladium complexes of bis-(di-tertbutylphosphinomethyl) benzene. Chem. Commun. 2004, 0, 1720-1721. (g) Quinzler, D.; Mecking, S. Linear Semicrystalline Polyesters from Fatty Acids by Complete Feedstock Molecule Utilization. Angew. Chem., Int. Ed. 2010, 49, 4306-4308. (h) Angew. Chem., Int. Ed. 2010, 49, 4306-4308. (i) Nobbs, J. D.; Low, C. H.; Stubbs, L. P.; Wang, C.; Drent, E.; Meurs, M. V. Isomerizing Methoxycarbonylation of Alkenes to Esters Using a Bis(phosphorinone)xylene Palladium Catalyst. Organometallics 2017, 36, 391-398.

(7) (a) Chen, C.; Dong, X. Q.; Zhang, X. Recent progress in rhodium-catalyzed hydroaminomethylation. Org. Chem. Front. 2016, 3, 1359-1370. (b) Seayad, A.; Ahmed, M.; Klein, H.; Jackstell, R.; Gross, T.; Beller, M. Internal Olefins to Linear Amines. Science 2002, 297, 1676-1678. (c) Wu, L.; Fleischer, I.; Jackstell, R.; Beller, M. Efficient and Regioselective Ruthenium-catalyzed Hydroaminomethylation of Olefins. J. Am. Chem. Soc. 2013, 135, 39893996. (d) Gülak, S.; Wu, L.; Liu, Q.; Franke, R.; Jackstell, R.; Beller, M. Phosphine- and Hydrogen-Free: Highly Regioselective RutheniumCatalyzed Hydroaminomethylation of Olefins. Angew. Chem., Int. Ed. 2014, 53, 7320-7323. (e) Liu, G.; Huang, K.; Cao, B.; Chang, M.; Li, S.; Yu, S.; Zhou, L.; Wu, W.; Zhang, X. Highly Regioselective Isomerization-Hydroaminomethylation of Internal Olefins Catalyzed by $\mathrm{Rh}$ Complex with Tetrabi-Type Phosphorus Ligands. Org. Lett. 2012, 14, 102-105.

(8) (a) van Leeuwen, P. W. N. M.; Claver, C. Rhodium Catalyzed Hydroformylation; Springer: Netherlands, 2002; Vol. 22. (b) Franke, R.; Selent, D.; Börner, A. Applied Hydroformylation. Chem. Rev. 2012, 112, 5675-5732. (c) Liu, J.; Kubis, C.; Franke, R.; Jackstell, R.; Beller, M. From Internal Olefins to Linear Amines: RutheniumCatalyzed Domino Water-Gas Shift/Hydroaminomethylation Sequence. ACS Catal. 2016, 6, 907-912.

(9) (a) Goldbach, V.; Roesle, P.; Mecking, S. Catalytic Isomerizing $\omega$-Functionalization of Fatty Acids. ACS Catal. 2015, 5, 5951-5972. (b) Stempfle, F.; Ortmann, P.; Mecking, S. Long-Chain Aliphatic Polymers To Bridge the Gap between Semicrystalline Polyolefins and Traditional Polycondensates. Chem. Rev. 2016, 116, 4597-4641.

(10) Cole-Hamilton, D. J. Nature's Polyethylene. Angew. Chem., Int. Ed. 2010, 49, 8564-8566.

(11) Fogg, D. E.; dos Santos, E. N. Tandem catalysis: a taxonomy and illustrative review. Coord. Chem. Rev. 2004, 248, 2365-2379.

(12) (a) Dewaele, A.; Meerten, L.; Verbelen, L.; Eyley, S.; Thielemans, W.; Puyvelde, P. V.; Dusselier, M.; Sels, B. Synthesis of Novel Renewable Polyesters and Polyamides with Olefin Metathesis. ACS Sustainable Chem. Eng. 2016, 4, 5943-5952. (b) Lwin, S.; Wachs, I. E. Olefin Metathesis by Supported Metal Oxide Catalysts. ACS Catal. 2014, 4, 2505-2520. 
(13) (a) France, M. B.; Feldman, J.; Grubbs, R. H. An iridium-based catalyst system for metathesis/isomerization of acyclic olefins, including methyl oleate. J. Chem. Soc., Chem. Commun. 1994, 0, 13071308. (b) Consorti, C. S.; Aydos, G. L. P.; Dupont. J. Tandem isomerisation-metathesis catalytic processes of linear olefins in ionic liquid biphasic system. Chem. Commun. 2010, 46, 9058-9060.

(14) (a) Ohlmann, D. M.; Tschauder, N.; Stockis, J. P.; Gooßen, K.; Dierker, M.; Gooßen, L. J. Isomerizng Olefin Metathesis as a Strategy To Access Defined Distributions of Unsaturated Compounds from Fatty Acids. J. Am. Chem. Soc. 2012, 134, 13716-13729. (b) Behr, A.; Vorholt, A. J.; Ostrowski, K. A.; Seidensticker, T.; Towards resource efficient chemistry: tandem reactions with renewables. Green Chem. 2014, 16, 982-1006. (c) Lohr, T. L.; Marks, T. J. Orthogonal tandem catalysis. Nat. Chem. 2015, 7, 477-482. (d) Goldman, A. S.; Roy, A. H.; Huang, Z.; Ahuja, R.; Schinski, W.; Brookhart, M. Catalytic Alkane Metathesis by Tandem Alkane Dehydrogenation-Olefin Metathesis. Science 2006, 312, 257-261.

(15) Porri, L.; Diversi, P.; Lucherini, A.; Rossi, R. Catalysts derived from ruthenium and iridium for the ring-opening polymerization of cycloolefins. Makromol. Chem. 1975, 176, 3121-3125.

(16) Dobereiner, G. E.; Erdogan, G.; Larsen, C. R.; Grotjahn, D. B.; Schrock, R. R. A One-Pot Tandem Olefin Isomerization/MetathesisCoupling (ISOMET) Reaction. ACS Catal. 2014, 4, 3069-3076.

(17) Mamone, P.; Grünberg, M. F.; Fromm, A.; Khan, B. A.; Gooßen, L. J. $\left[\mathrm{Pd}(\mu-\mathrm{Br})\left(\mathrm{P}^{t} \mathrm{Bu}_{3}\right)\right]_{2}$ as a Highly Active Isomerization Catalyst: Synthesis of Enol Esters from Allylic Esters. Org. Lett. 2012, 14, 3716-3719.

(18) (a) Carlsson, A. S.; Lindberg Yilmaz, J.; Green, A. G.; Stymne, S.; Hofvander, P. Replacing fossil oil with fresh oil - with what and for what? Eur. J. Lipid Sci. Technol. 2011, 113, 812-831. (b) Hill, K. Industrial development and application of biobased oleochemicals. Pure Appl. Chem. 2007, 79, 1999-2011. (c) Ronda, J. C.; Lligadas, G.; Galià, M.; Cádiz, V. Vegetable oils as platform chemicals for polymer synthesis. Eur. J. Lipid Sci. Technol. 2011, 113, 46-58. (d) Meier, M. A. R.; Metzger, J. O.; Schubert, U. S. Plant oil renewable resources as green alternatives in polymer science. Chem. Soc. Rev. 2007, 36, 1788-1802. (e) Xia, Y.; Larock, R. C. Vegetable oil-based polymeric materials: synthesis, properties, and applications. Green Chem. 2010, 12, 1893-1909.

(19) Baader, S.; Ohlmann, D. M.; Gooßen, L. J. Isomerizing Ethenolysis as an Efficient Strategy for Styrene Synthesis. Chem. - Eur. J. 2013, 19, 9807-9810.

(20) Baader, S.; Podsiadly, P. E.; Cole-Hamilton, D. J.; Gooßen, L. J. Synthesis of tsetse fly attractants from a cashew nut shell extract by isomerising metathesis. Green Chem. 2014, 16, 4885-4890.

(21) Trita, A. S.; Over, L. C.; Pollini, J.; Baader, S.; Riegsinger, S.; Meier, M. A. R.; Gooßen, L. J. Synthesis of potential bisphenol A substitutes by isomerising metathesis of renewable raw materials. Green Chem. 2017, 19, 3051-3060.

(22) Pfister, K. F.; Baader, S.; Baader, M.; Berndt, S.; Gooßen, L. J. Biofuel by Isomerizing Metathesis of Rapeseed Oil Esters with (Bio)ethylene for use in Contemporary Diesel Engines. Sci. Adv. 2017, 3, e1602624.

(23) (a) Dura-Vila, V.; Mingos, D. M. P.; Vilar, R.; White, A. J. P.; Williams, D. J. Reactivity studies of $\left[\mathrm{Pd}_{2}(\mu-\mathrm{X})_{2}\left(\mathrm{P}^{t} \mathrm{Bu}_{3}\right)_{2}\right](\mathrm{X}=\mathrm{Br}$, I $)$ with $\mathrm{CNR}\left(\mathrm{R}=2,6\right.$-dimethylphenyl), $\mathrm{H}_{2}$ and alkynes. J. Organomet. Chem. 2000, 600, 198-205. (b) Dura-Vila, V.; Mingos, D. M. P.; Vilar, R.; White, A. J. P.; Williams, D. J. Insertion of $\mathrm{O}_{2}$ into a $\mathrm{Pd}(\mathrm{I})-\mathrm{Pd}(\mathrm{I})$ dimer and subsequent $\mathrm{C}-\mathrm{O}$ bond formation by activation of a $\mathrm{C}-\mathrm{H}$ bond. Chem. Commun. 2000, 1525-1526.

(24) Prashad, M.; Mak, X. Y.; Liu, Y.; Repič, O. PalladiumCatalyzed Amination of Aryl Bromides with Hindered N-AlkylSubstituted Anilines Using a Palladium(I) Tri-tert-butylphosphine Bromide Dimer. J. Org. Chem. 2003, 68, 1163-1164.

(25) Stambuli, J. P.; Kuwano, R.; Hartwig, J. F. Unparalleled Rates for the Activation of Aryl Chlorides and Bromides: Coupling with Amines and Boronic Acids in Minutes at Room Temperature. Angew. Chem., Int. Ed. 2002, 41, 4746-4748

(26) (a) Hama, T.; Liu, X.; Culkin, D. A.; Hartwig, J. F. PalladiumCatalyzed $\alpha$-Arylation of Esters and Amides under More Neutral
Conditions. J. Am. Chem. Soc. 2003, 125, 11176-11177. (b) Hama, T.; Hartwig, J. F. $\alpha$-Arylation of Esters Catalyzed by the Pd(I) Dimer $\{[\mathrm{P}(\mathrm{t}-$ $\left.\left.\mathrm{Bu})_{3}\right] \mathrm{PdBr}\right\}_{2}$. Org. Lett. 2008, 10, 1545-1548. (c) Hama, T.; Hartwig, J. F. Palladium-Catalyzed $\alpha$-Arylation of Esters with Chloroarenes. Org. Lett. 2008, 10, 1549-1552.

(27) Nathel, N. F. F.; Shah, T. K.; Bronner, S. M.; Garg, N. K. Total syntheses of indolactam alkaloids (-)-indolactam V, (-)-pendolmycin, (-)-lyngbyatoxin A, and (-)-teleocidin A-2. Chem. Sci. 2014, 5, 21842190 .

(28) Bercot, E. A.; Caille, S.; Bostick, T. M.; Ranganathan, K.; Jensen, R.; Faul, M. M. Diastereoselective Palladium-Catalyzed $\alpha$ Arylation of 4-Substituted Cyclohexyl Esters. Org. Lett. 2008, 10, $5251-5254$.

(29) Huang, J.; Bunel, E.; Faul, M. M. Palladium-Catalyzed $\alpha$ Vinylation of Carbonyl Compounds. Org. Lett. 2007, 9, 4343-4346.

(30) Ryberg, P. Development of a Mild and Robust Method for Large-Scale Palladium-Catalysed Cyanation of Aryl Bromides: Importance of the Order of Addition. Org. Process Res. Dev. 2008, 12, $540-543$

(31) Eichman, C. C.; Stambuli, J. P. Zinc-Mediated PalladiumCatalyzed Formation of Carbon-Sulfur Bonds. J. Org. Chem. 2009, 74, 4005-4008.

(32) Hemgesberg, M.; Ohlmann, D. M.; Schmitt, Y.; Wolfe, M. R.; Müller, M. K.; Erb, B.; Sun, Y.; Gooßen, L. J.; Gerhards, M.; Thiel, W. R. Simple Access to Sol-Gel Precursors Bearing Fluorescent Aromatic Core Units. Eur. J. Org. Chem. 2012, 2012, 2142-2151.

(33) Aufiero, M.; Scattolin, T.; Proutière, F.; Schoenebeck, F. AirStable Dinuclear Iodine-Bridged Pd(I) Complex - Catalyst, Precursor, or Parasite? The Additive Decides. Systematic Nucleophile-Activity Study and Application as Precatalyst in Cross-Coupling. Organometallics 2015, 34, 5191-5195.

(34) Hooper, M. W.; Utsunomiya, M.; Hartwig, J. F. Scope and Mechanism of Palladium-Catalyzed Amination of Five-Membered Heterocyclic Halides. J. Org. Chem. 2003, 68, 2861-2873.

(35) (a) Kalvet, I.; Bonney, K. J.; Schoenebeck, F. Kinetic and Computational Studies on Pd(I) Dimer-Mediated Halogen Exchange of Aryl Iodides. J. Org. Chem. 2014, 79, 12041-12046

(36) Yin, G.; Kalvet, I.; Schoenebeck, F. Trifluoromethylthiolation of Aryl Iodides and Bromides Enabled by a Bench-Stable and Easy-To-Recover Dinuclear Palladium(I) Catalyst. Angew. Chem., Int. Ed. 2015, 54, 6809-6813.

(37) (a) Mondal, T.; De, S.; Maity, B.; Koley, D. Exploring the Oxidative Addition Pathways of Phenyl Chloride in Presence of Pd(II)abnormal N-heterocyclic Carbene (aNHC) Complexes: A DFT Study. Chem. - Eur. J. 2016, 22, 15778-15790. (b) Mondal, T.; De, S.; Dutta, S.; Koley, D. Mechanistic Exploration of the Transmetalation and Reductive Elimination Events from Pd(IV)-abnormal NHC Complexes in Suzuki-Miyaura Coupling: A DFT Study. Chem. - Eur. J. 2018, 24, 6155-6168.

(38) (a) Hill, L. L.; Crowell, J. L.; Tutwiler, S. L.; Massie, N. L.; Hines, C. C.; Griffin, S. T.; Rogers, R. D.; Shaughnessy, K. H. Synthesis and X-ray Structure Determination of Highly Active Pd(II), $\operatorname{Pd}(\mathrm{I})$, and $\mathrm{Pd}(0)$ Complexes of Di(tert-butyl)neopentylphosphine (DTBNpP) in the Arylation of Amines and Ketones. J. Org. Chem. 2010, 75, 6477-6488. (b) Colacot, T. J. A Highly Active Palladium(I) Dimer for Pharmaceutical Applications $\left[\mathrm{Pd}(\mu-\mathrm{Br})\left({ }^{t} \mathrm{Bu}_{3} \mathrm{P}\right)\right]_{2}$ as a Practical Cross-coupling Catalyst. Platinum Metals Rev. 2009, 53, $183-188$.

(39) Amatore, C.; Jutand, A. Anionic Pd(0) and Pd(II) Intermediates in Palladium-Catalyzed Heck and Cross-Coupling Reactions. Acc. Chem. Res. 2000, 33, 314-321.

(40) Lee, C. L.; James, B. R.; Nelson, D. A.; Hallen, R. T. Kinetics and Thermodynamics of the Reversible Reaction between Carbon Monoxide and Palladium(I) Dimers Containing Bis(diphenyIphosphino) methane. Organometallics 1984, 3, 13601364.

(41) Proutiere, F.; Aufiero, M.; Schoenebeck, F. Reactivity and Stability of Dinuclear Pd(I) Complexes: Studies on the Active Catalytic Species, Insights into Precatalyst Activation and Deactivation, and 
Application in Highly Selective Cross-Coupling Reactions. J. Am. Chem. Soc. 2012, 134, 606-612.

(42) (a) Das, R. K.; Saha, B.; Rahaman, S. M. W.; Bera, J. K. Bimetallic Catalysis Involving Dipalladium(I) and Diruthenium(I) Complexes. Chem. - Eur. J. 2010, 16, 1445914468. (b) Murahashi, T.; Takase, K.; Oka, M.; Ogoshi, S. Oxidative Dinuclear Addition of a Pd ${ }^{\mathrm{I}}-$ $\mathrm{Pd}^{\mathrm{I}}$ Moiety to Arenes: Generation of $\mu-\eta^{3}: \eta^{3}$-Arene-Pd ${ }_{2}{ }_{2}$ Species. $J$. Am. Chem. Soc. 2011, 133, 14908-14911. (c) Han, X.; Weng, Z.; Hor, T. S. A. Suzuki coupling catalyzed by a homoleptic Pd(I)-Pd(I) solvento complex. J. Organomet. Chem. 2007, 692, 5690-5696. (d) Boyd, P. D. W.; Edwards, A. J.; Gardiner, M. G.; Ho, C. C.; LeméeCailleau, M. -H.; McGuinness, D. S.; Riapanitra, A.; Steed, J. W.; Stringer, D. N.; Yates, B. F. Reduction of a Chelating Bis(NHC) Palladium(II) Complex to $\left[\{\mu \text {-bis }(\mathrm{NHC})\}_{2} \mathrm{Pd}_{2} \mathrm{H}\right]^{+}$: A Terminal Hydride in a Binuclear Palladium(I) Species Formed under Catalytically Relevant Conditions. Angew. Chem., Int. Ed. 2010, 49, 6315-6318.

(43) (a) Bonney, K. J.; Proutiere, F.; Schoenebeck, F. Dinuclear Pd(I) complexes - solely precatalysts? Demonstration of direct reactivity of a $\mathrm{Pd}(\mathrm{I})$ dimer with an aryl iodide. Chem. Sci. 2013, 4, 4434-4439. (b) Aufiero, M.; Sperger, T.; Tsang, A. S. K.; Schoenebeck, F. Highly Efficient $\mathrm{C}-\mathrm{SeCF}_{3}$ Coupling of Aryl Iodides Enabled by an Air-Stable Dinuclear Pd(I) Catalyst. Angew. Chem., Int. Ed. 2015, 54, 10322-10326.

(44) Davies, N. R. Palladium-catalysed Olefine Isomerization. Nature 1964, 201, 490-491.

(45) Kocen, A. L.; Brookhart, M.; Daugulis, O. Palladium-catalysed alkene chain-running isomerization. Chem. Commn. 2017, 53, 1001010013.

(46) Hassam, M.; Taher, A.; Arnott, G. E.; Green, I. R.; van Otterlo, W. A. L. Isomerization of Allylbenzenes. Chem. Rev. 2015, 115, 54625569.

(47) Kapat, K.; Sperger, T.; Guven. S.; Schoenebeck, F. E-Olefins through intramolecular radical relocation. Science 2019, 363, 391-396.

(48) Portnoy, M.; Milstein, D. A binuclear palladium(I) hydride. Formation, reactions, and catalysis. Organometallics 1994, 13, 600609.

(49) Sen, A.; Lai, T. W. Mechanism of Palladium(II)-Catalyzed C=C Bond Isomerization in Olefins. Inorg. Chem. 1984, 23, 3257-3258.

(50) Larionov, E.; Lin, L.; Guénée, L.; Mazet, C. Scope and Mechanism in Palladium-Catalyzed Isomerizations of Highly Substituted Allylic, Homoallylic, and Alkenyl Alcohols. J. Am. Chem. Soc. 2014, 136, 16882-16894.

(51) Barrios-Landeros, F.; Carrow, B. P.; Hartwig, J. F. Autocatalytic Oxidative Addition of $\mathrm{PhBr}$ to $\mathrm{Pd}\left(\mathrm{P}^{t} \mathrm{Bu}_{3}\right)_{2}$ via $\operatorname{Pd}\left(\mathrm{P}^{t} \mathrm{Bu}_{3}\right)_{2}(\mathrm{H})(\mathrm{Br})$. J. Am. Chem. Soc. 2008, 130, 5842-5843.

(52) Gauthier, D.; Lindhardt, A. T.; Olsen, E. P. K.; Overgaard, J.; Skydstrup, T. In Situ Generated Bulky Palladium Hydride Complexes as Catalysts for the Efficient Isomerization of Olefins. Selective Transformation of Terminal Alkenes to 2-Alkenes. J. Am. Chem. Soc. 2010, 132, 7998-8009.

(53) Frisch, M. J.; Trucks, G. W.; Schlegel, H. B.; Scuseria, G. E.; Robb, M. A.; Cheeseman, J. R.; Montgomery, Jr., J. A.; Vreven, T.; Kudin, K. N.; Burant, J. C.; Millam, J. M.; Iyengar, S. S.; Tomasi, J.; Barone, V.; Mennucci, B.; Cossi, M.; Scalmani, G.; Rega, N.; Petersson, G. A.; Nakatsuji, H.; Hada, M.; Ehara, M.; Toyota, K.; Fukuda, R.; Hasegawa, J.; Ishida, M.; Nakajima, T.; Honda, Y.; Kitao, O.; Nakai, H.; Klene, M.; Li, X.; Knox, J. E.; Hratchian, H. P.; Cross, J. B.; Bakken, V.; Adamo, C.; Jaramillo, J.; Gomperts, R.; Stratmann, R. E.; Yazyev, O.; Austin, A. J.; Cammi, R.; Pomelli, C.; Ochterski, J. W.; Ayala, P. Y.; Morokuma, K.; Voth, G. A.; Salvador, P.; Dannenberg, J. J.; Zakrzewski, V. G.; Dapprich, S.; Daniels, A. D.; Strain, M. C.; Farkas, O.; Malick, D. K.; Rabuck, A. D.; Raghavachari, K.; Foresman, J. B.; Ortiz, J. V.; Cui, Q.; Baboul, A. G.; Clifford, S.; Cioslowski, J.; Stefanov, B. B.; Liu, G.; Liashenko, A.; Piskorz, P.; Komaromi, I.; Martin, R. L.; Fox, D. J.; Keith, T.; Al-Laham, M. A.; Peng, C. Y.; Nanayakkara, A.; Challacombe, M.; Gill, P. M. W.; Johnson, B.; Chen, W.; Wong, M. W.; Gonzalez, C.; and Pople, J. A. Gaussian 03, Rev. E.01, Gaussian, Inc., Wallingford, CT, 2010.

(54) Frisch, M. J.; Trucks, G. W.; Schlegel, H. B.; Scuseria, G. E.; Robb, M. A.; Cheeseman, J. R.; Scalmani, G.; Barone, V.; Mennucci,
B.; Petersson, G. A.; Nakatsuji, H.; Caricato, M.; Li, X.; Hratchian, H. P.; Izmaylov, A. F.; Bloino, J.; Zheng, G.; Sonnenberg, J. L.; Hada, M.; Ehara, M.; Toyota, K.; Fukuda, R.; Hasegawa, J.; Ishida, M.; Nakajima, T.; Honda, Y.; Kitao, O.; Nakai, H.; Vreven, T.; Montgomery, J. A., Jr.; Peralta, J. E.; Ogliaro, F.; Bearpark, M.; Heyd, J. J.; Brothers, E.; Kudin, K. N.; Staroverov, V. N.; Kobayashi, R.; Normand, J.; Raghavachari, K.; Rendell, A.; Burant, J. C.; Iyengar, S. S.; Tomasi, J.; Cossi, M.; Rega, N.; Millam, N. J.; Klene, M.; Knox, J. E.; Cross, J. B.; Bakken, V.; Adamo, C.; Jaramillo, J.; Gomperts, R.; Stratmann, R. E.; Yazyev, O.; Austin, A. J.; Cammi, R.; Pomelli, C.; Ochterski, J. W.; Martin, R. L.; Morokuma, K.; Zakrzewski, V. G.; Voth, G. A.; Salvador, P.; Dannenberg, J. J.; Dapprich, S.; Daniels, A. D.; Farkas, Ö.; Foresman, J. B.; Ortiz, J. V.; Cioslowski, J.; Fox, D. J. Gaussian 09, Revision D.01; Gaussian, Inc.: Wallingford, CT, 2013.

(55) (a) Becke, A. D. Density-functional thermochemistry. III. The role of exact exchange. J. Chem. Phys. 1993, 98, 5648-5652. (b) Lee, C.; Yang, W.; Parr, R. G. Development of the Colle-Salvetti correlation-energy formula into a functional of the electron density. Phys. Rev. B: Condens. Matter Mater. Phys. 1988, 37, 785-789.

(56) (a) Grimme, S.; Antony, J.; Ehrlich, S.; Krieg, H. A consistent and accurate $\mathrm{ab}$ initio parametrization of density functional dispersion correction (DFT-D) for the 94 elements H-Pu. J. Chem. Phys. 2010, 132, 154104-154122. (b) Becke, A. D. Density-functional exchangeenergy approximation with correct asymptotic behavior. Phys. Rev. A: At., Mol., Opt. Phys. 1988, 38, 3098-3100.

(57) Hehre, W. J.; Radom, L.; Schleyer, L. v. R.; Pople, J. A. $A b$ Initio Molecular Orbital Theory, Wiley, New York, NY, 1986.

(58) (a) Hay, P. J.; Wadt, W. R. Ab initio effective core potentials for molecular calculations. Potentials for the transition metal atoms Sc to Hg. J. Chem. Phys. 1985, 82, 270-283. (b) Wadt, W. R.; Hay, P. J. $\mathrm{Ab}$ initio effective core potentials for molecular calculations. Potentials for main group elements Na to Bi. J. Chem. Phys. 1985, 82, 284-298. (c) Hay, P. J.; Wadt, W. R. Ab initio effective core potentials for molecular calculations. Potentials for $\mathrm{K}$ to $\mathrm{Au}$ including the outermost core orbitals. J. Chem. Phys. 1985, 82, 299-310.

(59) Helgren, T. A.; Lipscomb, W. N. The synchronous-transit method for determining reaction pathways and locating molecular transition states. Chem. Phys. Lett. 1977, 49, 225-232.

(60) (a) Hratchian, H. P.; Schlegel, H. B. Finding minima, transition states, and following reaction pathways on ab initio potential energy surfaces. In Theory and Applications of Computational Chemistry: The First 40 Years; Dykstra, C. E.; Frenking, G.; Kim, K. S.; Scuseria, G., Eds; Elsevier: Amsterdam, 2005; pp 195-249. (b) Hratchian, H. P.; Schlegel, H. B. Using Hessian updating to increase the efficiency of a Hessian based predictor-corrector reaction path following method. $J$. Chem. Theory and Comput. 2005, 1, 61-69. (c) Hratchian, H. P.; Schlegel, H. B. Accurate reaction paths using a Hessian based predictor-corrector integrator. J. Chem. Phys. 2004, 120, 9918-9924. (d) Fukui, K. The path of chemical-reactions - The IRC approach. Acc. Chem. Res. 1981, 14, 363-368.

(61) Marenich, A. V.; Cramer, C. J.; Truhlar, D. G. Universal Solvation Model Based on Solute Electron Density and on a Continuum Model of the Solvent Defined by the Bulk Dielectric Constant and Atomic Surface Tensions. J. Phys. Chem. B 2009, 113, 6378-6396.

(62) (a) Maseras, F.; Morokuma, K. IMOMM: A new integrated ab initio + molecular mechanics geometry optimization scheme of equilibrium structures and transition states. J. Comput. Chem. 1995, 16, 1170-1179. (b) Vreven, T.; Morokuma, K. On the application of the IMOMO (integrated molecular orbital + molecular orbital) method. $J$. Comput. Chem. 2000, 21, 1419-1432.

(63) (a) Glendening, E. D.; Reed, A. E.; Carpenter, J. E.; Weinhold, F. NBO Version 3.1; (b) Reed, A. E.; Curtiss, L. A.; Weinhold, F. Intermolecular Interactions from a Natural Bond Orbital, DonorAcceptor Viewpoint. Chem. Rev., 1988, 88, 899-926.

(64) Bader, R. F. W. A quantum theory of molecular structure and its applications. Chem. Rev., 1991, 91, 893-928.

(65) (a) Cooperand, J.; Ziegler, T. A Density Functional Study of $\mathrm{S}_{\mathrm{N}} 2$ Substitution at Square-Planar Platinum(II) Complexes. Inorg. Chem. 2002, 41, 6614-6622. (b) Tobisch, S. Organolanthanide-Mediated Ring-Opening Ziegler Polymerization 
(ROZP) of Methylenecycloalkanes: A Theoretical Mechanistic Investigation of Alternative Mechanisms for Chain Initiation of the Samarocene-Promoted ROZP of 2-Phenyl-1-methylenecyclopropane. Chem. - Eur. J. 2005, 11, 3113-3126. (c) Tommaso, S. D.; Tognetti, V.; Sicilla, E.; Adamo, C.; Russo, N. Computational Study of Alkynes Insertion into Metal-Hydride Bonds Catalyzed by Bimetallic Complexes. Inorg. Chem. 2010, 49, 9875-9883. (d) Maity, B.; Gooßen, L. J.; Koley, D. Computational study of the mechanism and selectivity of ruthenium-catalyzed hydroamidations of terminal alkynes. Chem. Sci. 2015, 6, 2532-2552.

(66) C. Y. Legault, CYLView, 1.0b, Universite de Sherbrooke, Sherbrooke, QC, Canada, 2009; http://www.cylview.org.

(67) Cui, P.; Iluc, V. M. Redox-induced umpolung of transition metal carbenes. Chem. Sci. 2015, 6, 7343-7354.

(68) Zanoni, G.; Porta, A.; Meriggi, A.; Franzini, M.; Vidari, G. 1,2Oxopalladation versus $\pi$-Allyl Palladium Route. A Regioconvergent Approach to a Key Intermediate for Cyclopentanoids Synthesis. New Insights into the Pd(II)-Catalyzed Lactonization Reaction. J. Org. Chem. 2002, 67, 6064-6069.
(69) Lim, H. J.; Smith, C. R.; RajanBabu, T. V. Facile Pd(II)- and $\mathrm{Ni}(\mathrm{II})$-Catalyzed Isomerization of Terminal Alkenes into 2-Alkenes. $J$. Org. Chem. 2009, 74, 4565-4572.

(70) (a)Minenkov, Y.; Occhipinti, G.; Jensen, V. R. Metal-Phosphine Bond Strengths of the Transition Metals: A Challenge for DFT. J. Phys. Chem. A. 2009, 113, 11833-11844. (b) Sandhya, K. S.; Suresh, C. H. DFT study on the mechanism of waterassisted dihydrogen elimination in group 6 octahedral metal hydride complexes. Dalton Trans. 2012, 41, 11018-11025.

(71) For better comparison, all structures from the catalytic cycle of $\mathrm{Pd} 1 \mathrm{c}^{\mathrm{Br}}$, in which the ONIOM method is used, were also exemplarily calculated without it. The energies obtained in both sets of calculations are very similar, see the SI; Table S5.

(72) Pirkl, N.; Del Grosso, A.; Mallick, B.; Doppiu, D.; Gooßen, L. J. Dihalogen-bridged NHC-palladium(I) dimers: synthesis, characterisation and applications in cross-coupling reactions. Chem. Commun. 2019, 55, 5275-5278. 
For Table of Contents Only

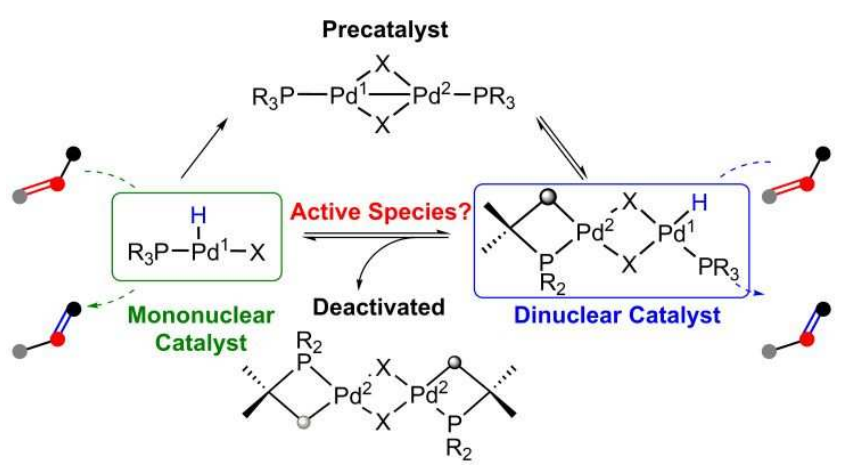




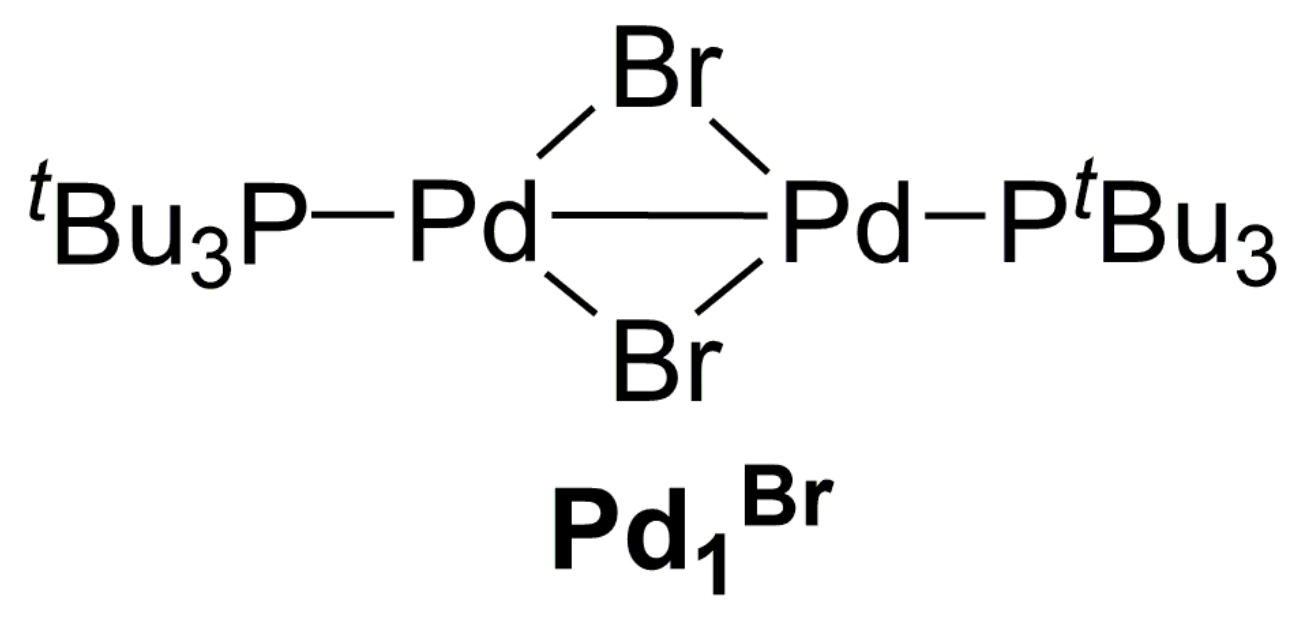

Figure 1. Structure and optimized geometry of dinuclear $\mathrm{Pd}^{\mathrm{I}}$ catalyst $\left[\mathrm{Pd}{ }^{\mathrm{I}}(\mu-\mathrm{Br})^{\mathrm{t}} \mathrm{Bu}{ }_{3} \mathrm{P}\right]_{2}\left(\mathbf{P d} \mathbf{1}^{\mathbf{B r}}\right)$. $40 \times 19 \mathrm{~mm}(600 \times 600 \mathrm{DPI})$ 


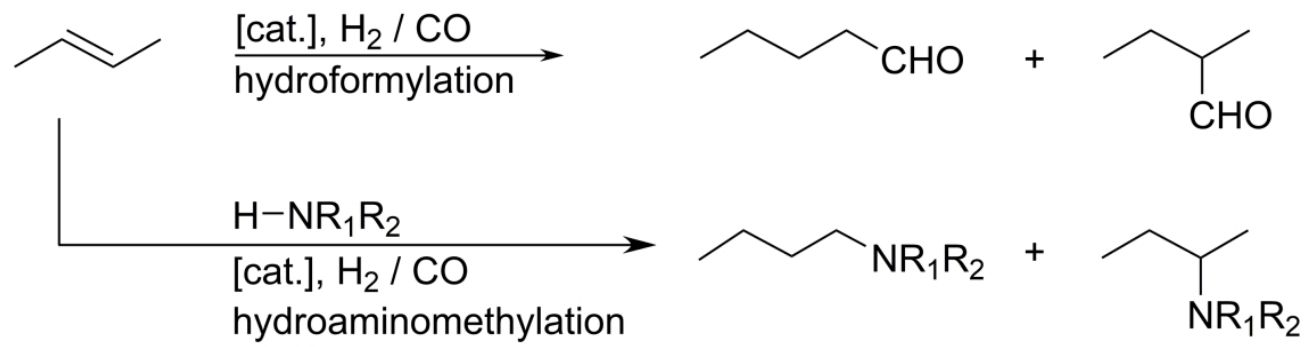

Scheme 1. Isomerizing hydroaminomethylation or hydroformylation of internal olefins.

$120 \times 33 \mathrm{~mm}(600 \times 600 \mathrm{DPI})$ 


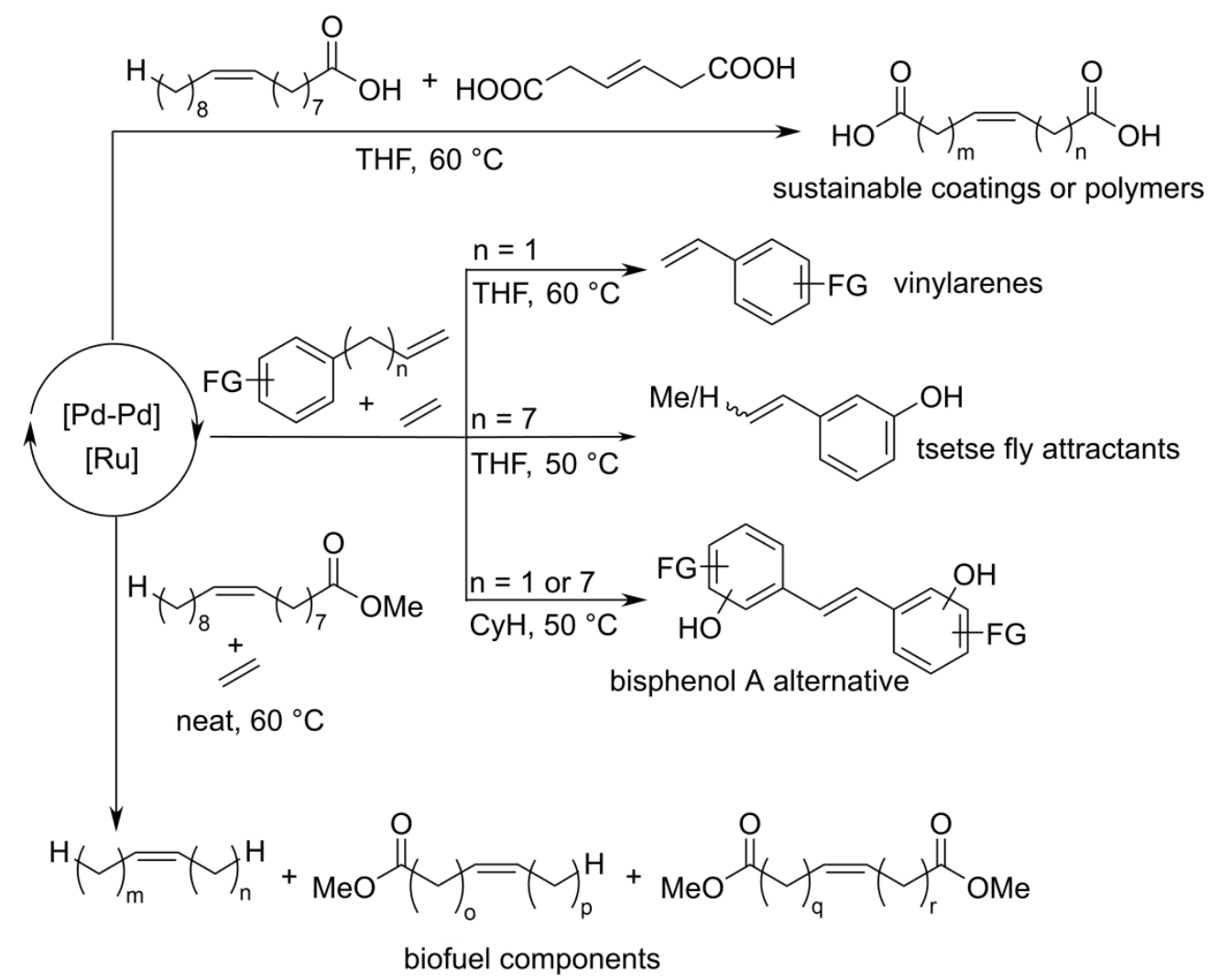

Scheme 2. Synthetic utility of isomerizing metathesis processes catalyzed by Ru/Pd systems. $141 \times 116 \mathrm{~mm}(600 \times 600 \mathrm{DPI})$ 


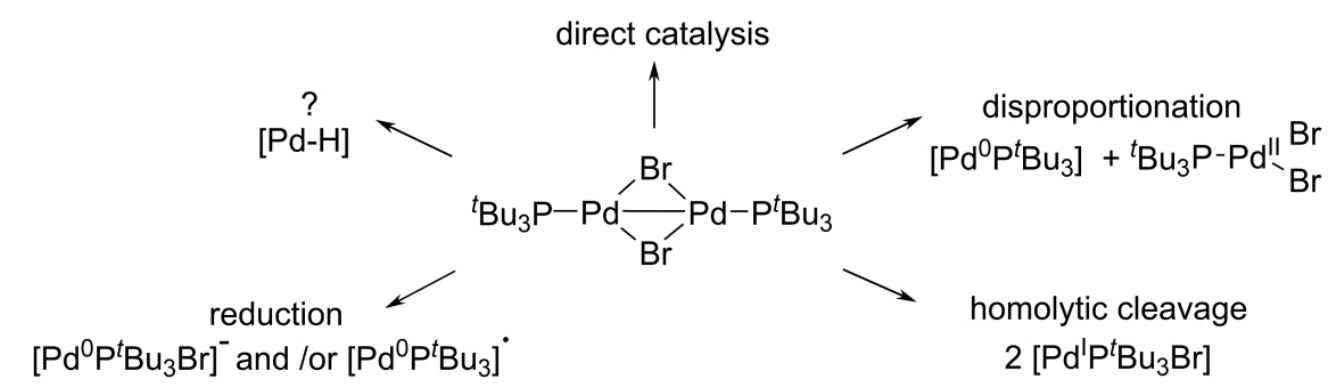

Scheme 3. Proposed pathways for the formation of catalytically active species from $\mathrm{Pd} 1^{\mathrm{Br}}$. $140 \times 40 \mathrm{~mm}(600 \times 600 \mathrm{DPI})$ 
a)

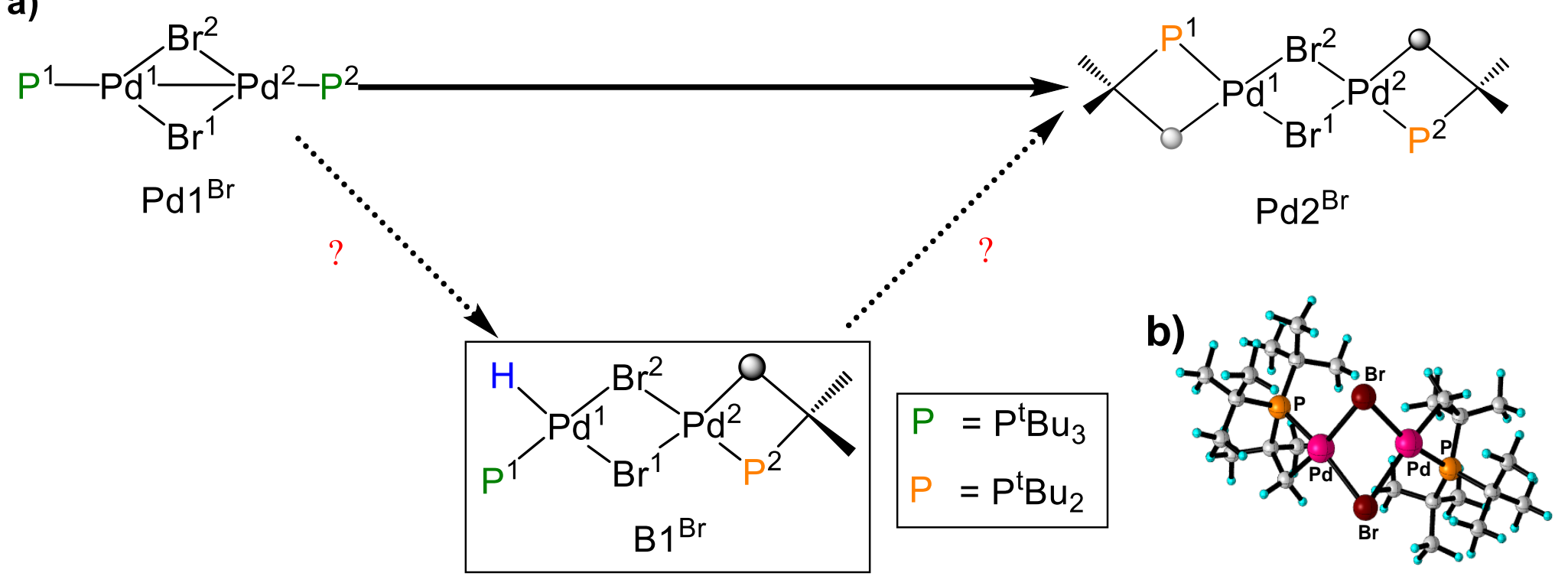




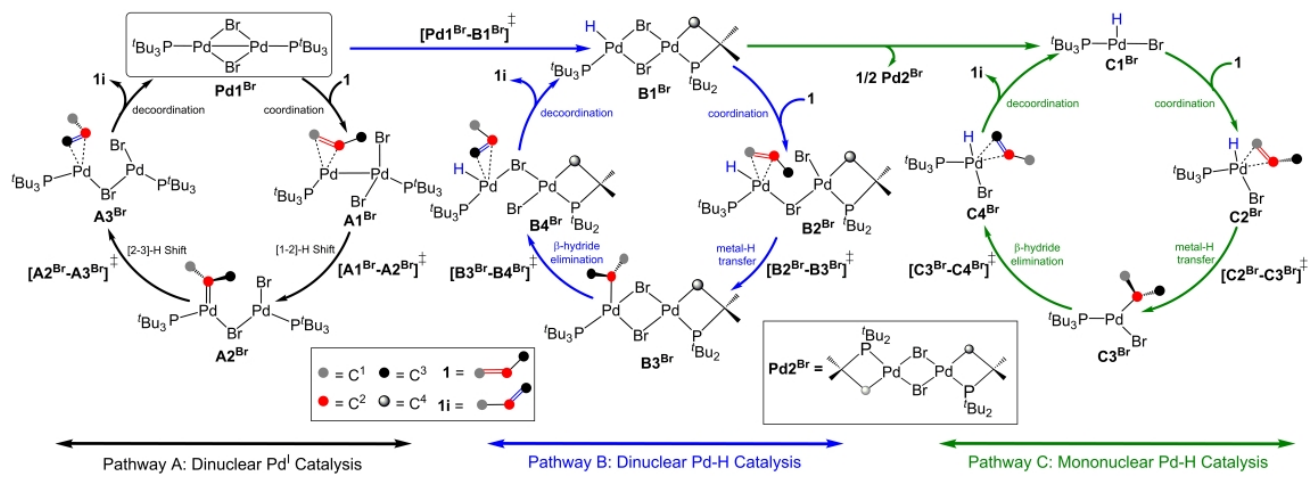

Scheme 6. Selected isomerization pathways starting from pre-catalyst $\left[\mathrm{Pd}(\mu-\mathrm{Br}){ }^{t} \mathrm{Bu}{ }_{3} \mathrm{P}\right]_{2} \mathrm{Pd} 1^{\mathrm{Br}}$. $414 \times 148 \mathrm{~mm}(600 \times 600 \mathrm{DPI})$ 


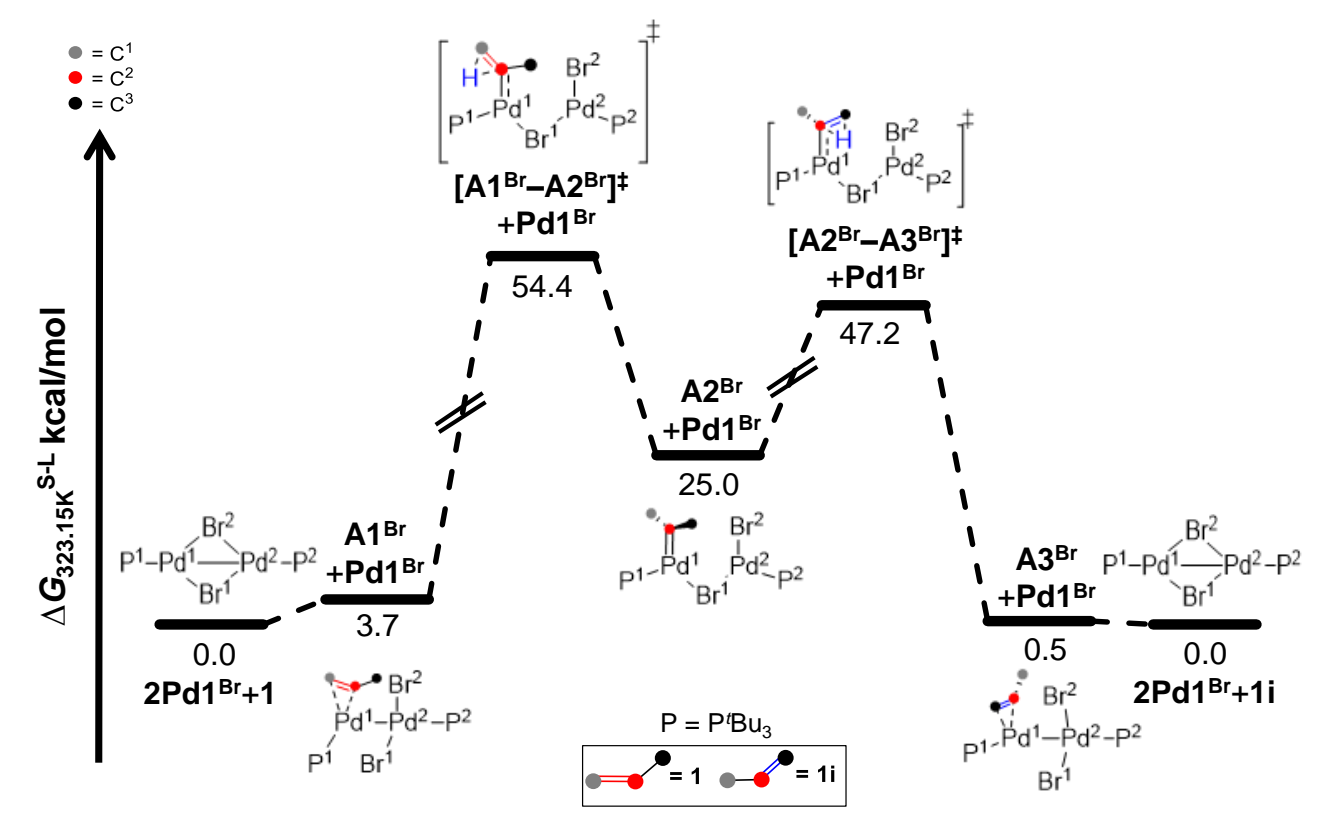




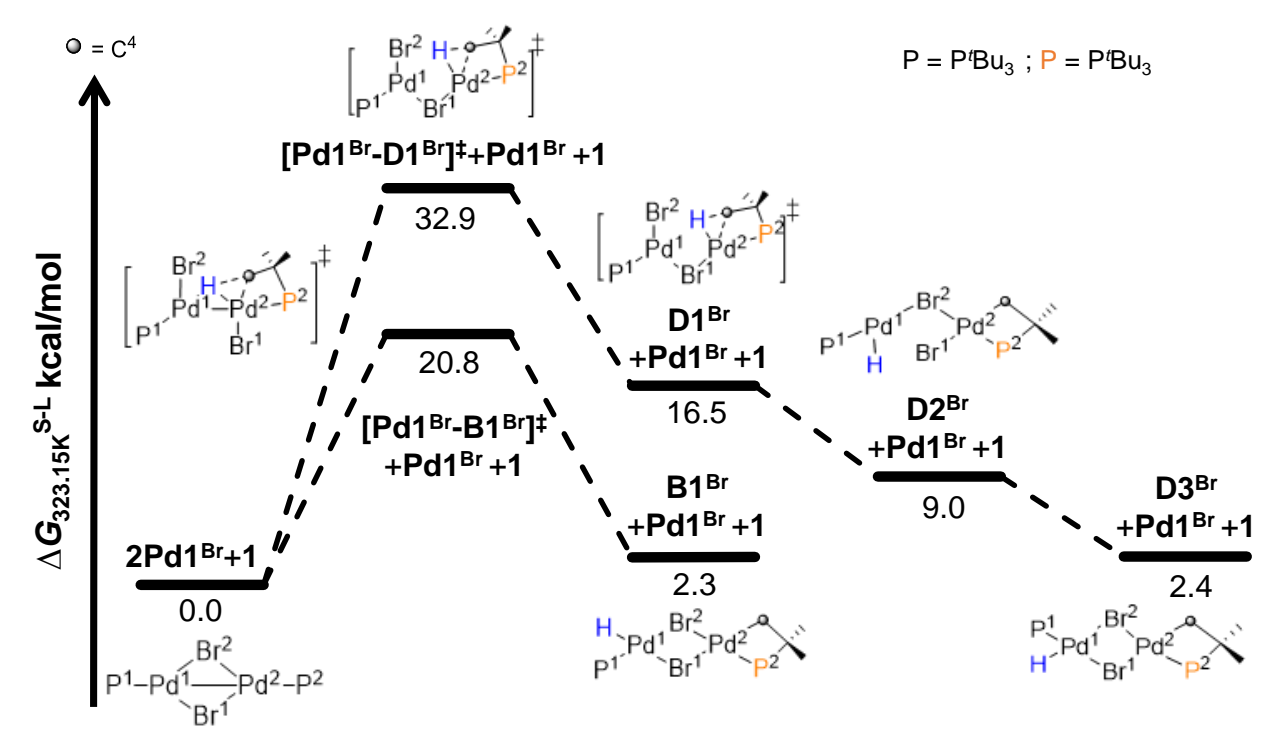




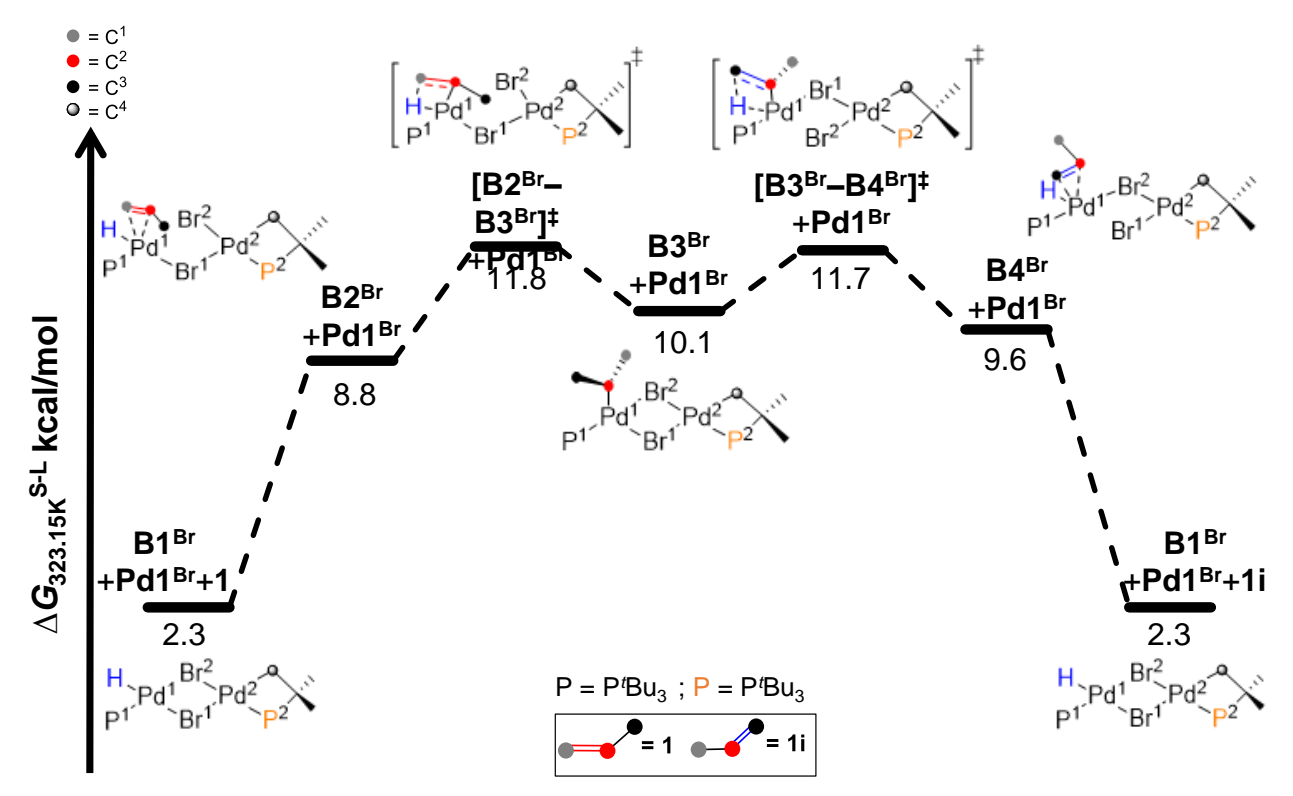




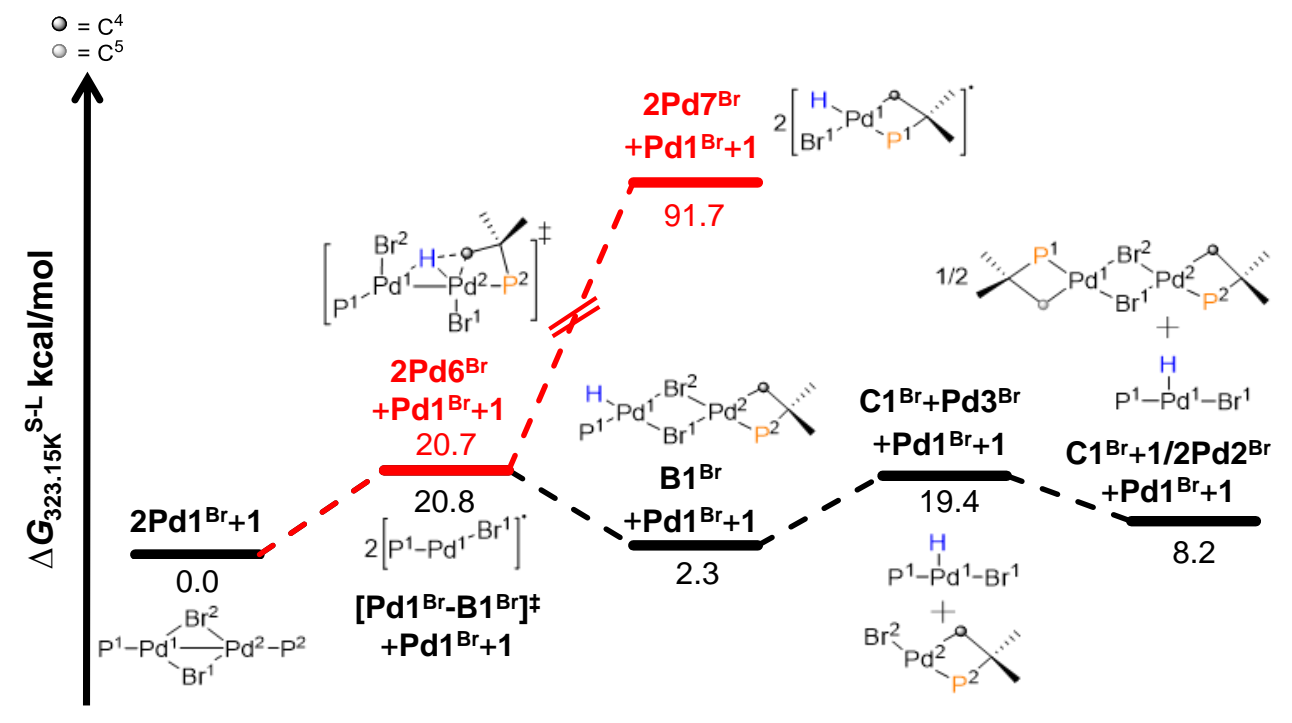




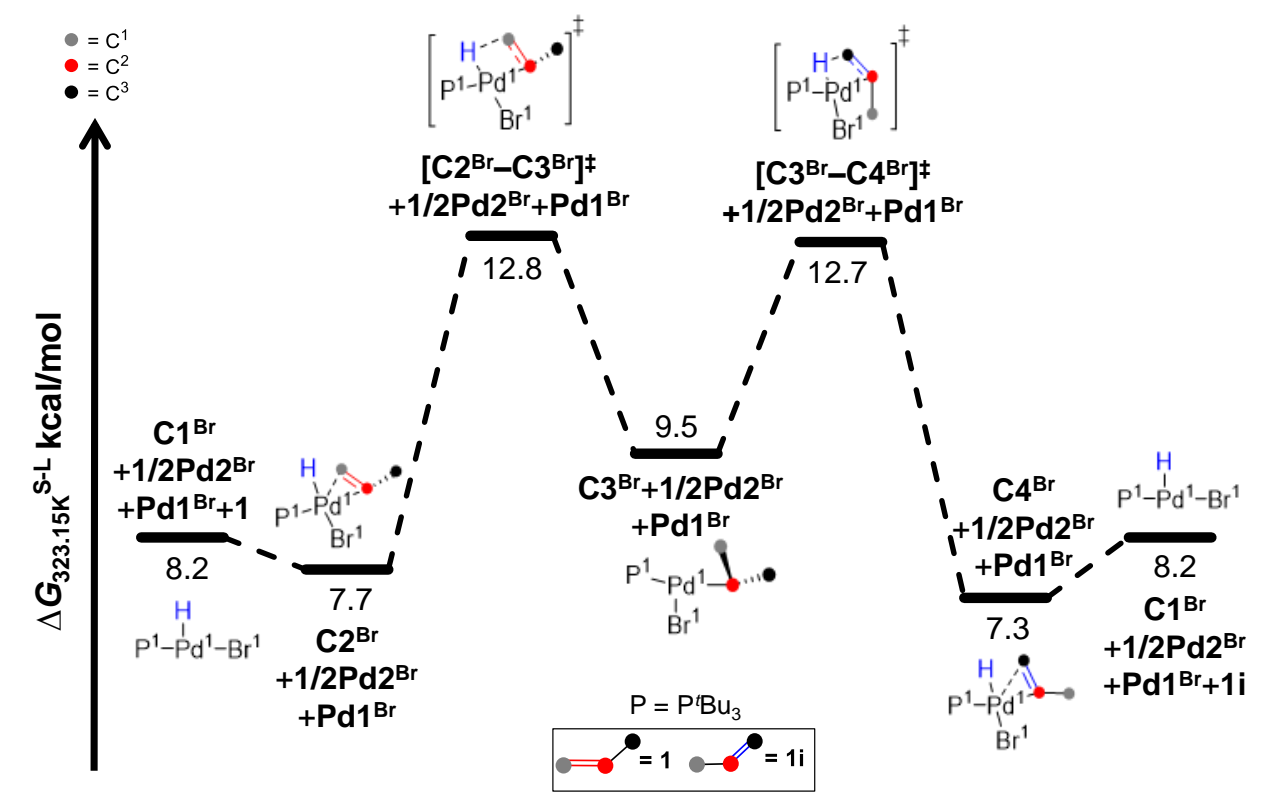




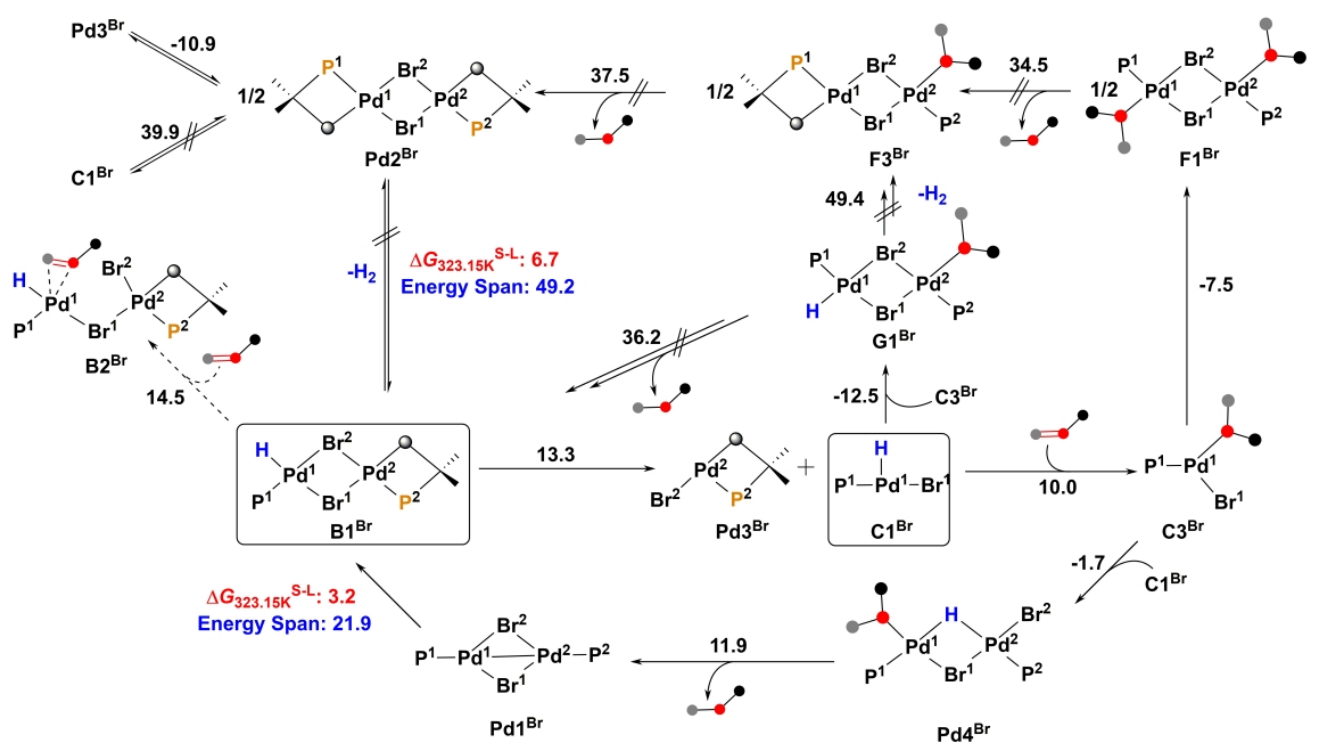

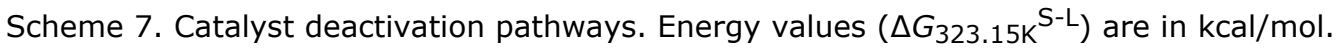

$228 \times 130 \mathrm{~mm}(600 \times 600 \mathrm{DPI})$ 


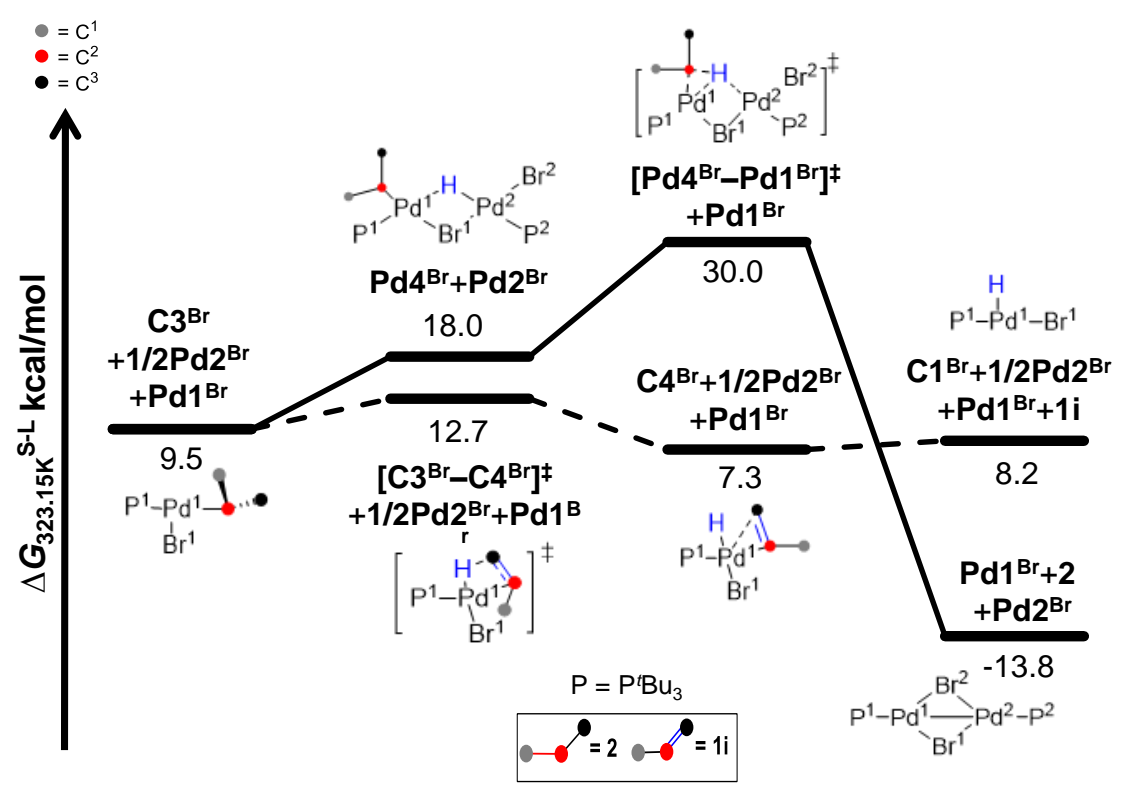



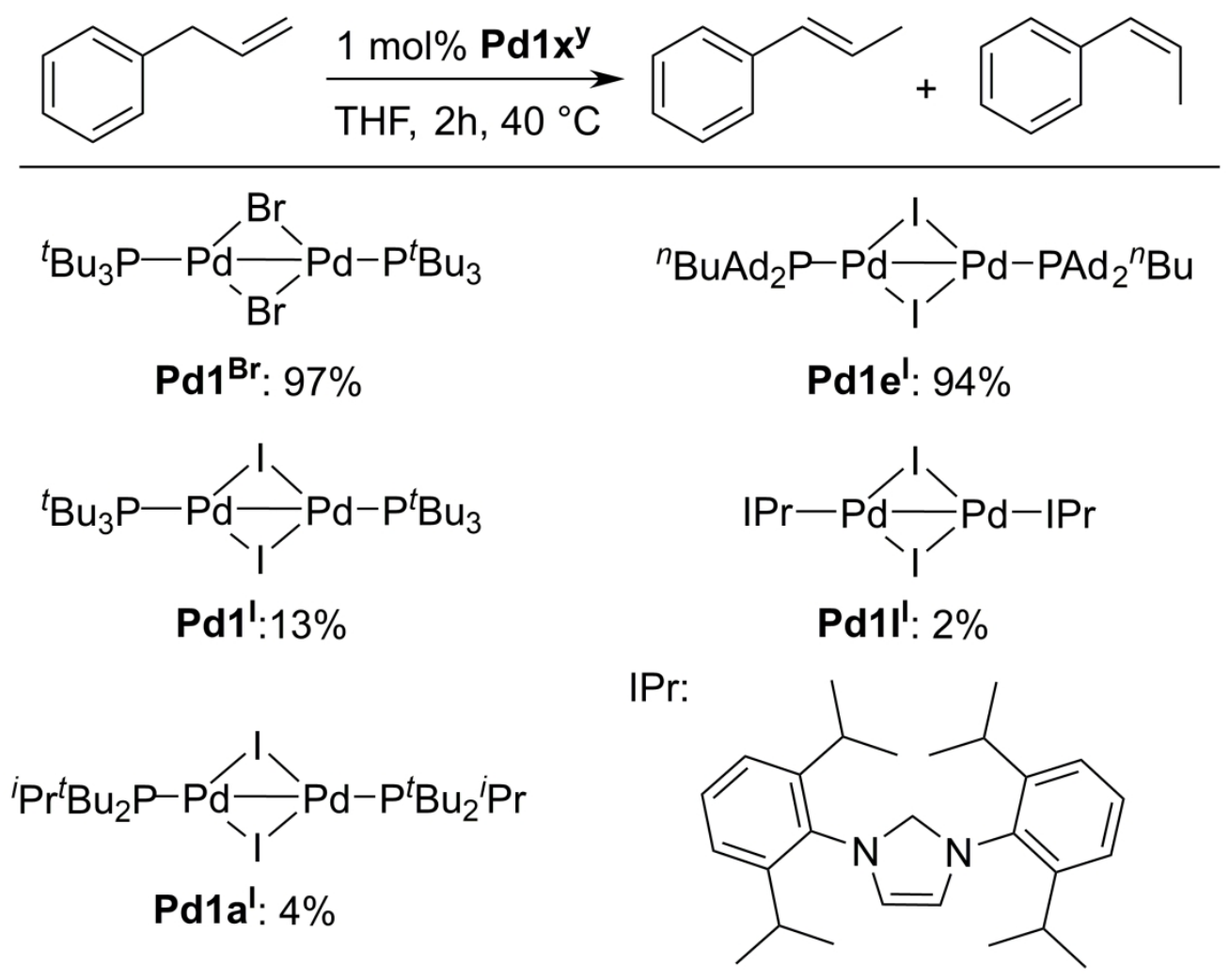

Reaction conditions: $0.5 \mathrm{mmol}$ of allylbenzene, $1 \mathrm{~mol} \%$ of Pd1xy, $1 \mathrm{ml}$ of THF, conversion determined via GC-analysis using $25 \mu \mathrm{l} n$-dodecane as internal standard.

Scheme 8. Experimental study of isomerization activity.

$$
108 \times 96 \mathrm{~mm}(600 \times 600 \mathrm{DPI})
$$




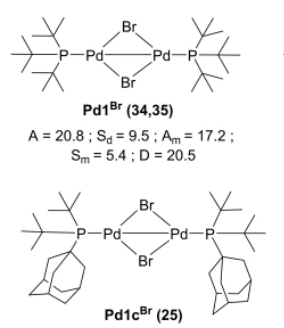

$A=20.2 ; S_{d}=9.3 ; A_{m}=16.7$
$S_{m}=5.2 ; D=21.3$

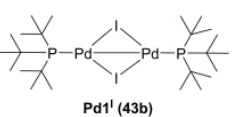

$A=26.2^{\mathrm{a}} ; S d=7.3 ; A_{m}=16.4$; $\mathrm{S}_{\mathrm{m}}=4.1 ; \mathrm{D}=19.9$

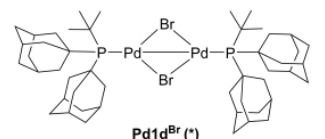

$\mathrm{Pd}^{\mathrm{B}} \mathrm{d}^{\mathrm{Br}}$ (*) $^{*}$

$A=18.6 ; S_{d}=9.2 ; A_{m}=17.4$
$S_{m}=4.8 ; D=20.5$
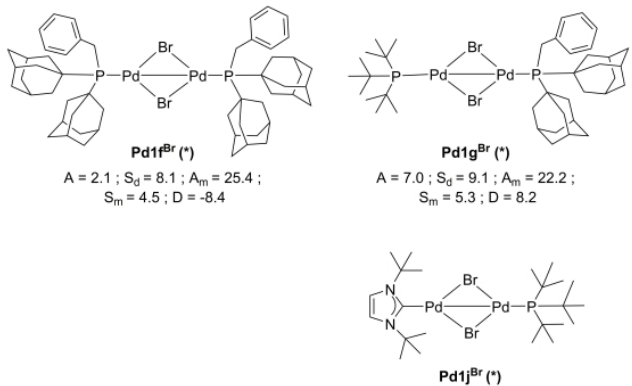

$\operatorname{Pd} 1 j^{\mathrm{Br}}\left({ }^{*}\right)$

$A=20.7 ; S_{d}=11.9 ; A_{m}=19.4$

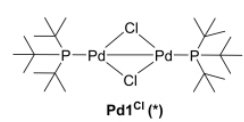

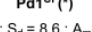

$2 ; S_{d}=8.6 ; A_{m}=16.9 ;$
$S_{m}=5$.

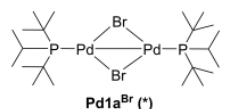
$\operatorname{Pd1a}^{\mathrm{Br}}\left(^{*}\right)$ $=23.0 ; S_{d}=8.1 ; A_{m}=16.9$
$S_{m}=5.6 ; D=11.4$

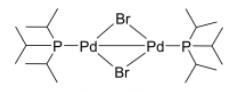
$\operatorname{Pd} 1 b^{B r}(*)$

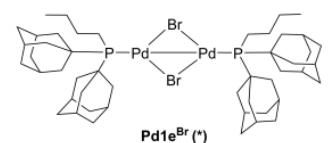

$A=13.4 ; S_{d}=8.0 ; A_{m}=12.2$;

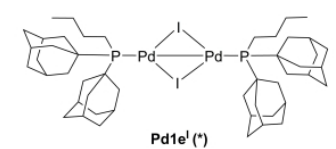

$A=21.5^{\mathrm{a}} ; \mathrm{S}_{d}=5.8 ; A_{m}=10.1 ;$

$\mathrm{S}_{\mathrm{m}}=4.8 ; \mathrm{D}=3.1$ $\mathrm{S}_{\mathrm{m}}=3.8 ; \mathrm{D}=14.0$
$\mathrm{~S}_{\mathrm{m}}$
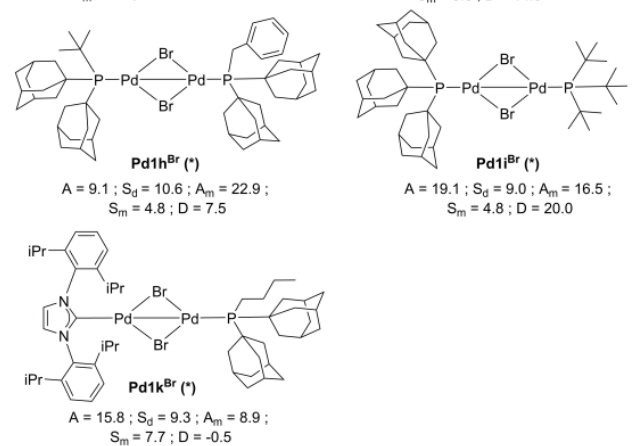

Figure 8. Catalyst structures screened in silico, and key descriptors of their catalytic performance. Literature references of known $\mathbf{P d 1} \mathbf{x}^{\mathbf{i}}$ dimers are provided in parentheses. (*) identifies purely speculative structures. A: catalyst activation barrier $\mathbf{P d 1} \mathbf{x}^{\mathbf{i}} \rightarrow\left[\mathbf{P d 1}^{\mathbf{i}}-\mathbf{B} 1 \mathbf{x}^{\mathbf{i}}\right]^{\neq}, \mathrm{S}_{\mathrm{d}, \mathrm{m}}$ : energy spans of the catalytic isomerization cycles, $\mathrm{A}_{\mathrm{m}}$ : activation barrier towards mononuclear isomerization cycle $\mathbf{B} \mathbf{1} \mathbf{x}^{\mathbf{i}} \rightarrow \mathbf{C 1} \mathbf{x}^{\mathbf{i}}$; D: highest barrier of

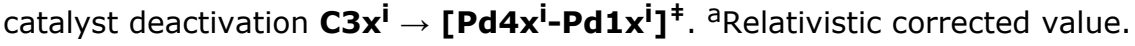

$309 \times 192 \mathrm{~mm}(600 \times 600 \mathrm{DPI})$ 


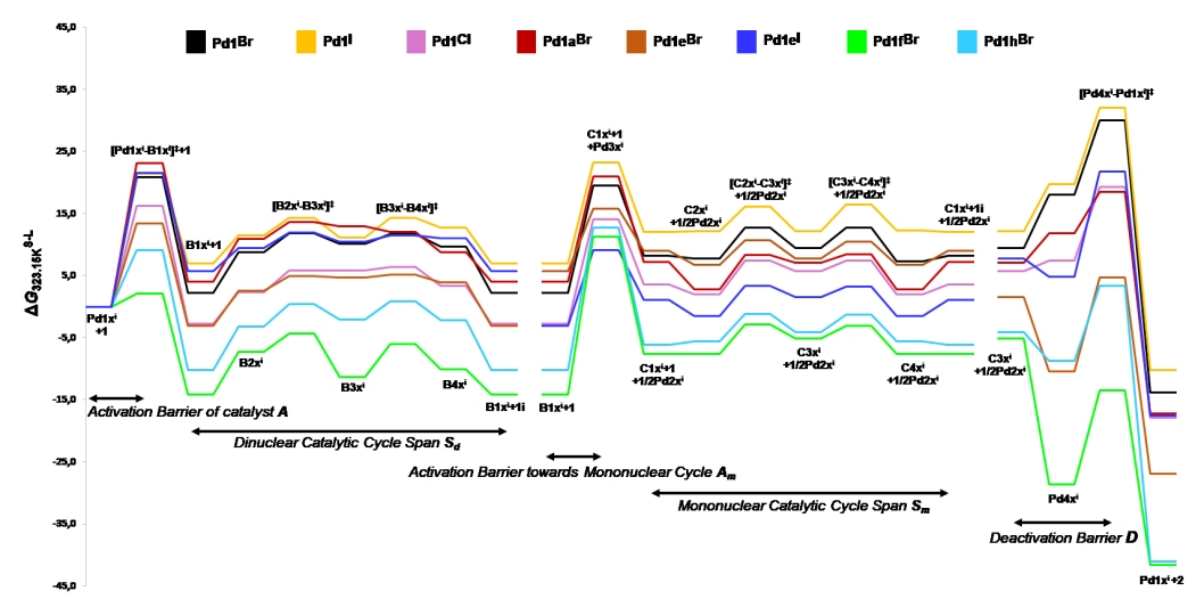

Figure 9. Overlay of selected energy profiles for all catalytic systems. The energy levels are labelled only with the most relevant species; other species included in the energy calculations (Table S6) are omitted for clarity.

$490 \times 221 \mathrm{~mm}(96 \times 96 \mathrm{DPI})$ 


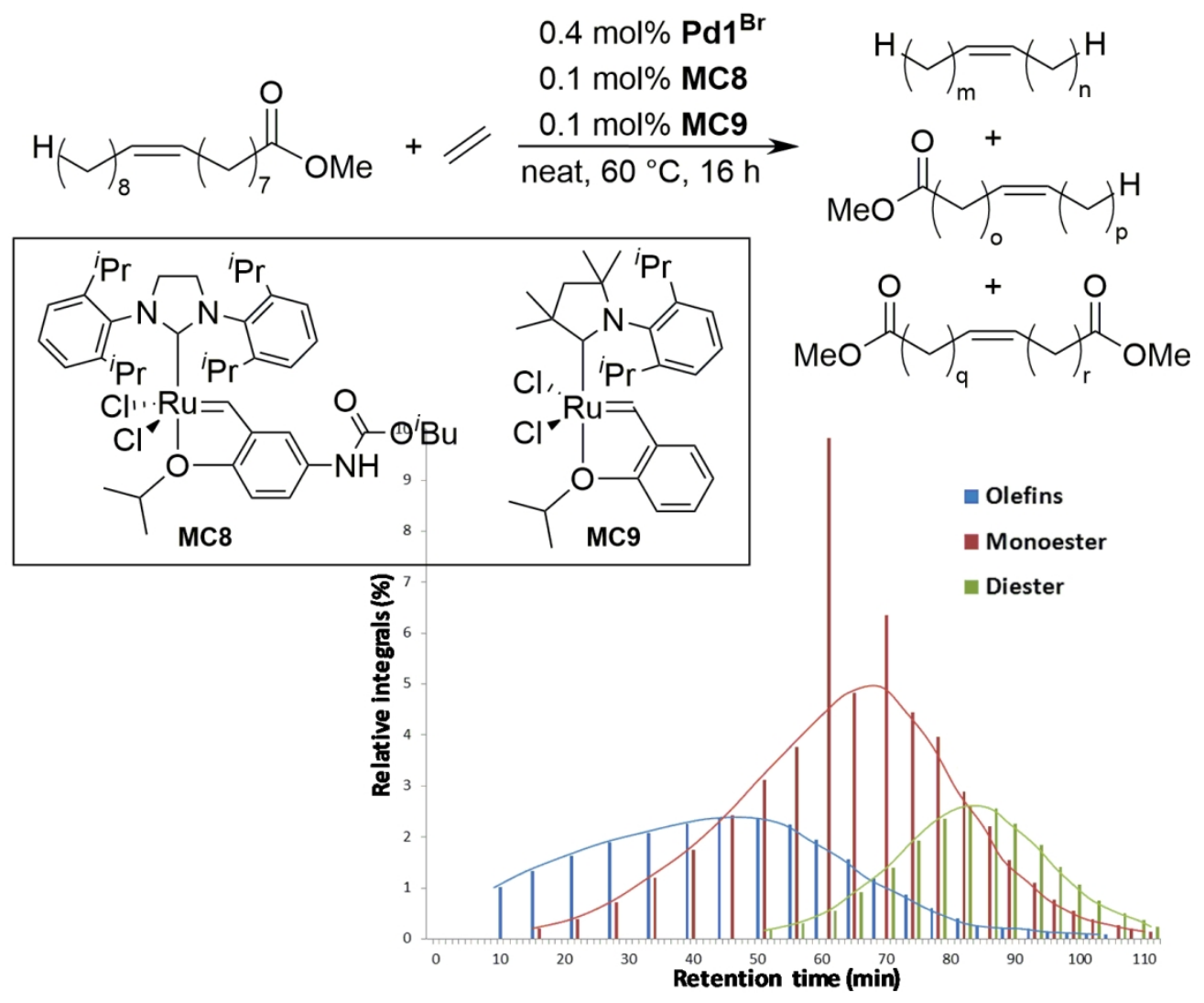

Scheme 4. Isomerizing ethenolysis of rapeseed methyl ester.

$131 \times 112 \mathrm{~mm}(300 \times 300 \mathrm{DPI})$ 